It has been reproduced for. ise beat avallable copy to perkisi : - -.:oadest possible aveilability.

\title{
Preparation and Properties of Hollow Glass Microspheres for Use in Laser Fusion Experiments
}

\author{
J. H. Campbell \\ J. Z. Grens \\ J. F. Poco
}

Manuscript date: November 1, 1983

\author{
DISCLAIMER
}

\begin{abstract}
This repurt wats prepared us an account of work sponsored by an agency of the United States Government. Neither the United States Government nor any agency thereof, nor any of their employees, makes any warranty, express or implied, or assumes any legal lis oility or responsibility for the accuracy, completeness, or usefulness of any information, apparatus, product, or process disclosed. or represents that its use would not infringe privately owned rights. Reference herein to any specilic commercial product, process, or service by trade name, trademark. manufacturer, or otherwise does not necessarily constitute or imply its endorsement. secommendation, or favoring by the United States Government or any agency thereof. The views and opinions of authors expressed herein do not necessarily state or reflect those of the United States Government or any agency thereof.
\end{abstract}

\section{LAWRENCE LIVERMORE NATIONAL LABORATORY University of California - Livermore, Cali 'ornia - 94550}




\section{Foreword}

In this report, we bring together data from both past as d present glass microsphere research and development done in support of the Lawrence Livermore National Laboratory (LLNL) inertial confinement fusion (ICF) program. This work represents the contributions of many individuals within the Target Fabrication Group. We have attempted to give credit to the work of former members of the Target Fabrication Group by citing the appropriate Journal publications, LLNL reports, and memos. We hope our search has been complete, and we apologize if any omissions have been made. Others who have gra. ciously contributed to our recent experimental efforts include:

Characterization and Analysis

Modeling

Experiments and Equipment

Prugram Operations

Novette Production

Consuliting
J. T. Weir, F. J. Ryerson, R. F. Schenz, V. K. Chen, G. J. Greiner, C. M. Mazuch, W. G. Halsey, P. 2. McCarthy. R. Lim

C. B. Thorsness, L. V. Griffith, R. W. Hopper

G. T. Jameson, B. H. Ives, W. E. Elsholz

I. F. Stowers, N. J. Barnes, M. S. Sindair

W. Hatcher

W. Haller (National Bureau of Standards) 


\section{Contents}

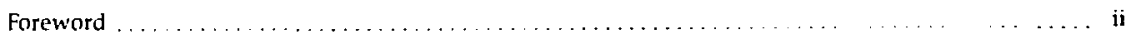

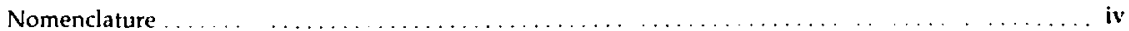

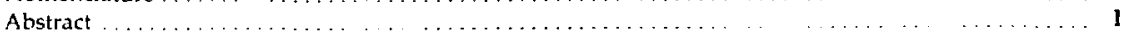

I. Iritroduction and Background $\ldots \ldots \ldots \ldots \ldots \ldots \ldots \ldots \ldots \ldots \ldots \ldots \ldots \ldots \ldots$

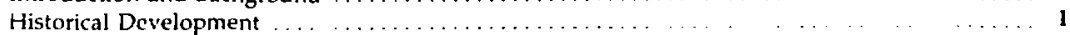

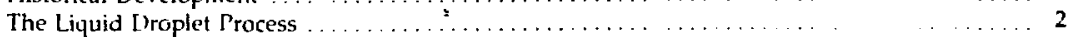

The Dried-C,el Process $\ldots \ldots \ldots \ldots \ldots \ldots \ldots \ldots \ldots \ldots \ldots \ldots \ldots \ldots \ldots \ldots$

Target Quality Specifications . . . . . . . . . . . . . . . . . . . 2

II. Composition and Properties of Glass Microspheres .... . . . . . . 4

Physical Properties ........................ . . 7

Viscosity $\quad \ldots \ldots \ldots \ldots \ldots \ldots \ldots \ldots \ldots \ldots \ldots \ldots \ldots \ldots \ldots \ldots \ldots \ldots$

Thermal Conductivity and Thermal Expansion . . . . . . . . . . . . 9

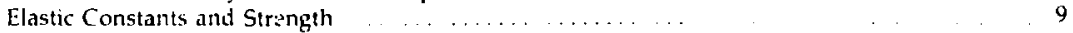

Optical Transmission . . . . . . . . . . . . . . . . . . . 11

Gas Permeability ... . . . ..................... 11

IIi. Microsphere Pruduction System ................. . 13

Preparation and Properties of the Glass Solution . . . . . . . 13

Droplet Generator ... . . . . . . . . . . . . . . . 13

Heated Droplet Tower _ _............... . . . . 15

Post-Run Treatment of Mlicrospheres. . . . . . . . . 20

Microsphere Washing _. . . . . . . . . . . . . . . . . . 20

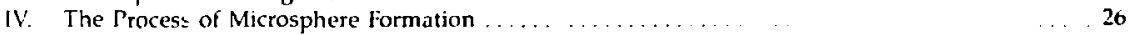

Physical Description of Droplet Drying and Fusion . . . . . . . . . . . 26

Droplet Drying, .......................... . 28

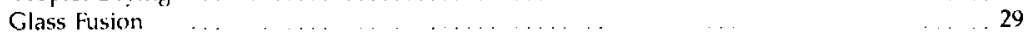

Mathematical Model of Microsphere Formation . . . . . . . 30

Droplet Drying and Gas Diffusion .............. . . . 31

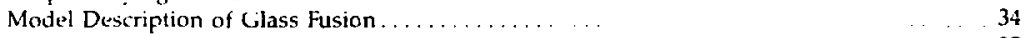

Input and Solution Method ................ . . . 35

Results from Model Calculations . . . . . . . . . . . . . . . 35

Reference System. ........................ . . 35

Effects of various Process Parameters . . . . . . . . . . 37

References ... . . ................... . . . . 40

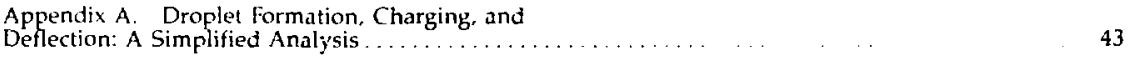

Appendix B. Microsphere Formation: Back-
of-the-Envelope Calculations $\ldots \ldots \ldots \ldots \ldots \ldots \ldots \ldots \ldots \ldots \ldots \ldots \ldots \ldots$ 


\section{Symbol}

$M_{\mathrm{A}}$

$h_{A}$

$P_{A}$

A.

$C_{\mathrm{i}}$

C.

$n_{\mathrm{i}}$

$\mathrm{D}_{\mathrm{B}}$

$c$

$S$

$P$

V

$P_{\mathrm{i}}$

$P_{\mathrm{r}}$

$\Delta P$

$P_{0}$

v

$\Delta P_{\mathrm{s}}$

$\Delta P_{\mathrm{g}}$

$K_{s}$

$K_{\mathrm{g}}$

$\gamma$

m

$t$

$D_{p}$

$R$

$\Delta p_{v}$

$T$

$Q$

$\dot{Q}$

$h_{\mathrm{m}}$

$h_{\mathrm{q}}$

$k_{f}$

It

Dv

i)

$\mu$

$\mathrm{C}_{\mathrm{p}}$

$\Delta H_{8}$

$h_{0}$

$\Delta p_{\mathrm{f}}$

$\ell$

$K_{m}$

$C_{d}$

$h_{\mathrm{b}}$

$M_{\text {w }}$

$\dot{\mathrm{M}}_{\mathrm{H}_{2} \mathrm{O}}$

$\dot{\mathrm{M}}_{\mathrm{H}_{2} \mathrm{O}}$

$v_{T}$

$\rho_{B}$

$\rho_{\mathrm{p}}$
Description

\section{(Units)}

Miass of alkali volatilized (g)

Mass transfer coefficient for alkali loss $(\mathrm{cm} / \mathrm{s})$

Vapor pressure of alkali (atm)

Sphere surface area $\left(\mathrm{m}^{2}\right)$

Gas concentration at internal surface $\left(\mathrm{mol} / \mathrm{cm}^{3}\right)$

Gas concentration at external surface $\left(\mathrm{mol} / \mathrm{cm}^{3}\right)$

Quantity of gas (mol)

Gas diffusion coefficient $\left(\mathrm{cm}^{2} / \mathrm{s}\right)$

Gas concentration at a glass surface $\left(\mathrm{mol} / \mathrm{cm}^{3}\right)$

Gas solubility $\left(\mathrm{mol} / \mathrm{cm}^{3} \cdot \mathrm{Pa}\right)$

Pressure (Pa)

Volume $\left(\mathrm{cm}^{3}\right)$

Internal gas pressure (Pa)

External gas pressure $(\mathrm{Pa})$

Initial pressure difference $(\mathrm{Pa})$

Initial internal pressure ( $\mathbf{P a})$

Frequency of signal generator $(\mathrm{Hz})$

Stean: pressure gradient across membrane (atm)

Purge gas pressure difference across membrane (atm)

Membrane permeability for steam (mol(STP) $/ \mathrm{cm} \cdot \mathrm{s} \cdot \mathrm{atm}$ )

Membrane permeability for purge gas (mol(STP)/cm.s.atm)

Glass surface tension ( $\mathrm{erg} / \mathrm{cm}^{2}$ )

Mass (g)

1 ime (s)

Drcplet c'jameter $(\mathrm{cm})$

Gas constant $\left(\mathrm{cm}^{3} \cdot \mathrm{atm} / \mathrm{g}\right.$-mole $\left.\mathrm{K}\right)$

Vapor pressure driving force across boundary layer (atm)

Temperature (K)

Energy (cal)

Rate of energy transport (cal/s)

Mass transfer coefficient $(\mathrm{cm} / \mathrm{s})$

Heat transfer coefficien $\left(\mathrm{cal} / \mathrm{cm}^{2} \cdot \mathrm{s} \cdot \mathrm{K}\right.$ )

Thermal conductivity of gas boundary layer (cal/cm.s.K)

Height of spherical segment $(\mathrm{cm})$

Vapor diffusivity $\left(\mathrm{cm}^{2} / \mathrm{s}\right)$

Droplet velocity $(\mathrm{cm} / \mathrm{s})$

Viscosity of drying medium (poise)

Heat capacity (cal/g K)

Latent heat of vaporization (cal/g)

Overall mass transfer coefficient $(\mathrm{cm} / \mathrm{s})$

Vapor pressure driving force across film membtane (atm)

Membrane thickness $(\mathrm{cm})$

Membrane perneability (mol (STP) $\left.\cdot \mathrm{cm} / \mathrm{cm}^{2} \cdot \mathrm{s} \cdot \mathrm{atm}\right)$

Drag coefficient (dimensionless)

Mass transfer coefficient through barrier $(\mathrm{cm} / \mathrm{s})$

Gram molecular weight (g/g $\cdot$ mole)

Rate of water vapor loss from unsaturated solution $(g / s)$

Rate of water vapor loss through film $(\mathrm{g} / \mathrm{s})$

Droplet terminal velocity $(\mathrm{cm} / \mathrm{s})$

Jensity of drying gas $\left(\mathrm{g} / \mathrm{cm}^{3}\right)$

Particle density $\left(\mathrm{g} / \mathrm{cm}^{3}\right)$ 


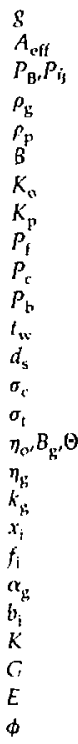

\section{Dimensionless Numbers}

Re
Pr
Sc
Nu
Sh
Gravitational constant $\left(\mathrm{cm} / \mathrm{s}^{2}\right)$

Effective surface area for heat transfer $\left(\mathrm{cm}^{3}\right)$

Gas pressure in hollow sphere (atm)

Density of drying medium $\left(\mathrm{g} / \mathrm{cm}^{3}\right)$

Particle density $\left(\mathrm{g} / \mathrm{cm}^{3}\right)$

Empirical sermeability parameter (K)

Empirical permeability parameter (mol/m.s. Pa.K)

Glass permeability (mol/m.s.Pa.K)

Maximum fill pressure (psi)

Compressive failure pressure (psi)

Buckling pressure (psi)

Wall thickness (m)

Shell diameter $(m)$

Compressive strength (psi)

Tensile strength (psi)

Empirically derived constants in Fulcher equmw, n

Glass viscosity (poise)

Glass thermal conductivity $(W / m \cdot K)$

Weight percent of oxide component

Thermal conductivity coefficient for oxide component, $i(W / m \cdot K)$

Thermal expansion coefficient $\left(10^{-6} \mathrm{~m} / \mathrm{m} \cdot \mathrm{K}\right)$

Thermal expansion coefficient for $\mathrm{i}^{\text {th }}$ oxide component $(\mathrm{m} / \mathrm{m} \cdot \mathrm{K})$

Bulk modulus (psi)

Shear modulus (psi)

Young's modulus (psi)

Poiss on's ratio

Reynolds number

Prandt number

Schmidt number

Nusselt number

Sherwood number 


\title{
Preparation and Properties of Hollow Glass Microspheres for Use in \\ Laser Fusion Experiments
}

\begin{abstract}
In this paper, we review the preparation of high quality, hollow-glass microspheres for use in laser driven fusion experiments at LLNL. The primary focus of this paper is on the liquid-droplet method for making glass spheres, which has been in use at LLNL for over six years. We have combined the results from previous studies with our current results to present a detailed description of the preparation and the composition and physical properties of the glass microspheres. We also present a mathematical model that simulates the microsphere formation process. Examples are given of the application of the model $t o$ study the effects of various process parameters.
\end{abstract}

\section{Introduction and Background}

The production of glass m:crospheres is part of an ongoing research and development program started in 1974, ${ }^{\prime 2}$ and aimed at developing a method for mass producing glass fuel containers for use in inertial confinement fusion (ICF) experiments. Several previous reports from $\mathrm{LLNL}^{3-5}$ have described the development of the liquiddroplet technique for the production of glass microspheres. In this paper, we review previous data along with the results from our more recent studies to preser it a detailed picture of the preparation method and properties of the glass microspheres.

The production of the high-quality glass microspheres needed for laser fusion targets requires us to optimize a number of processing parameters. In the past, we used a largely empirical approach to determine the proper operating conditions. Although this approach was successful, it was also time consuming and manpower intensive. To help guide and interpret our present experimental work, we have developed a simple, onedimensional (1-D) model to simulate the sphere formation process. The model has been used to quantify the effects of several key process variables surh as the column temperature profile, purge-bas composition, droplet size and connposition, and glass film properties. Details of this model and its application to our current glass microsphere production are discussed at length later in this paper.
After a brief introduction, this paper is divided into three main sections: the first summarizes data on the composition and properties of the glass spheres, the second reviervs the microsphere preduction method, and the third presents a discussion of the model development and application.

\section{Historical Development}

To put the present work in proper context, it is necessary to review briefly the development of glass-microsphere technology.

In the early phases of the ICF program, the target designs called for a simple deuteriumtritium (DT) filled microsphere of low $\mathrm{Z}$ material, also referred to as an exploding pusher target. Souers et al. ${ }^{1.2}$ evaluated a number of commercially available microspheres made from various materials. Glass was finally selected for several reasons:

- Its strength for holding high-pressure DT gas fills.

- The relative ease with which it could be filled with DT at elevated temperatures and then subsequently cooled to room temperature to retain the gas.

- Its eptical transparency, which permits visible inspection and characterization.

- Its relatively low atomic number. 
The first glass microspheres to be used as targets at LLNL came from two commercial sources: Emerson and Cummings (E\&C) ard Minnesota Mining and Manufacturing Co. (3M). ${ }^{\prime}$ The nominal oxide compositions of the glasses are given in Table 1. Note that the $3 M$ product is a soda-lime silicate glass, whereas the E\&C glass is primarily an aikali borosilicate. Also, the $\mathrm{SiO}_{2}$ concentration of the E\&C glass was varied to give a range of microsphere strengths; the highest silica concentration giving the strongest glass.

The initial tolerances for the diameter, surface finish, and wall-thickness uniformity of the exploding pusher targets were much less stringent than those of our current high-compression designs. Consequently, it was possible to find a few suitable glass microspheres (about on: out of one million) by suiting through large batches of commercially available product. This enormous screening and inspection process proved impractical as the specifications on the glass microspheres became more rigid. As a result, two new methods were developed for the specific purpose of supplying high-quality, glass shells for ICF targets: 1) the liquid droplet, and 2) the dried-gel processes.

\section{The Liquid Droplet Process}

The liquid droplet method for making glass microspheres was pioneered by Hendricks and co-workers $^{3-5}$ at LLNL in the late 1970's. In brief, the process involves the formation of highly uniform droplets of aqueous glass solutio ' by acoustically breaking up a capillary jet of this solution [Fig. 1(a)]. The droplets are subsequently dried and fused to form the desired microspheres [Fig. 1(b)]. Details of the early developments of this process are given in Refs. 3 through 5; more recent developments are summarized later in this paper.

The key to this process is the formation of uniform sized droplets using a suitably designed dropler generator. Early work by Hendricks and co-workers $^{3,6,7}$ provided the basic generator designs, which, with only minor modification, are still in use today.

\section{The Dried-Gel Process}

In the dried-gel process, a solution of glassforming oxides is dried to a hard residue, or gel, and then ground to a suitable particle size [Fig.
Table 1. Typical oxide composition of glass microspheres from E\&C and $3 M$ used in early ICF experiments ${ }^{1,2}$ vs that of our LLNL dropletgenerated glass spheres.

\begin{tabular}{|c|c|c|c|c|}
\hline Oxide & $\begin{array}{c}3 M^{2} \\
\text { (Batch } P-0097-1) \\
\text { wtre }\end{array}$ & $\begin{array}{c}\text { E\&C } \\
(1 G-25-1311) \\
\text { wt }\end{array}$ & $\begin{array}{c}\text { LLNL } \\
(1978) \\
w 1 r\end{array}$ & $\begin{array}{l}\text { LLN1: } \\
\text { (1983) } \\
\text { wt\% }\end{array}$ \\
\hline $\mathrm{SiO}_{2}$ & 80.7 & 76.6 & 70.6 & 86.0 \\
\hline $\mathrm{Na}_{2} \mathrm{O}$ & 6.9 & 21.3 & 21.9 & 10.0 \\
\hline $\mathrm{K}_{2} \mathrm{O}$ & - & - & 5.4 & 2.5 \\
\hline $\mathrm{CaO}$ & 10.3 & - & - & - \\
\hline $\mathrm{B}_{2} \mathrm{O}_{3}$ & 2.1 & 1.9 & 2.0 & 1.5 \\
\hline Other & 1.9 & 0.2 & 0.1 & - \\
\hline
\end{tabular}

- Composition dala normalized to $100 \%$.

b From Ret. 4.

- Average of SEM and electron microprobe EDS analysis.

2(a)]. The ground material is sieved into narrow size ranges and then mechanically dropped through a high-temperature furnace. Although the details of the process have yet to be analytically modelled, it appears that the chemically bound water in the gel inflates the particle as the surface melts, forming a hollow-glass microsphere [Fig. 2(b)].

Nolen, Downs, and co-workers ${ }^{8-10}$ at KMS Fusion, Inc., led the early development of the dried-gel technique and currently use it as their major microsphere production method. Some later work was also carried out at LLNL $^{5}$ and more recently in Japan. ${ }^{11}$

The dried-gel, and solution-droplet tenniques are complementary in many respects. Table 2 lists the advantages and disadvantages of each technique. From these data ' $t$ is clear that what is generally limiting for one method is not for the other.

At LLNL, we have chosen the solutiondroplet technique as our nuajor production method because it gives high-quality spheres with excellent size control. This choice, however, has been somewhat at the expense of lorig term durability to weathering. Certain dried-gel glass compositions may be more durable, notably the sodalime borosilicates.

\section{Target Quality Specifications}

The current specifications on glass microspheres used in ICF experiments at LLNL are very stringent. Acceptable shells must fall within a diameter tolerance of $\pm 5 \mu \mathrm{m}$ of the specified design 

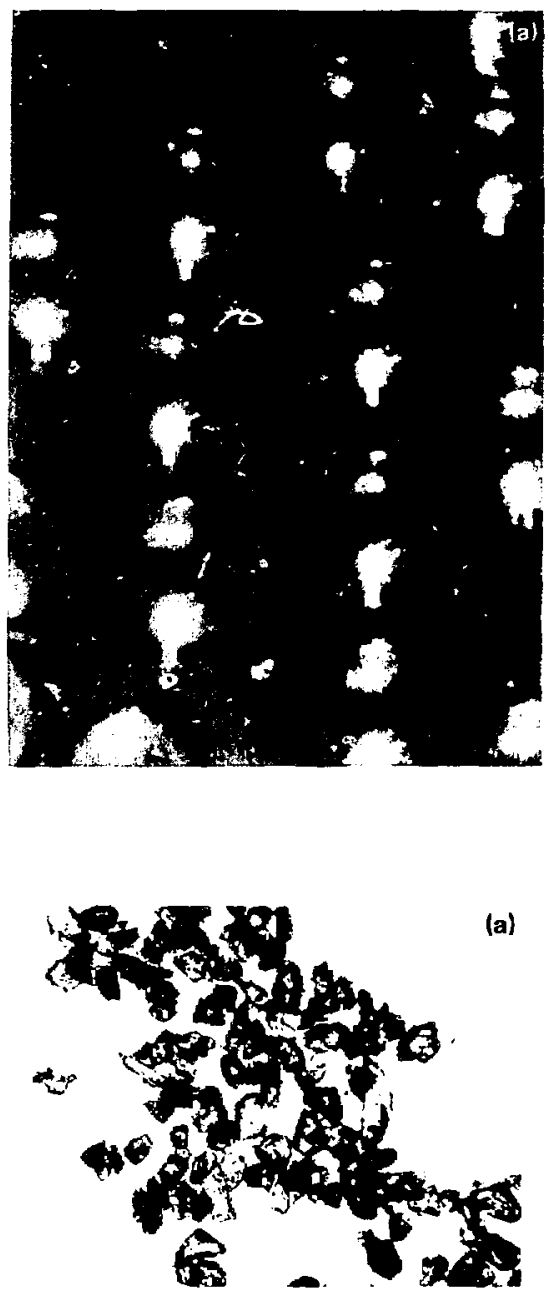

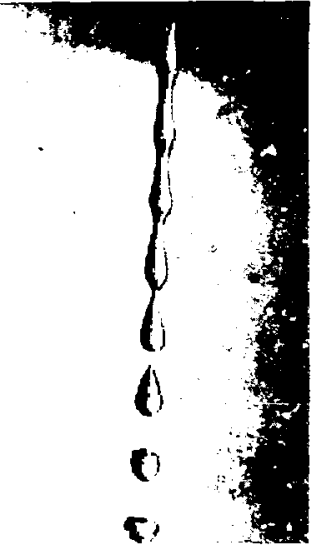

Fig. 1. (a) Droplets of aqueous glass solution formed by acoustically driven breakup of a liquid jet, and (b) the resulting glass microspheres ultimately produced from these droplets.

Fig. 2. (a) Particles of dried glass gel and (b) typical glass microsphere product.

size, and the average wall thickness of the shell must be within $\pm 0.5 \mu \mathrm{m}$ of the design value. The surface finish of the shells requires that defects be less than $1000 \AA$.

The conformance of the spheres to these specifications is continuously checked by an ex- tensive battery of quality assurance tests. Only those tests that relate to the microsphere production are discussed in this paper. The coated spheres that are selected for $1 \mathrm{CF}$ experiments are subjected to $4 \pi$ examination to verify all critical target dimensions and to map any small surface 
Table 2. Summary of major advartages and disadvantages of liquid droplet vs dried-gel glass sphere production methods.

\begin{tabular}{|c|c|c|}
\hline Method & Advantages & Disadvantages \\
\hline Liquid droplet & $\begin{array}{l}\text { - Excellent control of shell diameter and wall } \\
\text { thickness } \\
\text { - Moderate furnace requirements } \\
\text { - Excellent sturface quality and uniformity } \\
\text { - High production rate }\end{array}$ & $\begin{array}{l}\text { - Limited choice of glass compositions (with } \\
\text { generally poorer durability and strength) } \\
\text { - Present maximum size aboul } 300 \mathrm{\mu m} \text { diameter }\end{array}$ \\
\hline Dried gel & $\begin{array}{l}\text { - Wider choice of glass composition resulting in } \\
\text { better strength and durability } \\
\text { - Suitable for producing large (up to } 2-2 \mathrm{~mm} \text { ) } \\
\text { diameters spheres } \\
\text { - Relative ease of dopant addition to glass }\end{array}$ & $\begin{array}{l}\text { - Product has wide distribution in dìmeter and } \\
\text { wall thickness } \\
\text { - Generally requires, longer, hotter furnaces }\end{array}$ \\
\hline
\end{tabular}

defects. The quality of the DT fill is also verified. If acceptable, the inspected microspheres are added to an inventory that surplies material for the final target assemblies.

\section{Composition and Properties of Glass Microspheres}

The composition of the glass microspheres produced by the droplet technique is limited by two fundamental conditions: 1) the starting components must form a true aqueous solution, and 2) the viscosity of the glass at refining temperatures of $\sim 1200$ to $1500^{\circ} \mathrm{C}$ must be low enough to give good shell sphericity/concentricity and a high-quality surface finish. A third consideration that becomes important immediately following shell formation is the glass durability to weathering by atmospheric gases.

In the initial droplet work by Hendricks and Dressler, ${ }^{3}$ a sodium borosilicate glass was used that was similar in composition to the glass prepared by E\&C (see Table 1). As expected, the durability of this glass was quite poor. Rosencwaig et al. ${ }^{4}$ investigated a number of different glass compositions with the aim of improving durability while maintaining $a$ water soluble starting mixture and a low melting, low viscosity glass. Because of the solubility requirement, addition of alkaline earths and alumina, which are well known components for increasing durability, ${ }^{12}$ was not possible. Therefore, the app.oach taken was to develop a mixed-alkali borosilicate glass. It is well known that mixed alkali glasses generally have better durability than single alicali glasses of equivalent molar comporitions. ${ }^{12-16}$ This mixedalkali effect is thought to be related to the decreased mobility of each ion as a result of the addition of tine other. ${ }^{17}$
At the conclusion of their study, Rosencwaig et al. ${ }^{4}$ chose the solution compusition shown in Table 3. This particular composition has both a low melting point and low viscosity, and lies near the $\mathrm{Na}_{2} \mathrm{O} \cdot 2 \mathrm{SiO}_{2}$ eutectic (Fig. 3). ${ }^{18.19}$ Due to some volatilization during processing, the product gla 5 had a slightly lower alkali and boron content (Table 3). As might be expected, the loss of $\mathrm{K}_{2} \mathrm{O}$ was greater than that of $\mathrm{Na}_{2} \mathrm{O}$, due to its greater volatility.

Our current glass solution composition ( $\mathrm{Ta}$ ble 3 ) is very similar to the original Rosencwaig et al. ${ }^{4}$ mixture but with slight changes in $\mathrm{B}_{2} \mathrm{O}_{3}$ and $\mathrm{K}_{2} \mathrm{O}$ content. The $\mathrm{Li}_{2} \mathrm{O}$ was omitted from the more recent formulations because it was found to produce little, if any, improvement in durability at the $0.1 \%$ concentration level.

The present glass microsphere composition has a considerably higher silica content than those made in earlier experiments (Table 3 ). This is a direct result of the higher fumace temperature; we are now using (i.e. $1500^{\circ} \mathrm{C}$ vs $1200^{\circ} \mathrm{C}$ ). Because the current sphere sizes are larger, their terminal velocities are higher and residence times shorter in the refining/fusion furnace. Consequently we have had to operate at a higher fumace : nperature to get the equivalent level of produc: refinement.

In Fig. 4, our 1983 solution and glass compositions are projected on the $\mathrm{Na}_{2} \mathrm{O}-\mathrm{B}_{2} \mathrm{O}_{3}-\mathrm{SiO}_{2}$ (Ref. 20) and $\mathrm{K}_{2} \mathrm{O}-\mathrm{Na}_{2} \mathrm{O}-\mathrm{SiO}_{2}$ (Ref. 21) liquidus 
Table 3. Compositions of initial solution and final glass for LJ.NL droplet method of glass microspheres production.

\begin{tabular}{|c|c|c|c|c|c|c|c|c|}
\hline \multirow{3}{*}{$\begin{array}{l}\text { Oxide or } \\
\text { oxide ralio }\end{array}$} & \multicolumn{4}{|c|}{$\begin{array}{c}\text { High alkali } \\
\text { (Rosencwaig et al.t) }\end{array}$} & \multicolumn{4}{|c|}{$\begin{array}{c}\text { High silica } \\
\text { [Current (1983) production] }\end{array}$} \\
\hline & \multicolumn{2}{|c|}{ Solution } & \multicolumn{2}{|c|}{ Glass } & \multicolumn{2}{|c|}{ Solution } & \multicolumn{2}{|c|}{ Glass } \\
\hline & $\overline{\text { wire }}$ & moly & $\overline{w t \%}$ & molf & $\overline{w i s e}$ & molse & $\overline{w t x}$ & molse \\
\hline $\mathrm{SiO}_{2}$ & 66.3 & 68.9 & 70.6 & 72.7 & 062 & 69.0 & 86.0 & 87.3 \\
\hline $\mathrm{Na}_{2} \mathrm{O}$ & 227 & 22.9 & 21.9 & $2: .8$ & 20.6 & 20.8 & 10.0 & 9.6 \\
\hline $\mathrm{K}_{2} \mathrm{O}$ & 8.0 & 5.3 & 5.4 & 3.5 & 7,2 & 4.8 & 2.5 & 1.6 \\
\hline $\mathrm{B}_{2} \mathrm{O}_{3}$ & 2.9 & 2.6 & 2.0 & 1.8 & 6.1 & 5.5 & 1.5 & 1.3 \\
\hline $\mathrm{Li}_{2} \mathrm{O}$ & 0.1 & 2 & 0.1 & 0.2 & - & - & - & - \\
\hline $\mathrm{Na}_{2} \mathrm{O} / \mathrm{SiO}_{2}$ & - & $\mathbf{0 . 3 3}$ & - & 0.30 & - & 0.30 & - & 0.11 \\
\hline $\mathrm{Na}_{2} \mathrm{O}+\mathrm{K}_{2} \mathrm{O} / \mathrm{SiO}_{2}$ & - & 0.41 & - & 0.32 & - & 0.37 & - & 0.13 \\
\hline $\mathrm{K}_{2} \mathrm{O} / \mathrm{SiO}_{2}$ & - & 0.077 & - & 0.048 & - & 0.070 & - & 0.018 \\
\hline $\mathrm{B}_{2} \mathrm{O}_{3} / \mathrm{SiO}_{2}$ & - & 0.038 & - & 0.025 & - & o.680 & - & 0.015 \\
\hline
\end{tabular}
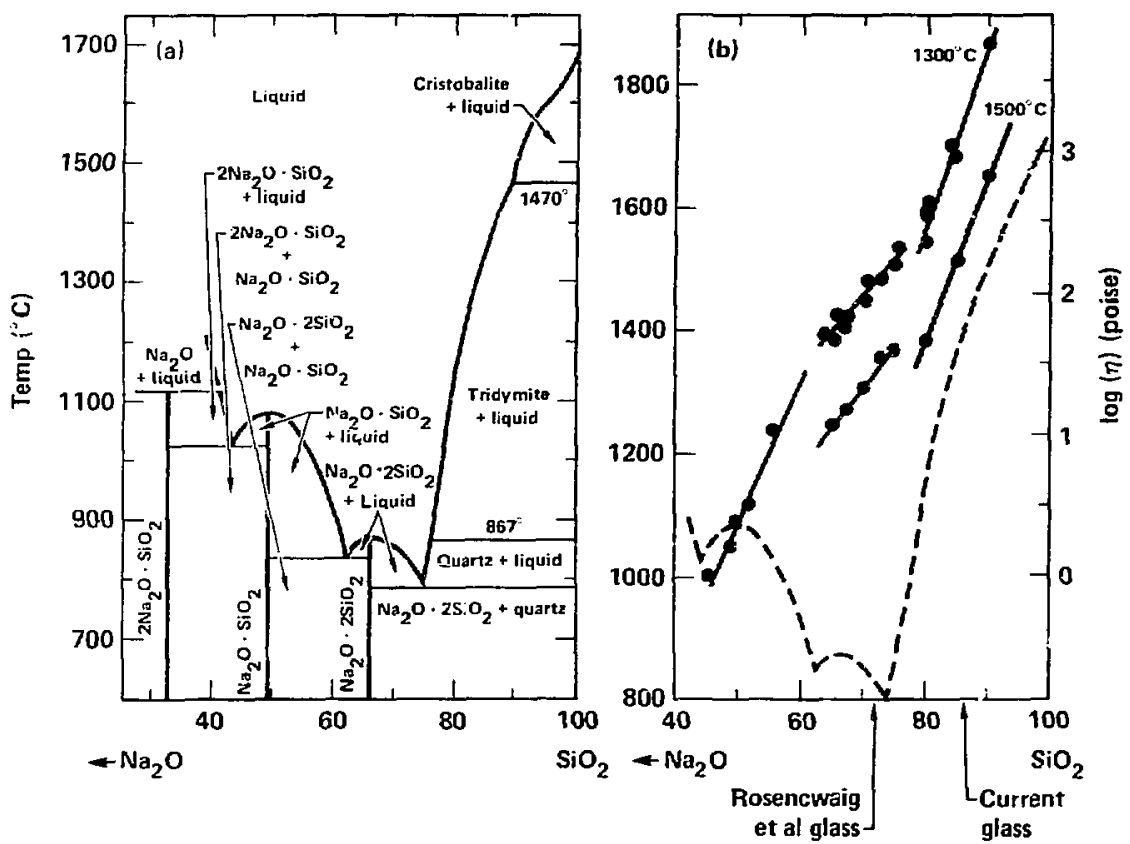

Fig. 3. (a) Phase diagram for the $\mathrm{SiO}_{2} 2 \mathrm{Na}_{2} \mathrm{O} \cdot \mathrm{SiO}_{2}$ system (from Ref. 18) and (b) composite plot for the same system showing the liquidus curve (dashed line) and corresponding viscosities (solid line) measure $i$ at 1300 and $1500^{\circ} \mathrm{C}$ (from Ref. 19). 

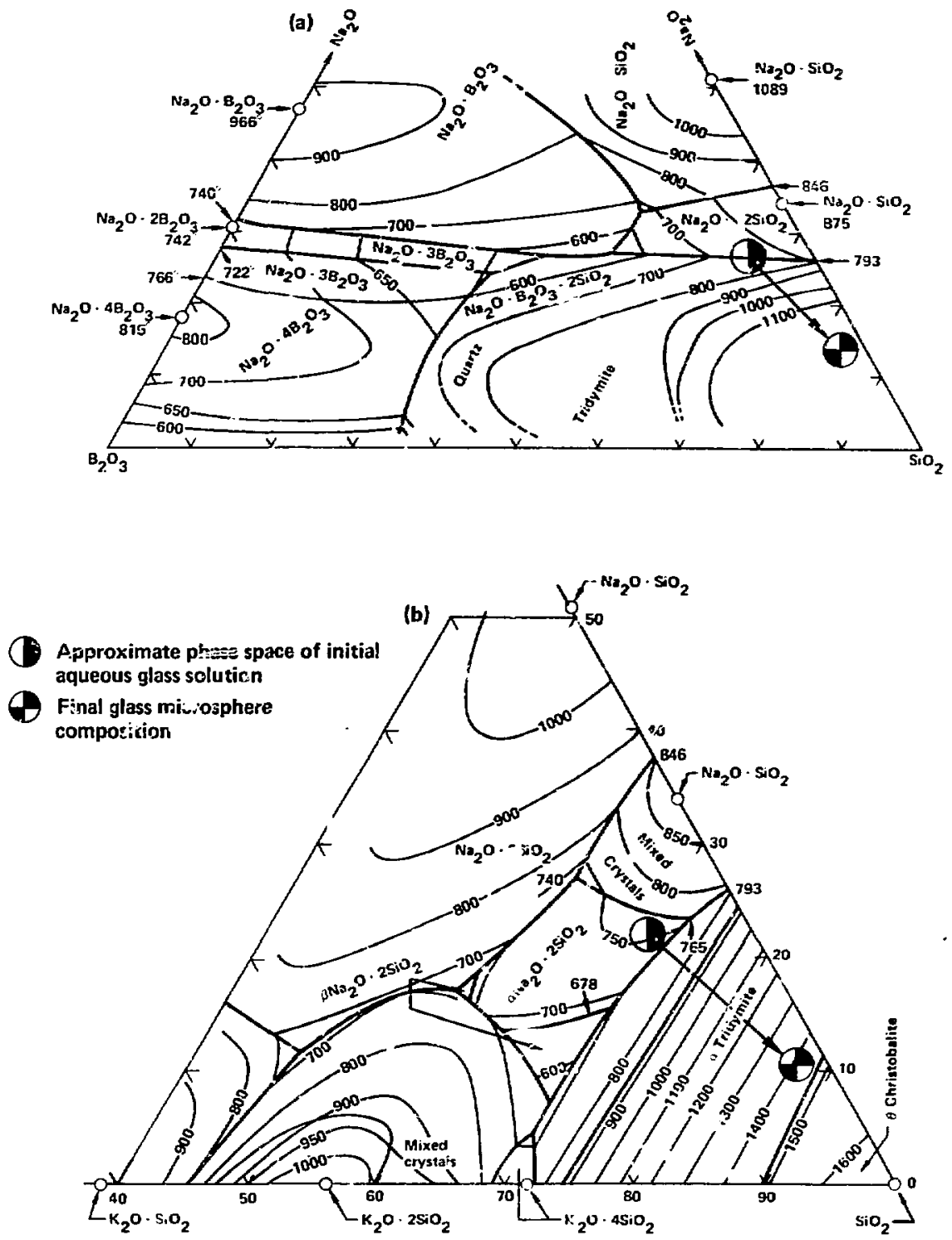

Fig. 4. Phase diagrams for $\mathrm{Na}_{2} \mathrm{O}-\mathrm{B}_{2} \mathrm{O}_{3}-\mathrm{SiO}_{2}$ (Ref. 20) and $\mathrm{K}_{2} \mathrm{O}-\mathrm{Na}_{3} \mathrm{O}-\mathrm{SiO}_{2}$ (Ref 21) systems. 
surfaces. The arrow between the solution and glass composition points on these diegrams indicates the compositional evolution of the glass sphere as ic falls through the refining/fusion furnace. As the sphere enters the furnace, it has an oxide composition nearly equal to that of the starting solution, and forms a low-viscosity melt at -1000 to $1100^{\circ} \mathrm{C}$. Fiowever, as the sphere continues to fall through the $1500^{\circ} \mathrm{C}$ furnace, a significant fraction of the alkal' and boron is volatilized, producing a higher s:ica glass (Fig. 4) with correspondingly greater viscosity and liquidus temperature (Fig. 3).

The final glass composition lies near the metastable, two-liquid solvus in the $\mathrm{Na}_{2} \mathrm{O}-\mathrm{B}_{2} \mathrm{O}_{3}$ $\mathrm{SiO}_{2}$ systern $^{22}$ (Fig. 5). However, we have not observed phase separation (i.e. opralescence, ilassglass grain boundaries, etc.) in any of our glass product. The extremely rapid cooling rates of the sphere' as they' exit the rurnace undoubtedly help prevent phase separation.

\section{Physical Properkies}

Physical property data ior the LLNL glass microspheies are summarized ir: Table 4. Values are given for two different glass compositions: one of higher alkali content, and the other of higher silica content (see Table 3 ).

Values for man; of the physical properties listed in Tat.le 4 were esiimated from data reported in the literature. I $\Gamma$ such cases, the corresponding reference sources are listed. Measurements made in our laboratory were carried out either on glass spheres or glass boules havirg th.e same composition. The boules were prepared by W. Haller at the National Bureau of Standards. ${ }^{32}$

Fig. 5. Subliquidus immiscibility region in the $\mathrm{Na}_{2} \mathrm{O}-\mathrm{B}_{2} \mathrm{O}_{3}-\mathrm{SiO}_{2}$ system ${ }^{22}$ showing the approximate phase space location for our current glass sphere composition (b) as well as that from earlier wo:k $(\oplus)$ reported by Rosencwaig ef al. 4

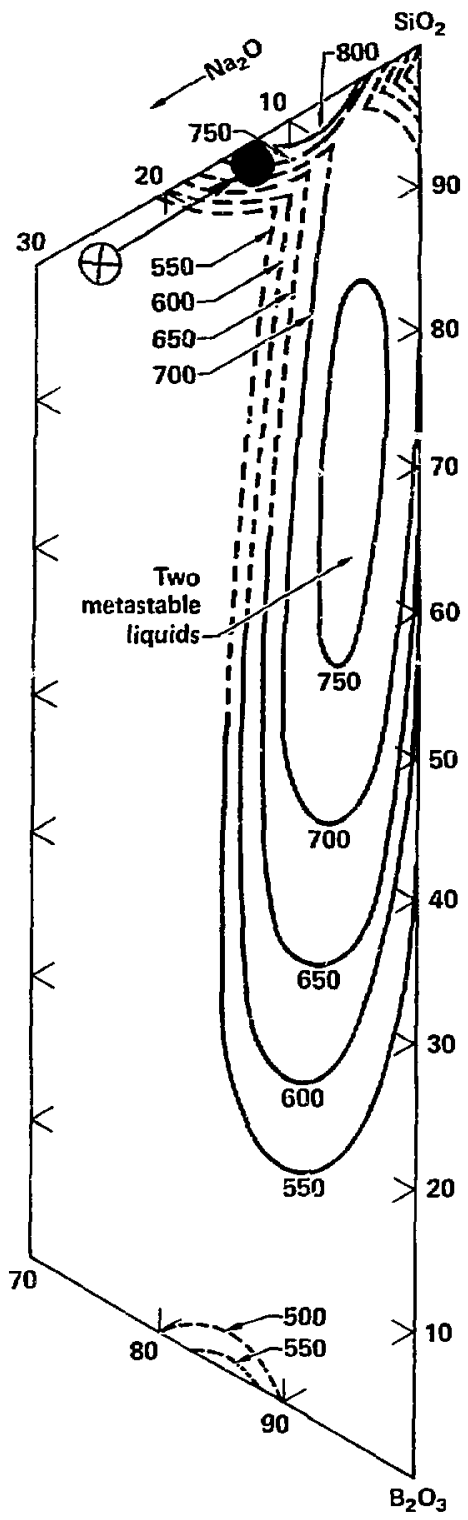


Table 4. Summary of physical properties of glass microspheres. (Complete glass compositions are given in Table 3.)

\begin{tabular}{|c|c|c|c|}
\hline & & High alkali & High silica \\
\hline & $\left(\mathrm{Na}_{2} \mathrm{O}+\mathrm{K}_{2} \mathrm{O}\right) / \mathrm{SiO}_{2}$ & 0.35 & 0.13 \\
\hline \multirow[t]{8}{*}{ I. } & Therma1 Properties & & \\
\hline & Heal capacity, $\mathrm{C}_{p} 5^{\circ} \mathrm{C}(\mathrm{cal} / \mathrm{g} \cdot \mathrm{K})$ (Ref. 24) & 0.18 & 0.18 \\
\hline & Thermal conductivity, $25^{\circ} \mathrm{C}(\mathrm{W} / \mathrm{m} \cdot \mathrm{K})$ (Refs 23,25$)$ & 0.864 & 1.11 \\
\hline & $\begin{array}{l}\text { Thermal expansion coefficient } 25^{\circ} \mathrm{C} \\
\left(\times 10^{-6} \mathrm{~m} / \mathrm{m} \cdot \mathrm{K}\right)(\text { Ref. } 26)\end{array}$ & 10.7 & 6.3 \\
\hline & Annealing temperature $\left({ }^{\circ} \mathrm{C}\right)$ & 435 & - \\
\hline & Littleton softening poítit $\left({ }^{\circ} \mathrm{C}\right)$ & 610 & - \\
\hline & Working point $\left({ }^{\circ} \mathrm{C}\right)$ & 850 & - \\
\hline & Liquidus temperature $\left({ }^{\circ} \mathrm{C}\right)$ & -800 & -1400 \\
\hline \multirow[t]{4}{*}{ II. } & Mechanical Properties & & \\
\hline & $\overline{\text { Densily, } 25 \times \mathrm{C}\left(\mathrm{g} / \mathrm{cm}^{3}\right)}$ & 241 & 2.31 \\
\hline & Yiscosity (poise); $T$ in $K$ & $0.029 \exp \frac{9393}{T-433.3}$ & (See text) \\
\hline & Elastic Properties & & \\
\hline (E) & Young's modulus (106 psi) (Ref. 27) & $9-10$ & $9-10$ \\
\hline$(K)$ & Bulk modulus $\left(10^{6}\right.$ psi) & $5.2-5.7$ & $5.2-5.7$ \\
\hline (G) & Shear modulus (106 $\mathrm{psi})$ & $3.7-4.1$ & $3.7-4.1$ \\
\hline (\$) & Poisson's ratio (Ref. 27) & 0.21 & 0.21 \\
\hline$\left(\sigma_{c}\right)$ & Compressive :trength (10 psi) (Refs. 28,10$)$ & $100-200$ & $100-200$ \\
\hline$\left\{\sigma_{\mathrm{b}}\right\}$ & Tensile strength $\left(10^{3}\right.$ psi) & $15-30$ & $15-30$ \\
\hline \multirow[t]{5}{*}{ IIl. } & Other & & \\
\hline & Refractive index (Sodium-D line) & 1.5026 & 1.4766 \\
\hline & Residual internal gas pressure (atm) (Ref. 29) & 0.2 & 0.2 \\
\hline & Internal gas & Argon & Argon \\
\hline & Surface tension of melt (erg/cm $\left.{ }^{2}\right)$ (Kefs. 30, 31) & $300-350$ & $300-350$ \\
\hline
\end{tabular}

\section{Viscosity}

Haller $^{33}$ measured the viscosity of our highalkali glass con position between 850 and $1500^{\circ} \mathrm{C}$ (Fig. 6). He fit the viscosity results to the Fulchertype equation

$\eta_{\mathrm{B}}=\eta_{\mathrm{o}} \exp \left(\frac{B_{\mathrm{g}}}{\Theta-T}\right)$,

where $\eta_{\mathrm{g}}$ is the glass viscosity (poise), $T$ the temperature $(K)$, and $\eta_{\alpha} B_{\mathrm{g}}$, and $\theta$ are empirically derived constants obtained by fitting the equation to the data. For this glass, the constants are $0.0290,9393$, and 433.2 , respectively. From these viscosity data, we estimated the glass working point $\left(\eta_{8} \sim 10^{4}\right.$ poise), Littleton softening point $\left(\eta_{g} \sim 10^{7.6}\right.$ poise), and annealing point $\left(\eta_{g} \sim\right.$ $10^{13.4}$ poise) (Ta'sle 4).

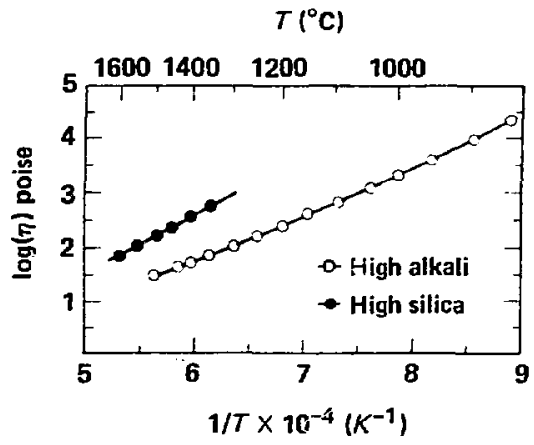

Fig. 6. Glass viscosity vs temperature for the high-alkali and high-silica glasses (see Table 3 and test for details). 
The viscosity of our current higher silica glass (Table 3) was not measured. Instead, it is assumed to have a viscosity similar to the 15.4 wt. $\% \mathrm{Na}_{2} \mathrm{O}$ and 84.6 wt.\% $\mathrm{SiO}_{2}$ glass reported by Bockris et al. ${ }^{34}$

\section{Thermal Conductivity and Thermal Expansion}

The thermal conductivities of the two glasses were calculated from the glass composition using the equation developed by Ammar et al. $^{23}$

$$
k_{\mathrm{g}}=\sum_{1=1}^{n} f_{\mathrm{j}} x_{\mathrm{i}}
$$

where $k_{\mathrm{g}}$ is the thermal conductivity $(\mathrm{W} / \mathrm{m} \cdot \mathrm{K}), f_{\mathrm{i}}$ the thermal conductivity coefficient for oxide component $i$, and $x_{i}$ the weight percent of that component. Values $f_{\mathrm{C}} \mathrm{r}$ the coefficient, $f_{\text {, }}$ for $\mathrm{SiO}_{2}$, $\mathrm{Na}_{2} \mathrm{O}, \mathrm{K}_{2} \mathrm{O}$, and $\mathrm{B}_{2} \mathrm{O}_{3}$ are $0.01333,-0.00479$, 0.00217 , and 0.00822 , respectively.

Similarly, the linear coefficient of thermal exfansion, $x_{g}$ was calculated using the additive method of English and Turner ${ }^{35}$ as summarized in Morey ${ }^{36}$

$\alpha_{\mathrm{g}}=\sum_{i=1}^{\mathrm{n}} b_{\mathrm{i}} x_{\mathrm{i}}$,

where $b_{\mathrm{i}}$ is the thermal expansion coefficient for component $i$; these values are $0.005,0.416,0.390$, and -0.0653 for $\mathrm{SiO}_{2}, \mathrm{Na}_{2} \mathrm{O}, \mathrm{K}_{2} \mathrm{O}$, and $\mathrm{B}_{2} \mathrm{O}_{3}$, respectively. ( $\alpha_{k}$ is in units of $10^{-6} \mathrm{~m} / \mathrm{m} \cdot \mathrm{K}$.)

\section{Elastic Constants and Strength}

The value for Young's modulus (Table 4) is based on data for glasses having compositions similar to ours. ${ }^{27}$ The bulk $(K)$ and shear $(G)$ moduli were then calculated from Young's modulus $(E)$ and Poissor's ratio $(\phi)$ :

$$
\begin{aligned}
& K=\frac{E}{3(1-2 \phi)} \\
& G=\frac{E}{2(\phi+1)} .
\end{aligned}
$$

In Table 4, we present a range of values for the glass compressive strengths based on data for bulk giasses ${ }^{28}$ and buckling pressure measure- ments by Downs et $3 .^{10}$ on their microsphere glass. Downs et al. showed their thin shells failed by buckling. However, these data can also be used to set a lower limit for the glass compressive strength. From in:e maximum observed buckling pressure of 4000 psi ar a shell :...jl-to-diam ratio of $9 \times 10^{-3}$, the lower limit for the compressive strength is calculated to be $1.1 \times 10^{5} \mathrm{psi}$.

The mechanical properties of the microsphen glass are important for establishing the prover DT fill procedure. During the fill cycle, the glass is heated to between $30 \mathrm{u}$ and $400^{\circ} \mathrm{C}$, and then subjected to an exiernal DT pressure. Because the fill rate is proportional to the pressure gradient across ihe she'l wall, the higher the extemal pressure, the greater the fill rate.

Failure of thin-walled glass spheres subjected to an external hydrostatic pressure occurs by either elastic buckling or compressive failure. ${ }^{37.10}$ The buckling pressure $P_{b}$ can be calculated from the Young's modulus and the square of the shell aspect ratio:

$P_{\mathrm{b}}=\frac{8 E}{\sqrt{3\left(1-\phi^{2}\right)}}\left(\frac{I_{\mathrm{w}}}{d_{\mathrm{s}}}\right)^{2}$,

where $t_{\mathrm{w}}$ and $d_{\mathrm{s}}$ are the shell wall thickne:s and diameter, respectively. Similarly, the presstre for compressive failure $P_{\mathrm{c}}$ is

$P_{\mathrm{c}}=4 \sigma_{\mathrm{c}}\left(\frac{t_{\mathrm{w}}}{d_{\mathrm{s}}}\right)$

where $\sigma_{\mathrm{k}}$ is the compressive strength of the glass. Note that for very thin walled shells, the failure mode is buckling (i.e. $P_{b}<P_{c}$ ), whereas for thicker shells the compressive strength is iimiting (i.e. $P_{\mathrm{c}}<P_{\mathrm{b}}$ ).

The aspect ratio for the crossover point from one failure mode to another can be determined from Eqs. (5) and (6) by setting $P_{c}=P_{b}$.

$\frac{d_{s}}{f_{w}}=\frac{2 E}{\left.\sigma_{c}\left(3 ! 1-\sigma^{2}\right)\right]^{1 / 2}}$.

Using the values of $\sigma_{\mathrm{c}}$ and $E$ given in Table 4, the crossover is estimated to be at a diameter-to-wall thickness ratio roughly between 50 to 100 .

The tensile strength $\left(\sigma_{t}\right)$ of the glass is critical to gas fill operations because it determines the maximum internal pressure $(P$ ) the shell can hold; i.e.

$P_{f}=4 \sigma_{t}\left(\frac{t_{w}}{d_{s}}\right)$ 
The tensile strength of a typical silicate jlasses is less than the compressive strength. This lack of strength in tension is related to surface flaws on the glass and has been the subject of study for over 60 years.

Quantitative measurements of the tensile strength of LLNL glass microspheres have not been reported. However, an estimate of tensile strength can be obtained by observing the maximum fill pressure that shells of a given aspect ratio can hold. An example of such data is given in Fig. 7 where the meas'dred maximum fill pressure, measured in psi, is plotted against the shell radius-to-wall-thickness $R_{5} / t_{w}$ ratio. The solid lines are calculated using Eq. (8) with different tensile strengths. The dots represent measured fill pressures for shells that have survived the fill and wash procedure. Note that the dots span a region of tensile strengths within the shaded area of roughly 15000 to $30000 \mathrm{psi}$.

The data in Fig. 7 provide a guide as to the maximum fill pressures that can be maintained in LLNL-type glass microspheres. However, there are several wamings in using these data. First, measured glass strengths have a statistical distribution. This is particularly true for glass microspheres because of their small size; some spheres may have several surface flaws and others none at all. Consequently, the fact that some spheres contain the gas pressures shown in Fig. 7 cannot be taken to mean that all spheres having the same aspect ratio will. We gentrally observe a large number of broken shells when we try to fill the spheres to the limits shown by the shaded region. Also, a few shells mav have strengths greater than indicated by the data in Fig. 7. This number, however, is normally very small and not significant for our current target production operations.

A second waming on the use of the data in Fig. 7 is that they do not include the effect of static fatigue. The strength of glass is known to deteriorate with the length of tine the stress is applied, particularly in the presence of water vapor. ${ }^{38}$ This static fatigue results from slow growith of preexisting ricicoflaws. The flaws eventually grow and cause catsst:ophic failure.

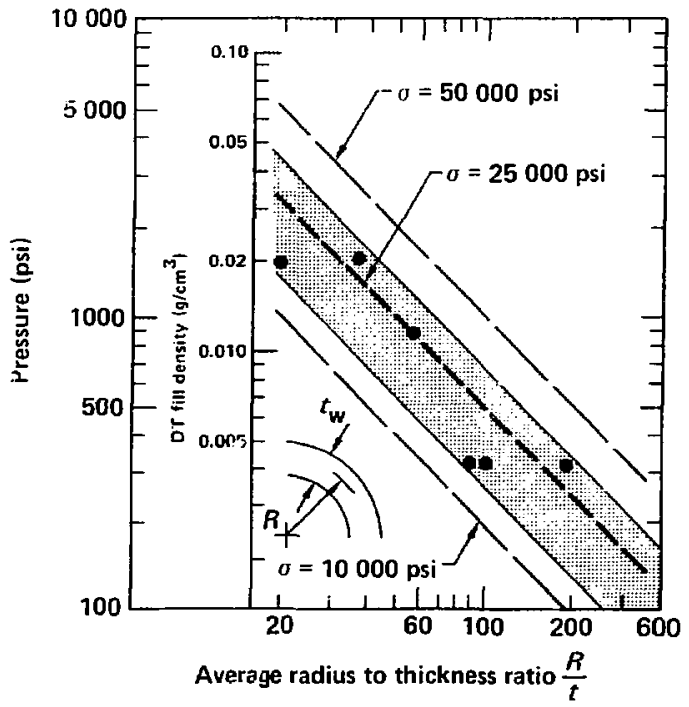

Fig. 7. Maximun fill pressure vs shell aspect ratio (radiusto-wall thickness ratio) for thin walled spherical shells. The solid lines are calculated curves for the indicated tensile strengths. The dots represent dafa for ELNL glass microspheres; most points are from earlier work by Woerner et al. ${ }^{37}$ 
The final point une must consider in using the microsphere strength data is the effect of the sphere washing cycle. Following the DT fill stap, the glass microspheres are subjected to a washing procedure designed to remove surface deposits caused by weathering. During this step, we often observe significant breakage, especially at higher fill pressures, probably due to stress corrosion at flaw sites. It is also possible that shards ejected from the failing spheres may hit neighboring shells, causing them to break.

The tensile strength of microspheres produced by the droplet technique is often lower than that for spheres produced by the dried-gel method. Spheres prepared by the gel miethod have been reported to have tensile strengths 0 : 50000 psi or greater. ${ }^{39}$ This higher strength may be due in the more durable soda-lime glass composition that is used, or the lack of a wash cycle following DT fill, or both.

To conclude this discussion of microsphere strength, we must emphasize that the tensile strength is probably the limitiag characteristic of the glass ciuring DT fill. In a previous paper, ${ }^{37}$ it was thought that the tensile and compressive strengths of the glass sphere were roughly equal and quite large $\left(\sigma_{r} \sim \sigma_{t} \sim 150000 \mathrm{psi}\right)$, and that most failures occurred by buckiing during application of the external DT pressure. As a consequence, we developed a DT fill procedure to help avoid buckling. Our current data, however, show that the effective tensile strength is much lower than previously thought, ard more in line with what is commonly measured, $A$ s a resuit, most failures occur under tension at surface flaws at the end of the DT fill cycle. The exception to this is very high aspect ratio spheres (i.e. $d_{\mathrm{s}} / t_{\mathrm{w}}>400$ ). For these size spheres the buckling pressure may be less than the desired fill pressure $\left(P_{\mathrm{f}}>P_{\mathrm{b}}\right)$. Therefore the fill would have to be carried out in steps to avoid large losses by buckling failure.

\section{Optical Transmission}

The optical transmission of the higl: and low alkalt microsphere glasses was measured between 200 to $600 \mathrm{~nm}$ (Fig. 8). The measurements were carried out on 1-mm-thick clabs cut from glass boules of nearly the same composition as our glass microspheres. As anticipated, the transmission of the higher silica content glass extends further into the ultraviolet (UV).

\section{Gas Permeability}

The permeability of silicate glasses has been extensively studied, and a sizeable body of data exists that can be used to predict the permeability hehavior of glass microspheres. The studies by Shelby ${ }^{30-46}$ and Altemose ${ }^{47,48}$ on $\mathrm{H}_{2}$ and $\mathrm{He}$ permeability in silicate glass are of particular value to our work. Souers et al. ${ }^{49}$ have reviewed these data and used them to interpret the permeability behavior of the $3 \mathrm{M}$ and $\mathrm{E} \& \mathrm{C}$ glass microspheres that were ased in early ICF experiments. More recently, Woerner et al. ${ }^{37}$ have measured the $\mathrm{D}_{2}$ and He permeability of the high alkali glass spheres and found excellent agreement with values predicted on the basis of the empirical equacions developed by Souers et al. ${ }^{4^{9}}$ These equations show the permeability $\left(K_{p}\right)$ of silicate glasses to vary with composition and temperature as

$$
K_{\mathrm{p}}=K_{\mathrm{o}} T \exp \left(-\frac{B}{T}\right) \text {. }
$$

where $K_{0}$ and $B$ depend on the concentration of network modifiers (e.g. $\mathrm{Na}_{2} \mathrm{O}, \mathrm{K}_{2} \mathrm{O}, \mathrm{CaO}, \mathrm{MgO}$,

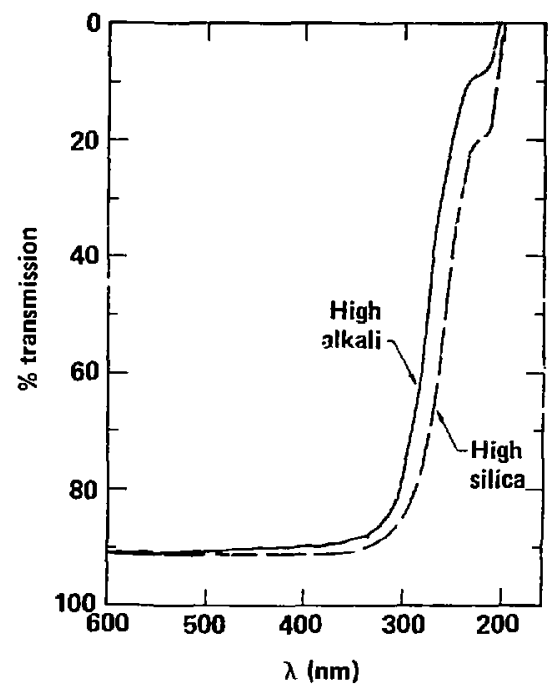

Fig. 8. Optical transm ission vs wavelength for the 1-mm-thick samples of high-alkali, and high-silica glass compositions. 
$\mathrm{Li}_{2} \mathrm{O}$, etc.) in the glass. The functional form of $K_{\mathrm{o}}$ (Table 5) is derived from the effect of the network modifiers on the interstitial holes in the silica matrix; the modifier oxides essentially block the motion of the species diffusing through the glass network. Values of the hydrogen and helit'm permeability for our high alkali and high silica glass are plotted as a function of temperature in Fig. 9.

From the given microsphere permeability values, it is a simple task to compute either gas leakage rates or gas fill rates at any given temperature. Considering the case of gas leakage, the molar flux is given by Fick's law as

$\frac{1}{A_{5}} \frac{d t_{1}}{d t}=\frac{-D_{\mathrm{g}}\left(\mathrm{C}_{\mathbf{i}}-C_{\mathbf{p}}\right)}{t_{\mathrm{w}}}$,

where $C_{\mathrm{i}}$ and $C_{\mathrm{b}}$ are the gas concentrations $\left(\mathrm{mol} / \mathrm{cm}^{3}\right)$ in the glass at the internal and external surfaces, $D_{\mathrm{g}}$ the gas diffusion coefficient $\left(\mathrm{cm}^{2} / \mathrm{s}\right)$, and $A_{s}$ the sphere surface area $\left(\mathrm{cm}^{2}\right)$. Assuming Henry's law type behavior, the concentration of gas at a glass surface is

$C_{s}=S \cdot P$

where $P$ is the gas pressure $(\mathrm{Pa}$ ) and $\mathrm{S}$ the solubility mole $/ \mathrm{cm}^{3}$. Pa. Also for an ideal gas;

$\frac{d n_{\mathrm{i}}}{d t}=\frac{V}{R T} \frac{d \mathrm{P}}{d t}$

where $V$ is the volume $\left(\mathrm{cm}^{3}\right)$, and $T$ the temperature (K). Combining Eqs. (10), (11), and (12) and noting that the permeability $\left(K_{p}\right)$ is defined by the product of the solubility and fffusion coefficient $\left(D_{g} \cdot S\right)$ gives the desired resul.

Table 5. Empirically derived gas permeability constants $K_{0}$ and $B$ reported by Souers et al. ${ }^{49}$ for $\mathrm{He}, \mathrm{H}_{2}$ and $\mathrm{D}_{2}$ in silicate glasses. [See Eq. (9) and text discussion.]

\begin{tabular}{llc}
\hline Gas & $\begin{array}{c}K_{0}^{2} \\
\left(10^{-17} \mathrm{~mol} / \mathrm{m} \cdot \mathrm{s} \cdot \mathrm{Pa} \cdot \mathrm{K}\right)\end{array}$ & $\begin{array}{c}\mathrm{B}^{2} \\
(\mathrm{~K})\end{array}$ \\
\hline${ }^{4} \mathrm{He}$ & $9.0+1.3 \times 10^{-6} \mathrm{M}^{5}$ & $2100+115 \mathrm{M}$ \\
$\mathrm{H}_{2}, \mathrm{D}_{2}$ & $3.4+8 \times 10^{-4} \mathrm{M}^{3}$ & $3600+165 \mathrm{M}$ \\
\hline
\end{tabular}

$\checkmark M$ is the mol\% of network modifiers. $\frac{d P_{i}}{d t}=\frac{3 K_{\mathrm{p}} R T}{-t_{\mathrm{s}} t_{\mathrm{u}}}\left(P_{\mathrm{i}}-P_{\mathrm{d}}\right)$

where, for the case of thin walled spheres we have assumed $\lambda / V_{s} \simeq 3 / r_{s}$. Solving Eq. (13) gives the pressure inside the sphere as a function of time

$P_{\mathrm{i}}(t)=P_{\mathrm{e}}+\Delta P[\exp (-t / \tau)]$

where $\tau$ is a time constant defined by

$\tau=\frac{r_{s} t_{w}}{3 K_{p} R T}$

and $د P$ is the initial pressure difference between the inside and outside of the sphere. Similarly, it is straightforward to show that for a step rise in the external gas pressure, the sphere will fill with gas according to

$P_{\mathrm{i}}(t)=P_{\mathrm{o}}+P_{\mathrm{e}}\left[1-\exp \left(-\frac{t}{\tau}\right)\right]$

where $P_{0}$ is the initial internal gas pressure.

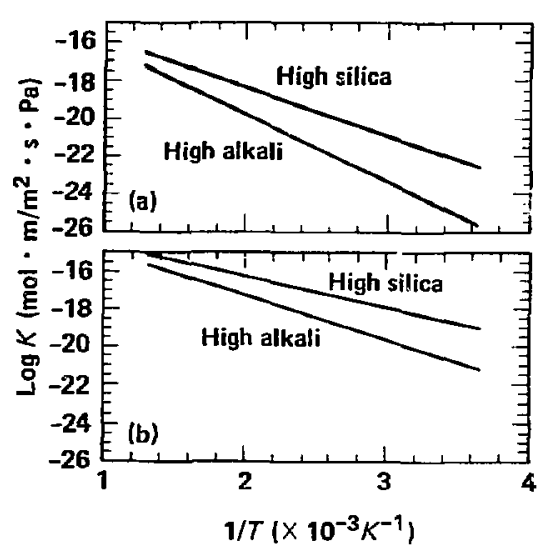

Fig. 9. (a) Hydrogen and (b) helium permeabilities as a function of $1 / T$ for the two glass microsphere compositions given in Table 3. 


\section{Microsphere Production System}

\section{Preparation and Properties of the Glass Solution}

The composition of the aqueous glass solution used in the droplet experiments is shown in Fig. 10. The initial solution typically has a solids concentration of $27.2 \%$ and is diluted to the desired concentration just prior to the experiment. For the microspheres currently being prepared, which are $\sim 150$ to $250 \mu \mathrm{m}$ in diameter, a solids concentration in the range of 14 to $18 \%$ is used. Varying the solids concentration produces a corresponding change in microsphere wall thickness as well as some charige in shell diameter.

The glass solution is prepared by mixing a commercially available sodium silicate solution with a pre-prepared solution of $\mathrm{KOH}$ and $\mathrm{H}_{3} \mathrm{BO}_{3}$. The sodium silicate solution his the composition and properties listed in Table $6 .{ }^{\top} 02150 \mathrm{~cm}^{3}$ of this silicate solution, we add $427 \mathrm{~cm}^{3}$ of distilled water. In a separate container $106.6 \mathrm{~g}$ of $\mathrm{KOH}$ and $135.2 \mathrm{~g} \mathrm{H}_{3} \mathrm{BO}_{3}$ are dissolved in $1000 \mathrm{~cm}^{3}$ of distilled water. The sodium silicate solution is then slowly added to the $\mathrm{KOH} / \mathrm{H}_{3} \mathrm{BO}_{3}$ it is important that the addition be at a slow rate to avoid high local concentrations that may cause the solution to gel. After being thoroughly mixed, the solution is filtered through $10 \mu \mathrm{m}$-pore-size millipore filters, and then stored at about $5^{\circ} \mathrm{C}$ in a Nalgene bottle. The solution has been found to be stable for several weeks. A few hours prior to making a run on the droplet system, the solution is brought to room temperature and diluted to the desired concentration. The density and viscosity ${ }^{50}$ of the solution as a function of concentration (wt\% solids; are plotted in Figs. 11 and 12, respectively.

\section{Droplet Generator}

The droplet generator is the key to the production of large numbers of uniform size, higinquality microspheres. The system presently in use

Table 6. Properties and composition of sodium silicate " $E$ " solution used in preparation of alkali borosilicate glass solution.

\begin{tabular}{lcc}
\hline Composition & w1\% & Moles/liter \\
\hline (As Oxidn) & 8.6 & 1.39 \\
\hline $\mathrm{Na}_{2} \mathrm{O}$ & 27.7 & 4.61 \\
$\mathrm{SiO}_{2}$ & & \\
$\mathrm{SiO}_{2}$ \\
$\mathrm{Na}_{2} \mathrm{O}$ & & \\
Properties (20 & & \\
\hline Visiosity $(\mathrm{cp})$ & & \\
Density $\left(\mathrm{g} / \mathrm{cm}^{3}\right)$ & 100 \\
pH & 1.37 \\
\hline
\end{tabular}

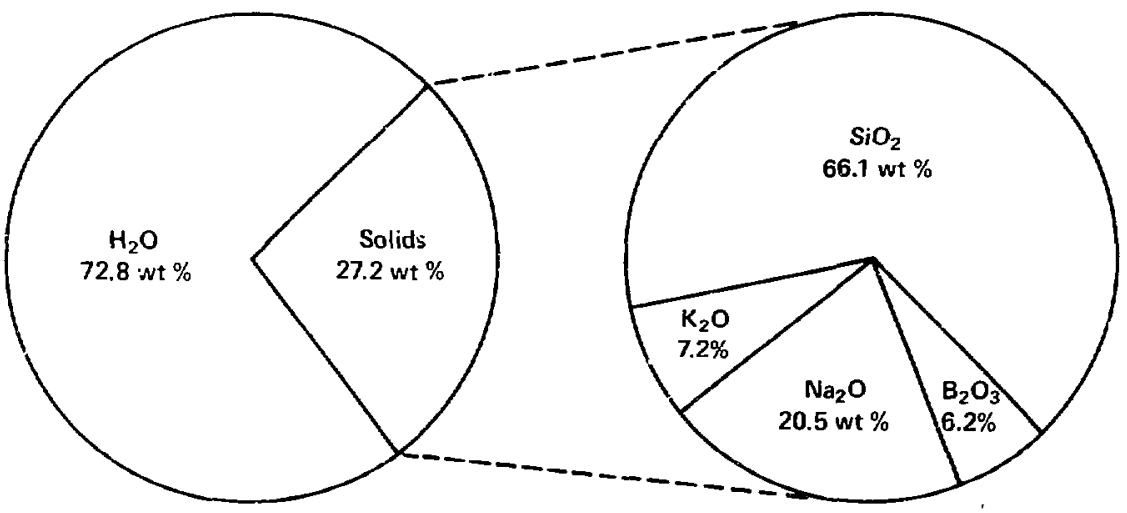

Fig. 10. Composition of aqueous alkali borosilicate glass solution used in droplet experiments. 


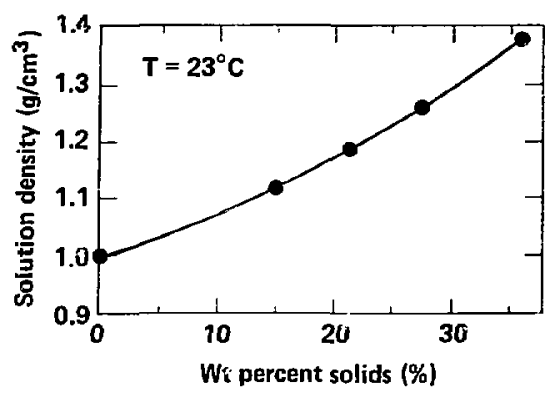

Fig. 11. Glass solution density $\left(\mathrm{g} / \mathrm{cm}^{3}\right)$ vs weight percent solids (as oxides).

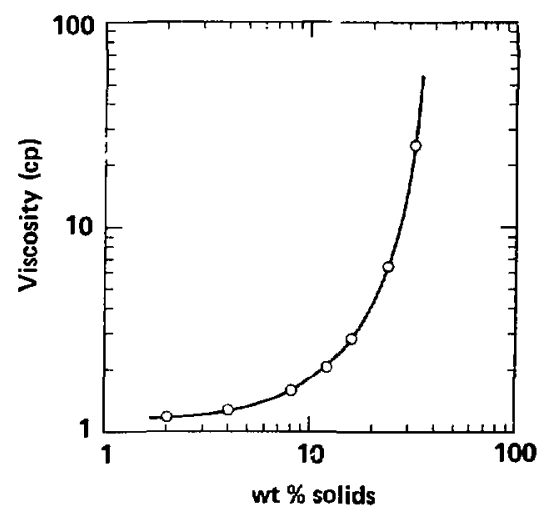

Fig. 12. Glass :olution viscosity (centipoise) as a function of weight percent solids (a : oxides). ${ }^{50}$

is based on early designs by Hendricks and coworkers, ${ }^{3,4,7}$ although some modifications and improvements have been made.

The droplet generator produces a uniform jet of fluid that is broken up into droplets by application of a constant frequency perturbation. The mechanism to break up the fluid jets was first investigated by Rayleigh ${ }^{51}$ and is often referred to as the Rayleigh mechanism. An analysis of the operation of the drop generator is given in Appendix A.
Figure 13 shows a typical fluid jet undergoing breakup by the Rayleigh mechanism. The disturbance causing the breakup has constant ivavelength $\lambda$, and grows in amplitude as it travels down the length of the jet. At the point of separation the amplitude of the disturbance is equal to or greater than the initial, unperturbed jet diameter. The photograph in rig. 13 is also interesting because it shows the oscillating droplet shape below the separation point, and the rapid damping of this oscillation by viscous effects within the droplet.

Figure 14 shows a schematic drawing of the solution feed system tn the droplet generator. The glass solution is driven under pressure from a reservoir through a millipore filter to the droplet generator. Ifre solution feed pressure is maintained at $7,00 \pm 0.01$ psi by means of a control loop that uses a pressure transducer located downstream of the millipore filter. The feed system is designed to operate at room temperature $\left(\sim 23^{\circ} \mathrm{C}\right)$.

Figure 15 shows a schematic drawing of the droplet generator, which is composed of three main parts: a piezoelectrically driven resonator stub, a droplet charging ring, and a deflectioncatcher system. These components are assembled together on a support stand.

The initial fluid jet is produced by driving the glass solution through a small orifice at the base of the resonator stub. The jet is broken up by the oscillations generated by two sinusoically driven, piezoelectric ceramic disks placed along the axis of the resonator stub.

The charging ring is placed at the point of droplet separation. By applying a positive voltage to the ring, a negative charge is induced on the drople: by the flow of electrons down the jet. Any given number of the droplets can be charged by applying a pulse to the charge ring that is both synchronous with the resonant stub and of the proper duration.

The purpose of the charging ring and the defection-catcher system is to permit the operator to select only a few of the droplets (typically 1 out of 20 to 40 ) to pass down into the drying column. Without this, a large numher of interdroplet collisions would occur within the column.

The deflection-catcher system consists of two flat electrodes, one of which contains a small fluid trough at its base. During operation, the charged droplets are defected to and caught by the trough, and then removed to a waste reservoir by an aspirator. The uncharged droplets pass through the deflection region and down into the drying column. 


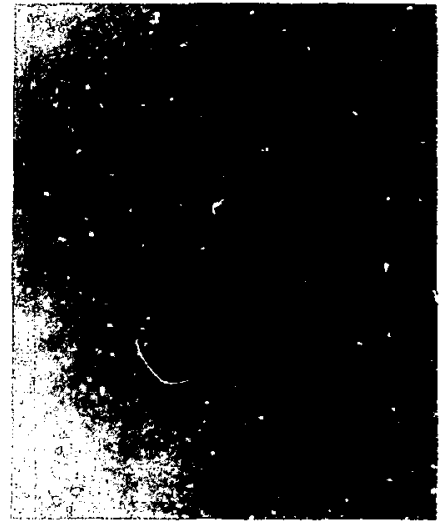

Fig. 13. Breakup of a capillary jet of glass solution into uniformly sized drops. The photo was taken using a strobe light synchronized to the frequency of the applied perturbation.

A schematic diogram of the generator system electronics is given in Fig. 16. The sinusoidal output from a sigrial generator is fed to both a variable gain amplifíter and an event counter. The output from the amplifier ( $\sim 406 \mathrm{~V}$ peak to peak maximum) is used to drive the two piezoelectric ceramic disks on the resonator stub. The events counter produces a series of output pulses each equivalent in duration to $N$ cycles of the input.
Following $N$ cycles the signal returns to baseline for the duration of the next cycle.

The output from the events counter goes to a pulse generator that produces the driving signal for both the charging amplifier and strobe light. A charging voltage of about $220 \mathrm{~V}$ is typically used. Note that the signal to the piezoelectric disk is synchronous with that to the charging ring (Fig. 16). The operator can easily change the ratio of charged-to-uncharged droplets by simply varying the number $(N)$ on the events counter. The pulse generator is coupled with an LLNL-built delay circuit permitting the operator to fine tune the width of the charging pulse.

A strobe light is used to illuminate the generator during system tuning and operation. The strobe fires on the leading edge of the $0-$ to $5-\mathrm{V}$ signal from the pulse generator. Thus the strobe operates at a frequency of $v_{g^{\prime}}(N+1)$ where $\nu_{g}$ is the frequency of the signal generator.

\section{Heated Droplet Tower}

The heated vrical column used to dry and fuse the glass microspheres is shown schematically in Fig. 17. Additional details about the dimensions and materials are given in Fig. 18.

The column is composed essentially of three heated sections: an upper, relatively cool (200 to $400^{\circ} \mathrm{C}$ ) dreple: drying and gas diffusion section, a hot $\left(1200\right.$ to $\left.1500^{\circ} \mathrm{C}\right)$ glass fusion zone, and a cool $\left(\sim 200^{\circ} \mathrm{C}\right)$ microsphere collection zone. Further details of the physical and chemical processes that

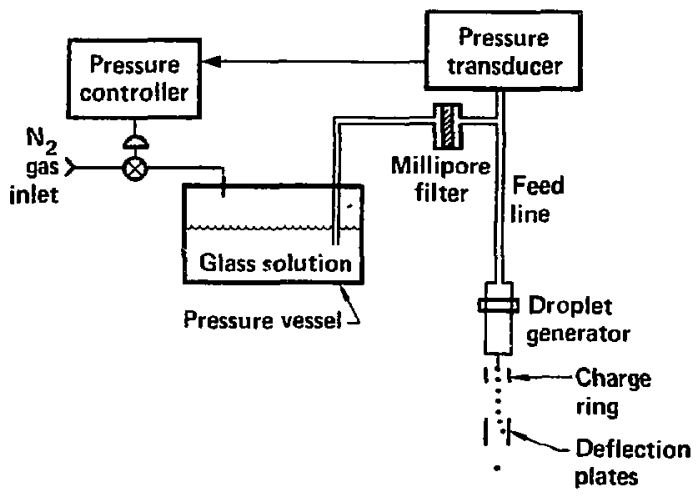

Fig. 14. Schematic drawing of solution feed system. 


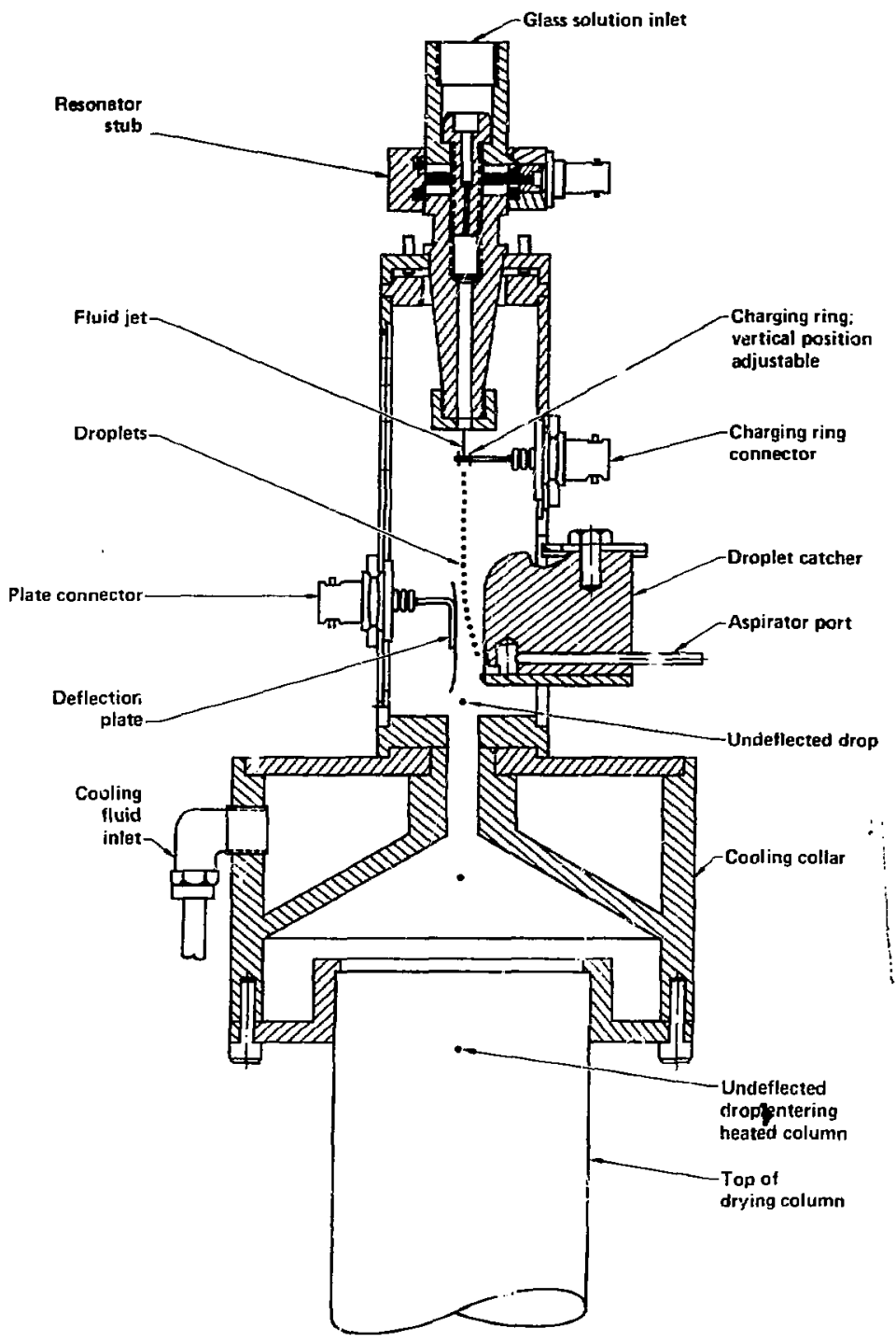

Fig. 15. Schematic drawing of droplet generator. 


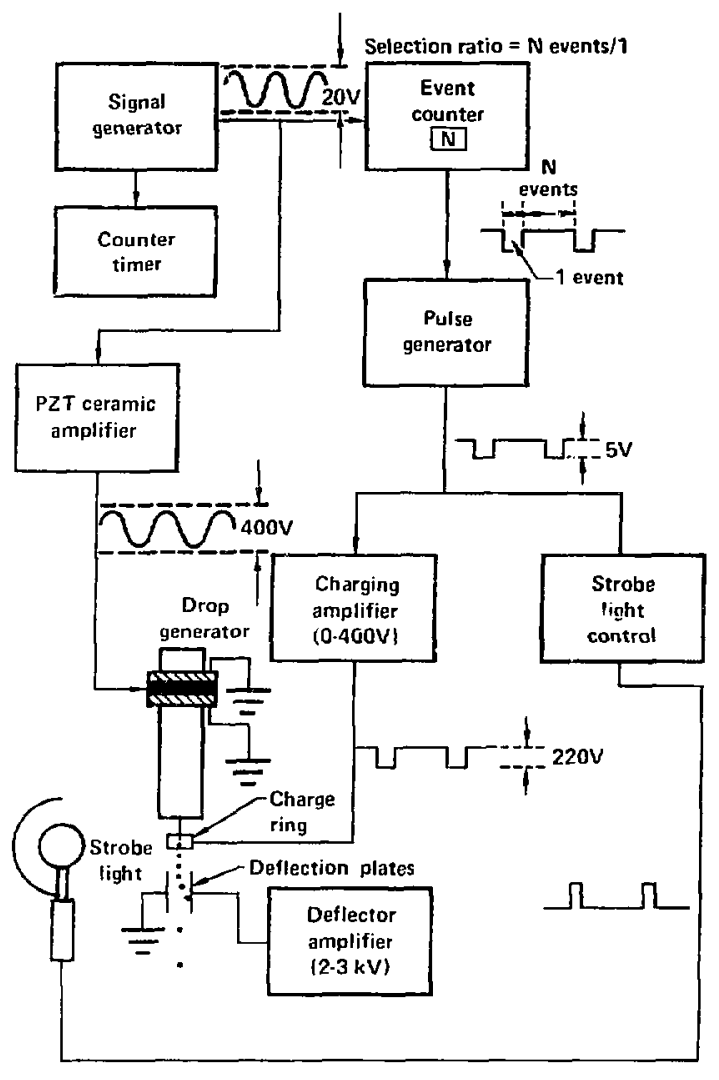

Fig. 16. Schematic drawing of generatos system electronics.

occur in these zones, and the transition regions between them, will be discussed in Section IV.

The droplet generator sits on top of a water cooled collar that caps the drying section (Figs. 15 and 17 ). This prevents heat transfer to the droplet generator and permits stable operation for prolonged periods. The dropiets pass through a hole in the center of the cooling collar and down into the drying section.

A purge gas, generally argon, is introduced through a port just below the cooling collar and vented at the base of the column near the collection plate. The purge-gas flow rate that produces the best product is about $2.4 \mathrm{~L} / \mathrm{min}$. This corre- sponds to a flow velocity of about $0.9 \mathrm{~cm} / \mathrm{s}$, at STP, in the nominal $7.6-\mathrm{cm}$-diam tube. The major purpose of the purge gas is to eliminate small convection currents that may develop in the transition regions (i.e. where the axial thermal gradient is largesi). The purge gas also serves to keep the gas composition in the column constant. This prevents time-dependent changes in the gas heat transfer characteristics (particularly thermal conductivity) and permits steady state operation over long time periods.

The ir!et and exit gas flow rates must be rlosely maiched to : void gas going in or out of the cooling collat hole (see Fig. 15). We use a wet test 


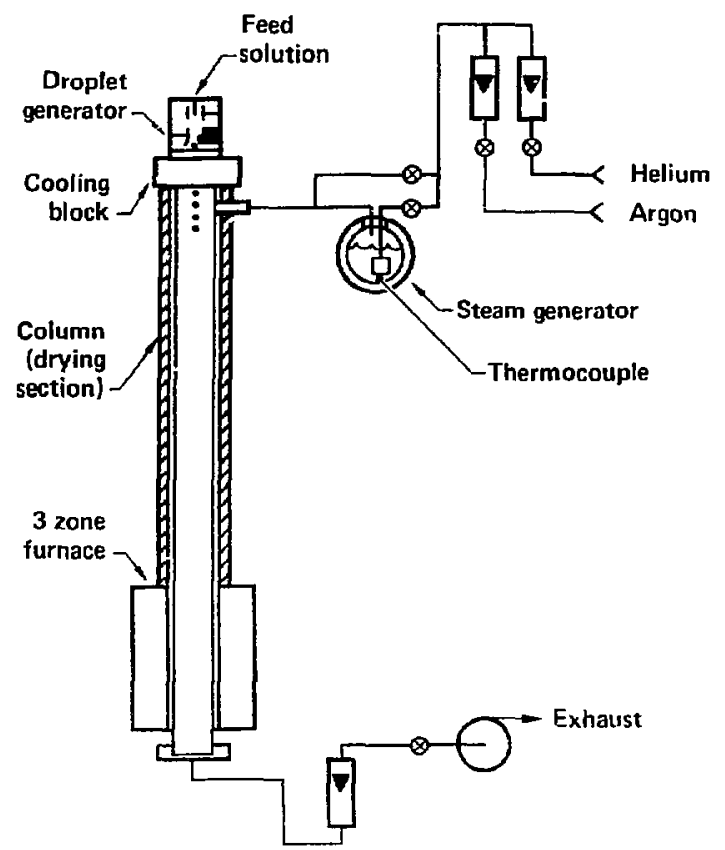

Fig. 17. Schematic diagram of droplet column and purge-gas system.

meter to balance the flow accurately. Failure to balance the flow rates causes changes in the thermal conductivity of the furnace gas. This can produce significant deterioration in microsphere quality.

We also observed that small additions of water vapor improve the sphere concentricity while retaining good surface quality. For this reason the argon purge gas is saturated with water vapor at $23^{\circ} \mathrm{C}\left(2.8\right.$ vol $\left.\% \mathrm{H}_{2} \mathrm{O}\right)$. Further additions of $\mathrm{H}_{2} \mathrm{O}$ to the gas are possible by heating the water bath. Generally, however, the additional steam seems to produce little further improvement in product quality, but it does produce some changes in product size.

By a simple mass balance, we have found that over $70 \%$ of the glass introduced in to the columr. (as droplet solution) eventually reaches the product collection plate. The $30 \%$ or less of product loss is from collisions with the column wall. Periodically the column is mechanically cleaned to remove agglomerates of glass spheres that may collect at certain points. Note that during a typical run the solids feed rate to the kolumn is only about $10 \mathrm{mg} / \mathrm{min}$, so the rate of product accumulation on the column walls is very slow.

The materials used to fabricate the column are different for the different thermal zones (Fig. 18). The upper drying section is comprised of a $265 \times 7.6 \mathrm{~cm}$ ID stainless sterl tube. Belo: this is a $122 \mathrm{~cm} \mathrm{Al} \mathrm{O}_{3}$ ceramic tu'n that passes through the $1500^{\circ} \mathrm{C}$ furnace. The ceramic tuhe is attached to the upper section using a stainless steel sleeve and Sauerizen cement (Fig. 18). The other end of the ceranic tube fits into a stainless steel collar bolted to the base of the furnace. This in turn is fastened to a $30-\mathrm{cm}$-long collector section.

The glass spheres are collected in a petri dish that rests on a remosable end cap fitted to the hottom of the column.

The upper section of the column is wrapped with six laboratory-type fiberglass heating tapes, which can withstand temperatures up to $400^{\circ} \mathrm{C}$. 


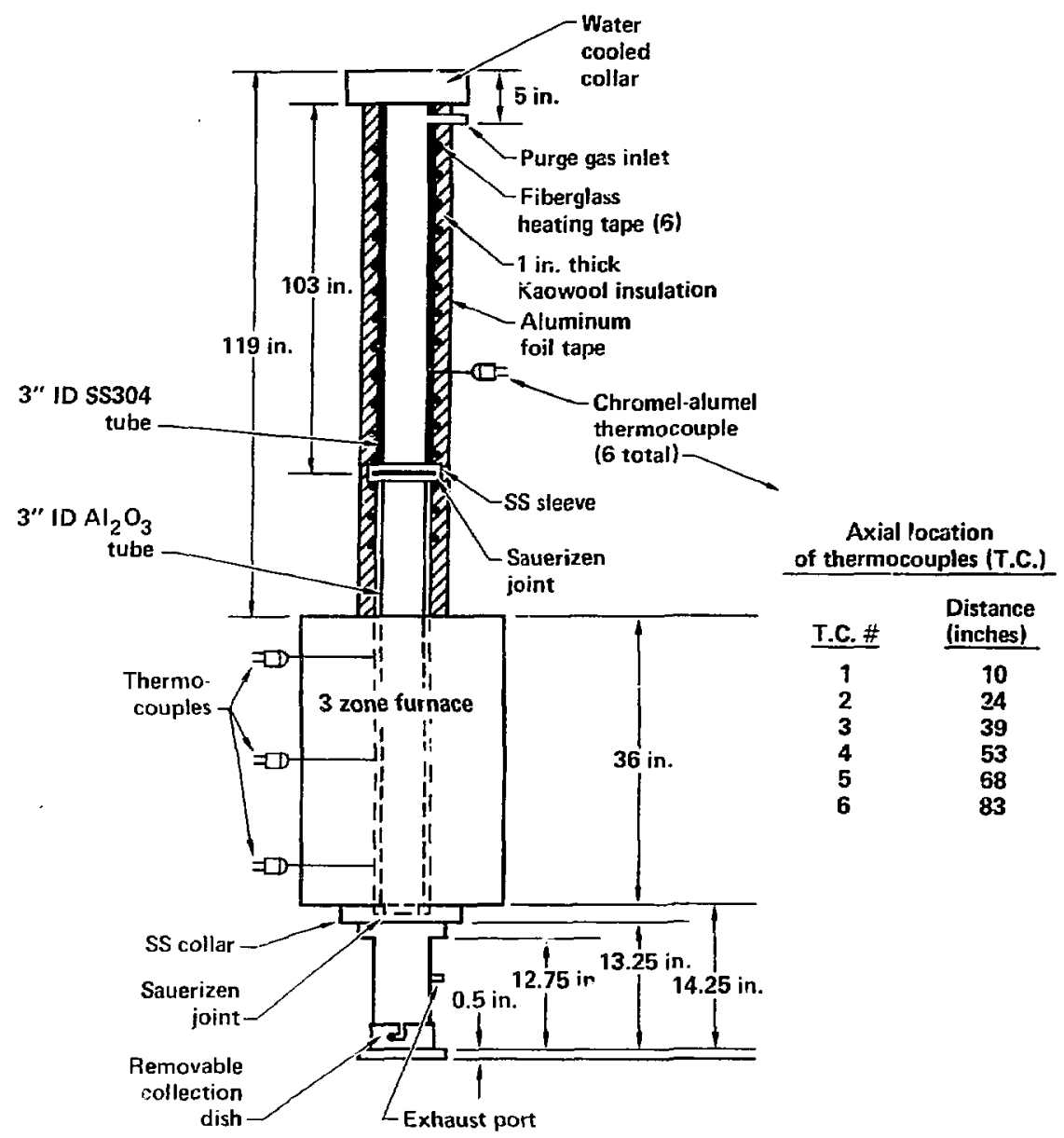

Fig. 18. Details of column construction shn wing approximate dimensions and materials.

The column is also insulated with $3.8 \mathrm{~cm}$ of Kaowool, which is over-wrapped with aluminum foil tape (Fig. 18). The temperature of each tape is controlled using a Fenwal controller with input from a type-K rhromel/alumel thermocouple. The locations of the thermocouples are given in Fig. 18.

A three zone furnace is used to fuse the dried glass spheres (Fig. 18). It is routinely operated at $1500^{\circ} \mathrm{C}$ during the course of experiments, typically about four hours. At other times it is idled at $1200^{\circ} \mathrm{C}$. The system can generally be brought up and operated within one hour. The temperature profile used during a typical production nun is shown in Fig. 19.

Except for the occasional replacemeni of a furnace heating element (about one per month) or a heating tape (about one every two months) the 


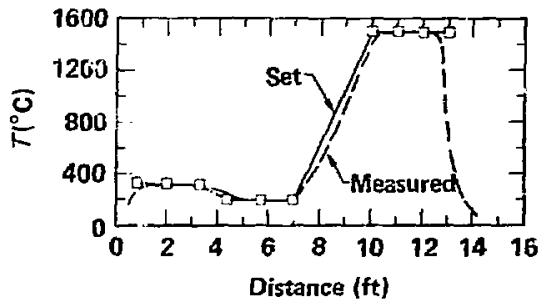

Fig. 19. Temperature profile cur:antly used to produce glass microspheres. Squares refer to controller settings.

system is essentially maintenance free. Our present droplet system has been operating continuously without a major repair for over 18 months.

Photographs of the present droplet column and droplet generator system during operation are shown in Figs. 20 and 21.

\section{Post-Run Treatment of Microspheres}

A typical production run on the droplet column lasts about 15 to 30 minutes during which time about 1.5 to $3.0 \times 10^{5}$ spheres are produced. During the course of a day, many such runs can be completed if the demand for material is great.

Once produced, the microspheres are sieved, analyzed for concentricity and wall thicknes;, washed to ren.uve weathering products and debris, and finally stored in ethanol (Fig. 22). The stored product becomes part of a larger inventory that is available for either $1 \mathrm{CF}$ target production or support of other target fabrication experiments.

We currentiy sieve the product through screens that differ in mesh size by $-25 \mu \mathrm{m}$. Ordinarily about 20 to $40 \%$ of the product falls within the sieve cut range. The remainder of the material is either too large or small and is discarded.

The wall thickness and uniformity of the microspheres are checked using an interferometric method developed by Stone et al..$^{53.53}$ and Weinstein. ${ }^{54.55} \mathrm{~A}$ dorble pass, two arm, TwymanGreen interferometer is used to make the measurements. To measure wall uniformity, several hundred microspheres are placed on a mirror in one arm of the interferometer. This mirror and the reference inirror are then adjusted until they are parallel (i.e., no "tilt" fringes are visible along the plane of the mirror). At this point each sphere will give a particular fringe patten: (Fig. 23). If the halt is unitiom, tinen the pstern of fringes will be cir cular and symmetric about the center of the sphere [Fig. 23(a)]; if there are defects, there w:!l] be deviations from the symmetrical pattern [Fig. 23(b)]

When measuring individual spheres one can only get an accurate picture of the def cis present by repositinning and remeasuring the sphere. This is because in some orientations defects may not be visible. 5 With our present production scheme we do not look at individual spheres and then reposition them. Instead, because the droplet method proc'sces very large numbers of pheres, we determine the batch quality statistical'y by examining groups of 30 to 59 sriseres at a time (Fig. 21). By counting the number of spheres showing nonsymmetric pattens (typically ahout 4) and dividing by the total number in the field of view, wo determine the fraction that is nonuniform. If this amounts tn more than $20 \%$, the batch is discarded. Most batches are beween 85 to $95 \%$ uniform product.

In a similar fashion the average wall thick. ness of a given batch of microspheres is measured using the interferometer. ${ }^{n}$ Likewise, if the wall thickness is not within specifications the entire batch is discarded.

As indicated in Fig. 22 only abc it 1 out of every 20 batches of glass spheres is rejected This gives a good indication of the consistent quality of material that can be produced by the droplet method.

\section{Microsphere Washing}

The quality of the microsphere surface finish deteriorates shortly after it is made $T \cdot \ldots$ cause of deterioration is related to either onte or both of the following: 1) weathering and assoriated accumulation of surface deposits caused by glass reaction with the gaseouc environment, or 2) contamination with debi.s $11 \mathrm{~m}$ the glass making process or particulate matter in the air or on contacted surfaces. KMS Fusion, Inc., ${ }^{11.56}$ is also investigating a third source of deterioration caused by the beta radi istion from the DT till. (Similar studies have bersn carried out to determine the effect of jonizing radiation on the weathoring of glass used to store nuclear waste; for examples, see Refs. 57 and 58.)

Weathering of glass has been the subject of intense scientific study for many years. This is primarily because of the widespread use of glass as 


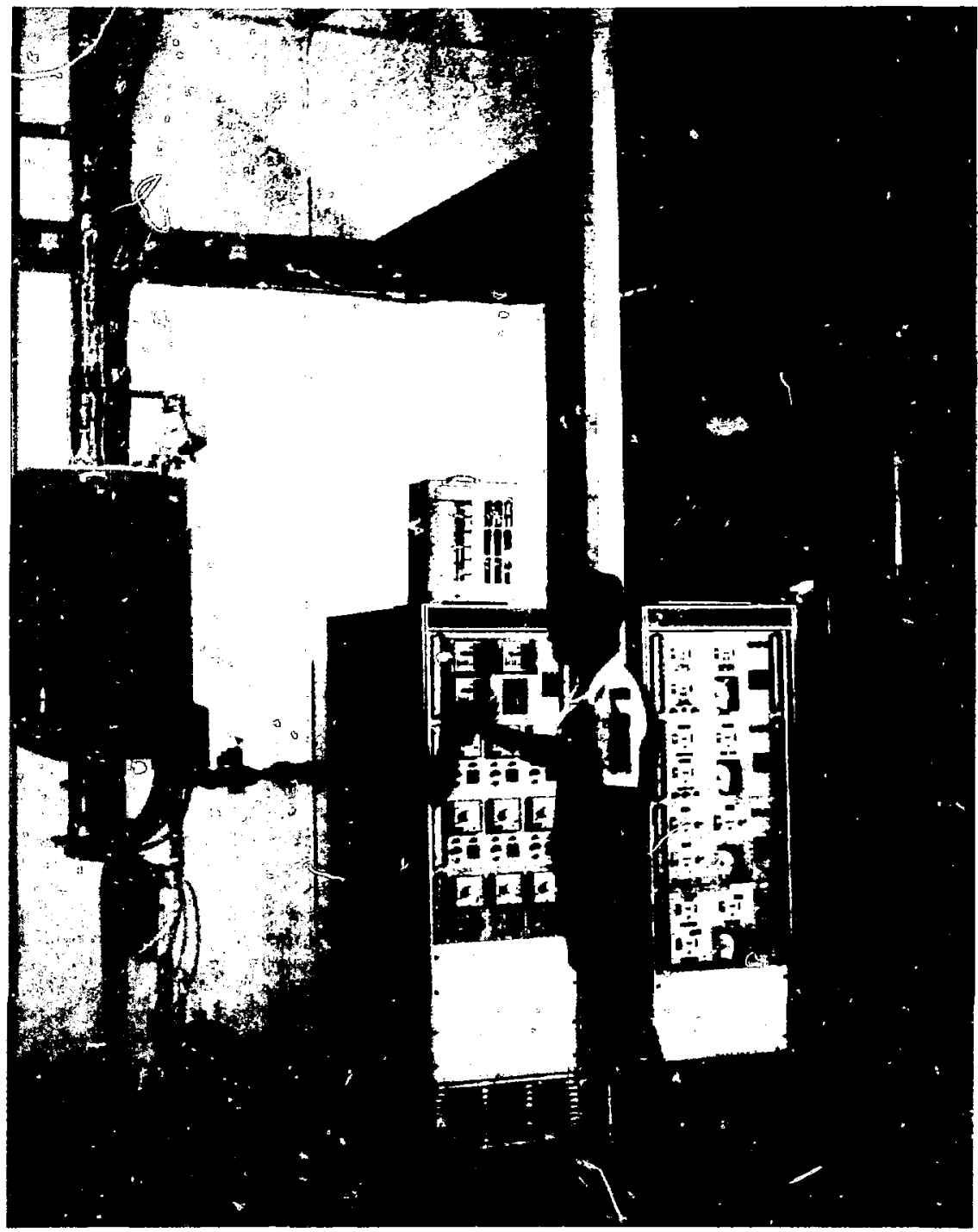

Fig. 20. Photograph of glass droplet column currently being used for glass microsphere production: (a) Drying column and glass fusion furnace (details in Fig. 18). The drying column passes up through a catwalk where the operator stands to control the drop generator. 


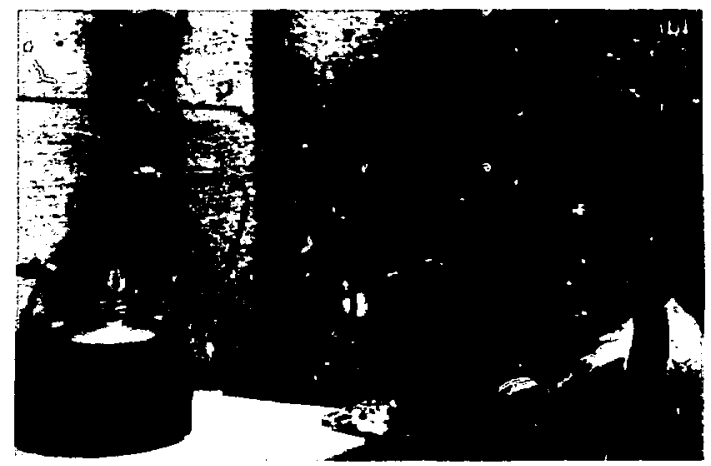

Fig. 20(b). The drop generator is mounted on the water-cooled collar that rests on top of the drying column.

both a container and optical material. An excellent review of this subject is given by Clark et al. ${ }^{12}$

Two general approaches have been used to deal with the problem of microsphere surface quality. One has been to develop methods to clean and, in some cases, passivate the glass surface. ${ }^{56.59 .60}$ The second is to prepare microspheres from glass compositions that are known to be more durable yet still meet target specifications for permeability, atomic number, strength, etc. ${ }^{10.56,61}$ T1:e latter approach has been more successful for the dried-gel technique because there are fewer solubility constraints in preparation of the starting mixture.

In the case of the alkali silicate microspheres made by the droplet techniques, the resuiting glass has very poor durability. The alkali at the glass surface rapidly reacts with waier vapor and/or $\mathrm{CO}_{2}$ in the surrounding gas environment producing surface deposits of alkali hydroxides and carbonates. The depletion of alkali at the glass surface produces a concentration gradient within the glass, which leads to further alkali migration to the surface, more reaction, and further growth of weathering products. The hydros:opic nature of the alkali hydroxides eventually causes these deposits to form small droplets of hydroxid: = solutions on the glass surface. The $\mathrm{pH}$ is sufficiently great that these droplets can dissolve the silica network and produce pits in the glass surface. ${ }^{12.59}$
Figures 25 and 26 show optical and scanning electron microscope (SEM) photographs of glass microspheres with typical growth of surface deposits from weathering.

During the course of research and development on the preparation of microspheres, a procedure was developed by Rosencwaig et al. "ig for the treatment of the glass surface to remove weathering products. This procedure entails a series of four wash steps, earn of which is repeated three consecutive times. ${ }^{54}$ The first step involves washing the spheres with a $0.5 \mathrm{M} \mathrm{HNO}_{3}+0.1 \mathrm{M} \mathrm{NH}_{4} \mathrm{~F}$ solution that is heated to $80^{\circ} \mathrm{C}$. This treatment dissolves any alkali hydroxide/carbonate deposits and aiso any small particies of siliceous debris that may be adhering to the surface.

Following the acid wash, the spheres are rinsed with distilled water that is preheated to $80^{\circ} \mathrm{C}$ This has the dual purpose of removing any remaining acid from the spheres and also exchanging $\mathrm{H}^{-}$for $\mathrm{Na}^{+}$and $\mathrm{K}^{+}$at the glass surface (i.e., leaching out alkali). It was initially hoped that this depleted zone would provide a highsilica passivation layer at the glass surface. Unfortunately, even though this wash is carried out at $80^{\circ} \mathrm{C}$, the $\mathrm{H}^{-}$and alkali diffusion rates are sufficiently large at room temperature that an equilibrium distribution of alkali is reestablished throughout the glass within about 24 hours. Haller $^{62}$ has suggested prolonged $(\sim 24$ ii) leaching of the microspheres with $100^{\circ} \mathrm{C}$ distilled water 


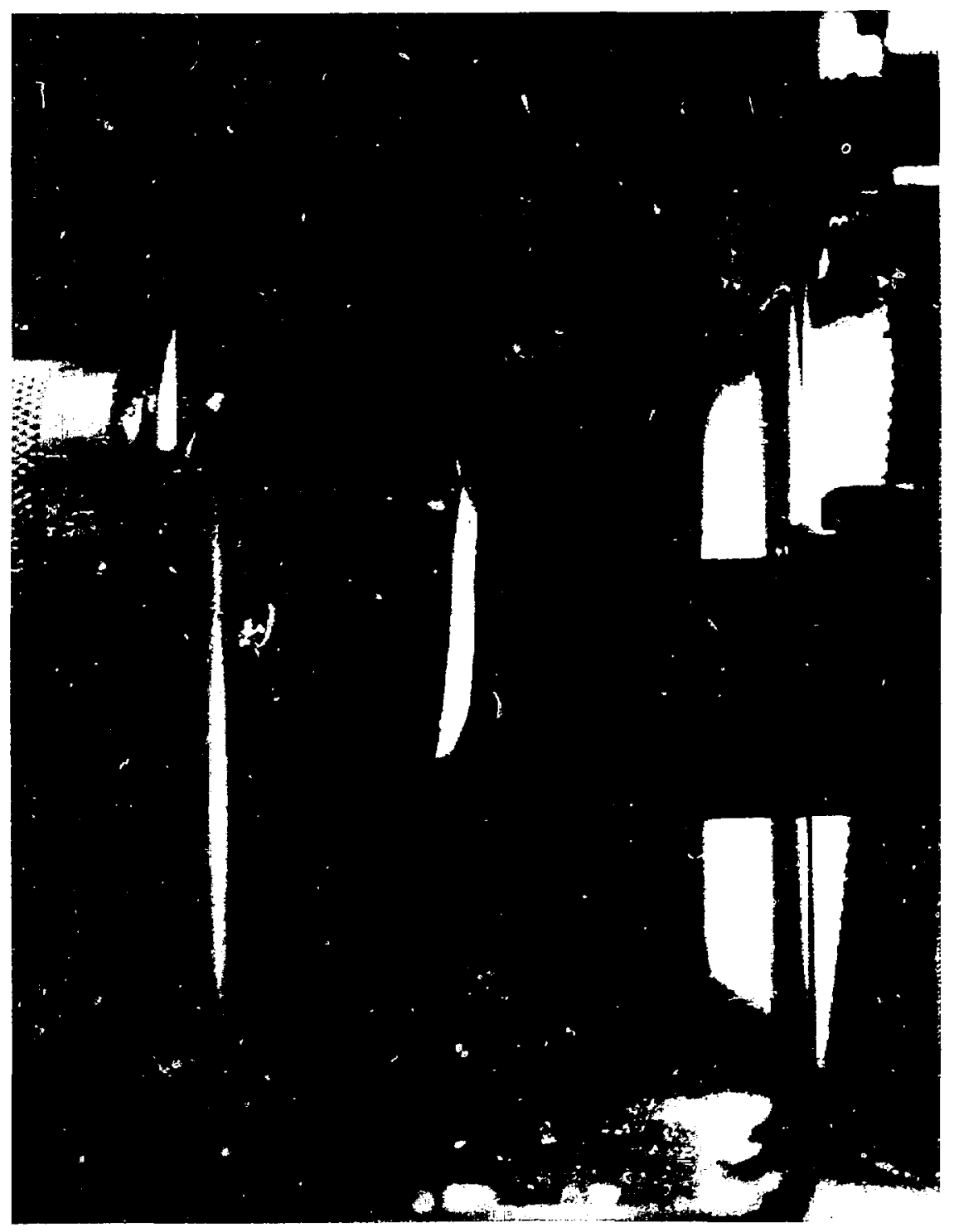

Fig. 21. Photograph of drop generator during operation. 


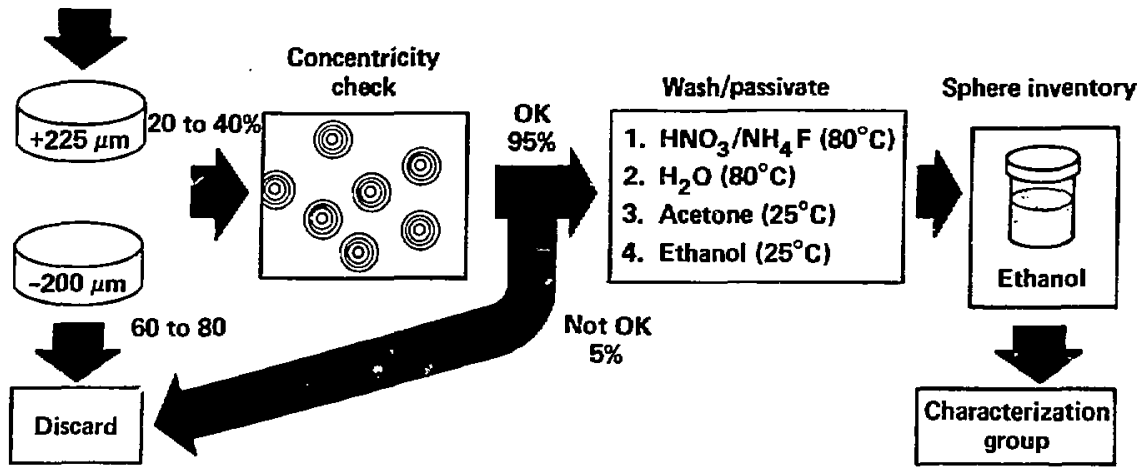

Fig. 22. Steps in post processing treatment of glass microspheres. The treated spheres become part of a larger inventory that is used to supply many other target fabrication activilies.
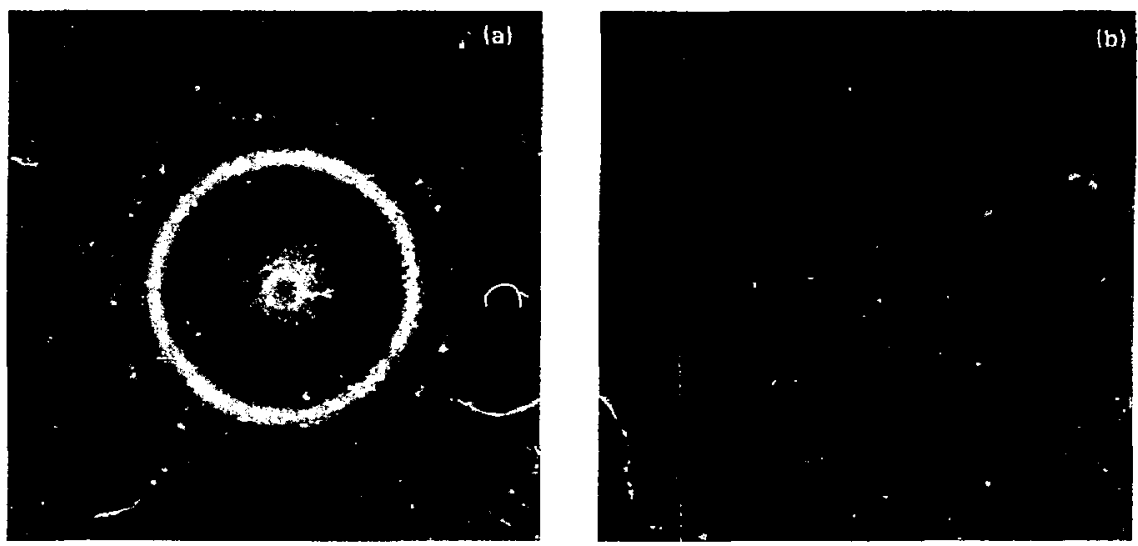

Fig. 23. Pholographs of interferometric patterns for (a) a uniform sphere and (b) sphere with wall defect. 


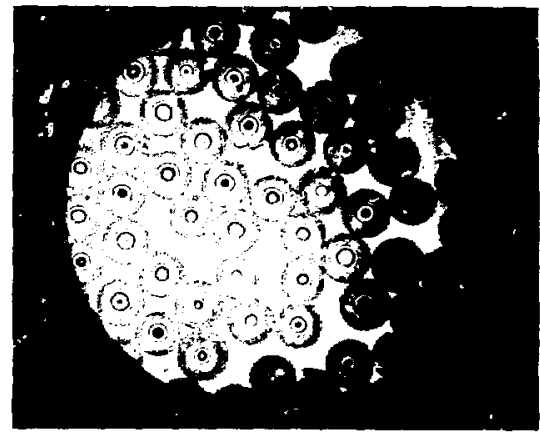

Fig. 24. Interference photo of a sample of about 50 microspheres taken from a typical batch of microspheres being used for recent ICF experiments at LLNL.

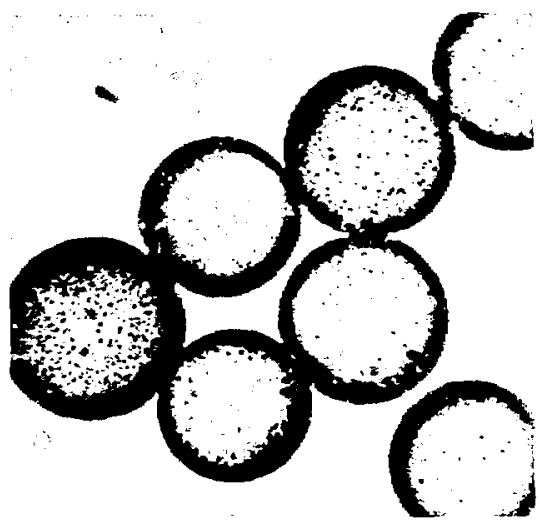

Fig. 25. Optical (back-lighted) photograph showing typical weathering spots on glass microspheres.

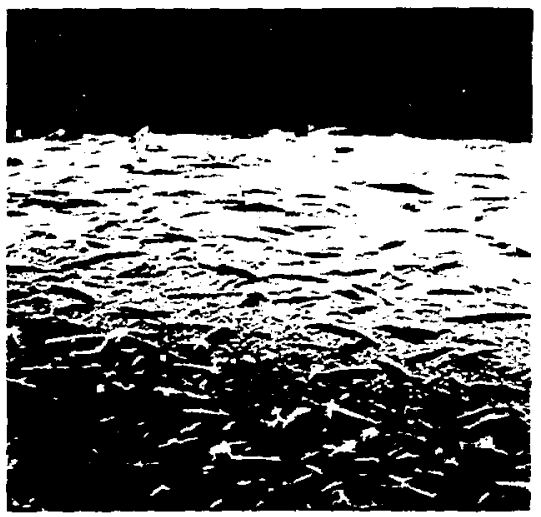

Fig. 26. SEM photograph showing typical surface growth caused by the reaction of alkali with water vapor and/or $\mathrm{CO}_{2}$ in the air. 

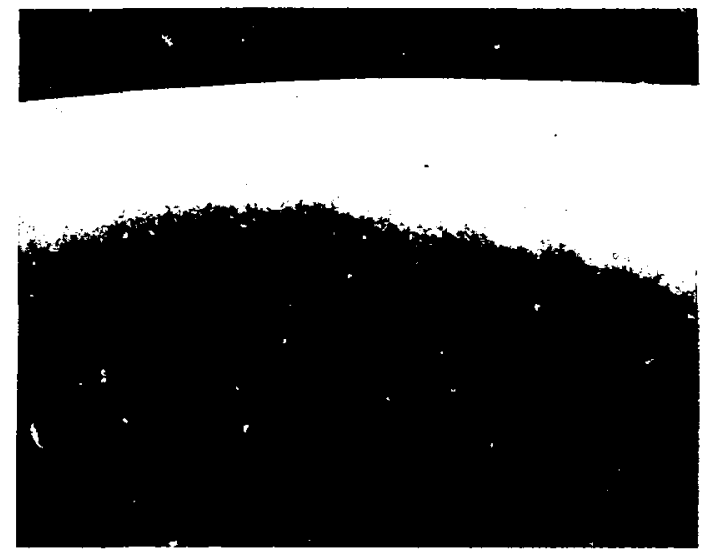

Fig. 27. SEM photograph of glass surface following treatment via the wash procedure described in the text.

to p-oduce a sufficiently thick passivation layer so that it would take many days to reestablish the equilibrium alkali distribution.

The third and fourth steps in the procedure call for washirg in reagent grade acetone and finally, $100 \%$ ethanol. The washed spheres are stored as individual batches in small, sealed vials of ethanol. Under such storage conditions the sphere surfaces remain good enough to be used for targets even after periods of up to six months. SEM photographs of the surface of a iypica! washed, glass microsphere are shown in $\mathrm{Fig} .27$.

\section{The Process of Microsphere Formation}

In this section we present a detailed description of glass microsphere formation via the droplet process. This account is based on both past ${ }^{4}$ and current experimental results, and the output from a series of 1-D model calculations. In the first part of this section, we present a physical description of the major steps in the process, using various experimental observations to support this view. On the basis of this physical picture, we develop a numerical model that simulates the major physical and chemical processes in microsphere formation. The model is used to study the effects various system parameters on the final microsphere product It is appropriate to note that droptot drying has been thoroughly investigated because of its wide spread applications in the chemical processing industry. ${ }^{63}$ In developing our physical description of the drying portion of the process, we have made extensive use of the early droplet work by Marshall and coworkers. th th Many of the experiments and their corresponding analyses pertain to the drying of single droplets of various aqueous solutions. Thus, much of this previous work serves as a strong foundation ior describing the drying stage of our process.

\section{Physical Description of Droplet Drying and Fusion}

The fate of the droplet after it leaves the droplet generator and enters the heated column is shown schematically in Figs. 28 and 29. Note that to a good approximation the process can be treatcd in two parts: the first is a drying and gas diffusion siep (Fig. 28); the second is the melting, or fusion of the sphere into the final glass product (Fig. 29). 
(a)

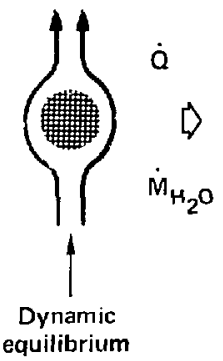

(b)

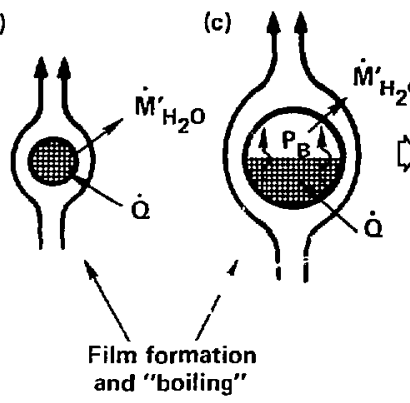

(d)

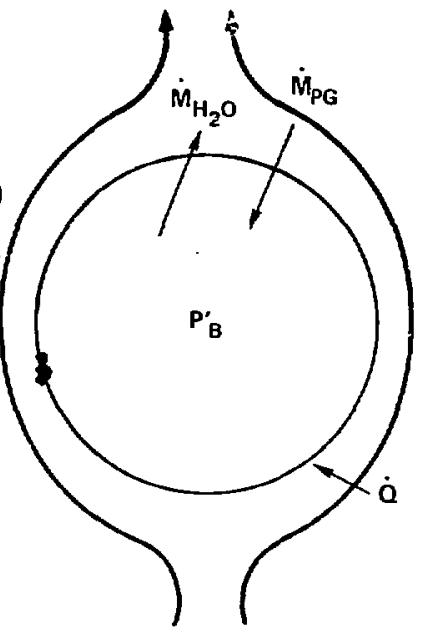

Final dry (unfused) sphere

Fig. 28. Schematic diagram of variou: stages if droplet drying. The first stage (a) is free evaporas tion from the droplet at a rate in dynamic equilibrium with the heat transfer to the surface. At the critical concentration a film forms (b) retarding evaporation; the droplet heats to the solution boiling point and begins to blow a sphere. During this stage some water vapor is still being lost through the film. Finally (c) a large hollow sphere of unfused glass is formed. Loss of steam and an influx of furnace purge gas continues at this point.

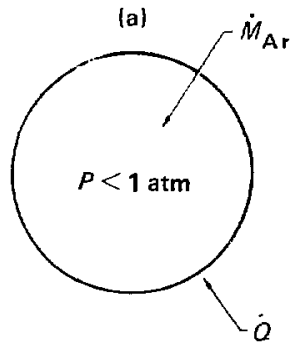

$T<900-1000^{\circ} \mathrm{C}$ (b)

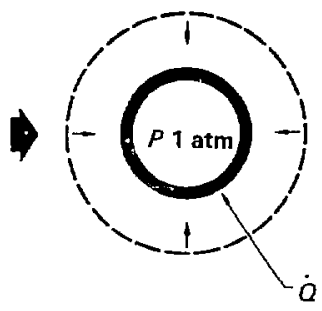

$T \sim 1000^{\circ} \mathrm{C}$ (c)

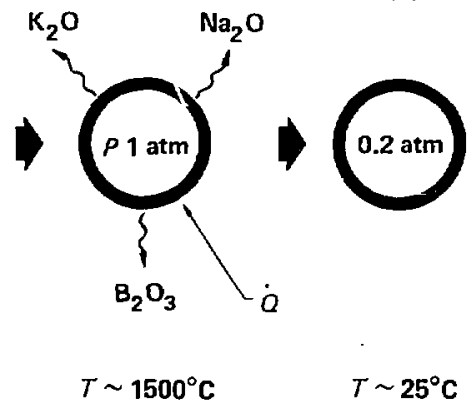

$T \sim 1500^{\circ} \mathrm{C}$

(d)

Fig. 29. Schematic diagram of the major stages in the glass fusion step: (a) transition from the drying/gas diffusion region to the high temperature zone, (b) uniform sphere collapse, (c) refining and alkali volatilization and (d) cool-down to the final microsphere product. 


\section{Droplet Drying}

Consider first the drying step. As the droplet leaves the generator, its initial velocity of approximately $700 \mathrm{~cm} / \mathrm{s}$ is much greater than the terminal velocity (see Appendix A). Accordingly, the droplet decelerates and approaches terminal velocity over roughly the first meter of the column. During deceleration a significant amount of evaporation occurs.

Having reached terminal velocity, the droplet enters a period of drying during which the moisture flux from the droplet surface is almost constant. At this stage the droplet temperature remains fixed at the adiabatic saturation, or wet bulb temperature as moisture continues to evaporate from the surface. Furthermore, the rate of evaporation is in equilibrium with the heat transfer from the surrounding gas.

Eventually the moisture content of the particle diminishes to the critical point and a surface film forms. Marshall ${ }^{65}$ observed film formation during drying of single droplets. He found that film development begins on the leading edge, or base of the droplet, spreads up to the equator, and then rapidly closes over the trailing surface, or top. In the earlier microsphere work by Rosencwaig et al., this step was referred to as encapsulation.

In our experience, the time interval for the surface film to grow completely over the surface of the droplet is small compared to the time to dry down to that point. Consequently, in our model it is assumed the surface film forms instantaneously once the droplet reaches the critical concentration.

The added mass transfer resistance of the surface film causes the evaporation rate to drop while the heat transfer rate remains largely unchanged. Hence, the temperature of the droplet begins to increase and ultimately reaches the solution boiling point (Fig; 28). The temperature of the droplet remains at the boiling point as the balance of free moisture evaporates, blowing a large, hollow shell. This drying period is critical. Whether an unruptured hollow sphere forms depends strongly on the type and strength of the surface film formed and its permeability for water vapor and the furnace purge gas.

We have measured the critical concentrations for film formation in a series of laboratory drying experiments on the silicate glass solution. Shallow pools of the solution, contained in small dishes, were dried in air at $\sim 25^{\circ} \mathrm{C}$ over a period of several days. The evaporative mass loss was determined by measuring the sample weight at various times. These data, expressed in terms of the solution concentration and rate-of-mass loss are plotted in Fig. 30. During the experiment we recorded the concentration at the first sign of film formation; this occurred at $\sim 46 \mathrm{wt} \%$. The rate of mass loss begins to decline soon after this point and becomes quite low at concentrations of about 50 to $55 w t \%$.

In our calculations we assume a concentration of $52 \%$ as the point where the film covers the sphere and decreases the mass transfer rate. This value may be slightly lower than the true value because the wet bulb temperature of the droplet is about $45^{\circ} \mathrm{C}$ as opposed to $25^{\circ} \mathrm{C}$ used for the drying experiments. Therefore, any increase in solubility with temperature will lead to correspondingly higher solution concentrations at the point of film formation.

Assuming a solution concentration of $52 \mathrm{wt} \%$ as the point of film formation, the diameter of the droplet at film-over can be easily calculated from the initial droplet size and solution concentration (Fig. 31). For example, for an initial droplet size of $250 \mathrm{~mm}$ in diameter and a solution concentration of about $18 \%$, the droplet will be about $170 \mu \mathrm{m}$ in diameter at the film-over point.

The growth of the sphere during the blowing stage [Fig. 28(b)] is controlled by the rate at which new material is being added to the shell wall and the rate of accumulation of vapor within the bubble; in other words, the difference between the boiling rate and diffusion loss. Control of this

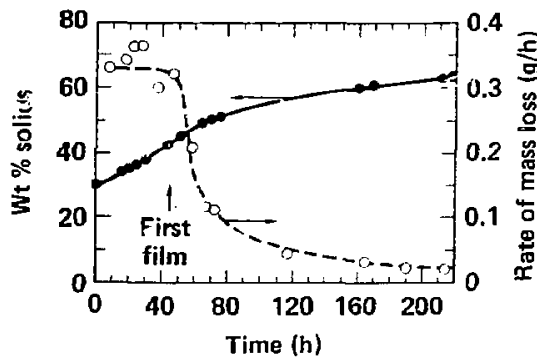

Fig. 30. Measured concentration increase and rate of mass loss during evaporative drying of the aqueous alkali borosilicate glass solution at $25^{\circ} \mathrm{C}$. The first sign of film formation was observed at about 45 hours at a solid concentration of $46 \mathrm{wt} \%$. 


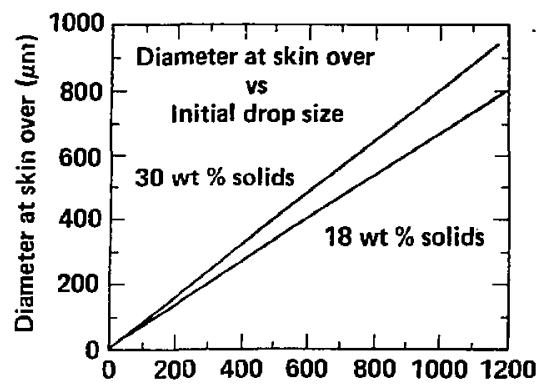

Initial droplet diameter $(\mu \mathrm{m})$

Fig. 31. Droplet diameter at film-over vs the initial (generator) droplet size. The plot is for starting glass solution concentrations of 18 and $30 \mathrm{wt} \%$.

stage of the process is important. If the drying rate is too high, the strain rate will exceed some critical value and the shell membrane will rupture. On the other hand, if the drying rate is too low, the shell will have insufficient time to dry and/or diffuse out water vapor and thus will rupture or deform upon entering the $\mathbf{h i}_{\zeta}$ h temperature region of the column.

For a single solvent syslem there are essentially two variables for contioiling the rate of drying: 1) the furnace temperature, and 2) the thermal conductivity of the purge gas. Normally for our system, we rontrol drying via the column temperature profile. However, variations in the purge-gas composition can be just as effective.

Because of the drying sensitivity to purge-gas composition (i.e., thermal conductivity) we have found that a slight influx of air into uur normal argon purge gas is sufficient to upset the normal drying process and drastically reduce product yield; the thermal conductivity of air is about $50 \%$ greater than that for argon. This effect is quantified in the modelling section and Appendix B.

Once the hollow sphere forms, the water vapor within continues to diffuse out through the shell wall. Similarly, the purge-gas counter diffuses into the sphere [Fig. 28(c)]. However, because the shell permeability is greater for water vapor than the furnace purge gas, the internal gas pressure declines. The strength of the unfused glass shell is sufficient to maintain the pressure difference up until the shell enters the glass fusion furnace.
A photograph of a typical large unfused glass microsphere is shown in Fig. 32. We have measured the diameter of these spheres at the end of the drying section of our present production column and found they range frum $\sim 1300$ to $1450 \mu \mathrm{m}$ with an average of $1385 \mu \mathrm{m}$. The wall thickness is about $0.2 \mu \mathrm{m}$. The starting droplet is approximately $230 \mu \mathrm{m}$ in diameter and contains 18 wt\% solids as oxides.

If the column is operating correctly, more than $50 \%$ of the dried product will be large, unfused glass spheres. Therefore, examination of the product at this point provides a rapid appraisal of whether the temperature, purge-gas composition, flow rate, etc. are properly adjusted.

\section{Glass Fusion}

The unfused glass sphere eventually falls out of the drying zone and begins to enter the high temperature zone. The terminal velocity of the large unfused sphere is quite low $(\sim 5 \mathrm{~cm} / \mathrm{s}) \mathrm{sn}$ it requires several seconds to drift through the transition region between the two zones. The purgegas tow is $\sim 3 \mathrm{~cm} / \mathrm{s}$ in this temperature region, so the velocity of the sphere relative to the column is about $8 \mathrm{~cm} / \mathrm{s}$. The temperature gradient in this portion of the column is about $13^{\circ} \mathrm{C} / \mathrm{cm}$ (see Fig. 19) so the sphere heats at a raise of roughl; $100^{\circ} \mathrm{C} / \mathrm{s}$.

During this time th: purge gas and water vapor continue to diffuse in and out of the shell respectively (Fig. 29). The diffusion rates increase

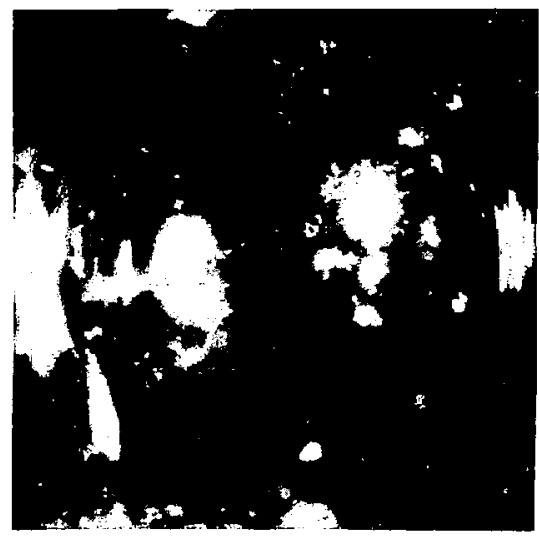

Fig. 32. Large, unfused glass sphere produced at the end of the drying section. 
due to the Arrhenius type temperature dependence of the diffusiun constant and permeability. The time in this zone is important since the next stage of the process depends on having the correct gas pressure rithin the sphere.

As the sphere continues to heat, the viscosity of the glass decreases. A point is reached where the sphere begins to collapse under the driving force of the pressure gradient across the shell wall [Fig. 29(b)]. Hopper ${ }^{70}$ has recently examined the mechanism of microsphere collapse in this region and calculated that the collapse occurs quite rapidly, usually in less than 1 s once the temperature reaclies about $800^{\circ} \mathrm{C}$. This agrees well with our recent observations and also the earlier work by Rosencwaig et al. ${ }^{4}$ As soon as the sphere collapses, its terminal velocity increases about an order of magnitude.

The aphere continues to heat as it falls into the highest tcmperature regions of the furnace. The viscosity of the glass becomes low enough that the sphere will expand slightly with the heating of the interior gas.

Oncr the sphere reaches $15 \mathrm{iU}^{\circ} \mathrm{C}$, the glass viscosity is quite low and refining of the concentricity and surface finish can occur even with the short residence time ( $\sim 1$ to $2 \mathrm{~s})$ in this zone.

As discussed in Section II, the composition of the glass changes in the high temperature region due to alkali volatilization (Fig. 33). This has the effect of increasing the glass viscosity markedly (e.g., see Fig. 6). There is a subtle but important

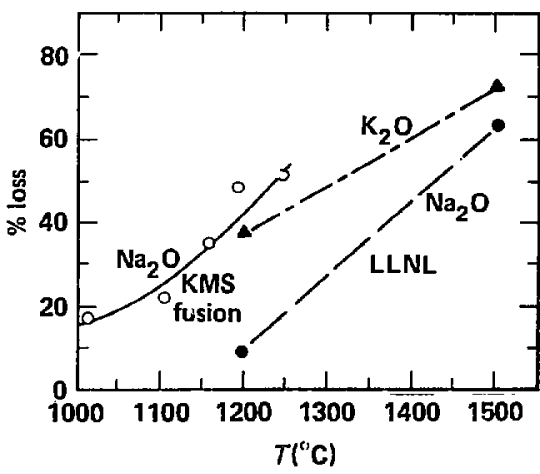

Fig. 33. Percent alkali loss by volatilization during glass microsphere formation. The $\mathrm{Na}_{2} \mathrm{O}$ data labelled "KMSF" are from Ref. 71 for the dried-gel method. point that emerges in regard to this observation. One would often like to run the glass fumace at as high a tempcrature as possible in order to increase the amount of refining of the glass. The refining is generally thought to be controlled by the viscosity, so operating at higher temperatures should produce better spheres. This is true to a point. At the higher temperatures, such as $1500^{\circ} \mathrm{C}$, so much alkali is lost, and the viscosity greatly increased, that further increases in temperature may be self defeating.

During the course of our experiments we observed that increasing furnace temperatures up to $1300^{\circ} \mathrm{C}$ has a dramatic effect on improving the concentricity and wall uniformity of the product. On the other hand, increasing the temperature from 1400 to $1500^{\circ} \mathrm{C}$ produces very little improvement in the product (Fig. 34), possibly as a result of the increasing glass viscosity caused by additional alkali loss.

The sodium loss at $1200^{\circ} \mathrm{C}$ is about $9 \%$ (Fig, 33) based on the glass analysis reported by Rosencwaig et al. ${ }^{4}$ Based on data from Doletzky et al. ${ }^{71}$ at KMSF, this value may be low. They have measured sodium loss during microsphere formation by the dried-gel technique between 1000 and $1300^{\circ} \mathrm{C}$. Their data show a smooth trend following an Arrhenius-lype temperature dependence (F:g. 33) with a $\mathrm{Na}_{2} \mathrm{O}$ loss of about $45 \%$ at $1200^{\circ} \mathrm{C}$. The KMS Fusion, Inc., dried-gel method uses a longer hot zone $(\sim 2 \mathrm{~m})$ so some increase in volatilization is expected. However, it is unlikely that the difference in sodium loss between the two methods would be as large as indicated. Data from some unpublished analysis of the $1200^{\circ} \mathrm{C}$ droplet glass indicate the $\mathrm{Na}_{2} \mathrm{O}$ concentration may be nearer 17 to $19 \mathrm{wt} \%$. This would represent a sodium loss of about $25 \%$, in closer agreement with the data from Doletsky et al. ${ }^{71}$ As expected the $\mathrm{K}_{2} \mathrm{O}$ loss is higher than that for $\mathrm{Na}_{2} \mathrm{O}$.

As the sphere exits the fusion region, it shrinks slightly as the column temperature decreases. However, the sphere soon cools to where the glass becomes rigid enough to stop further shrinkage. Based on the measured residual gas pressure of $0.2 \mathrm{~atm},{ }^{29}$ this occurs at about $1100^{\circ} \mathrm{C}$, corresponding to a glass viscosity of $10^{3.5}-10^{4}$ poise, a value determined from an extrapolation of the low alkali glass data in Fig. 6 .

\section{Mathematical Model of Microsphere Formation}

Based on the physical description given in the previous section, we have developed a numerical 

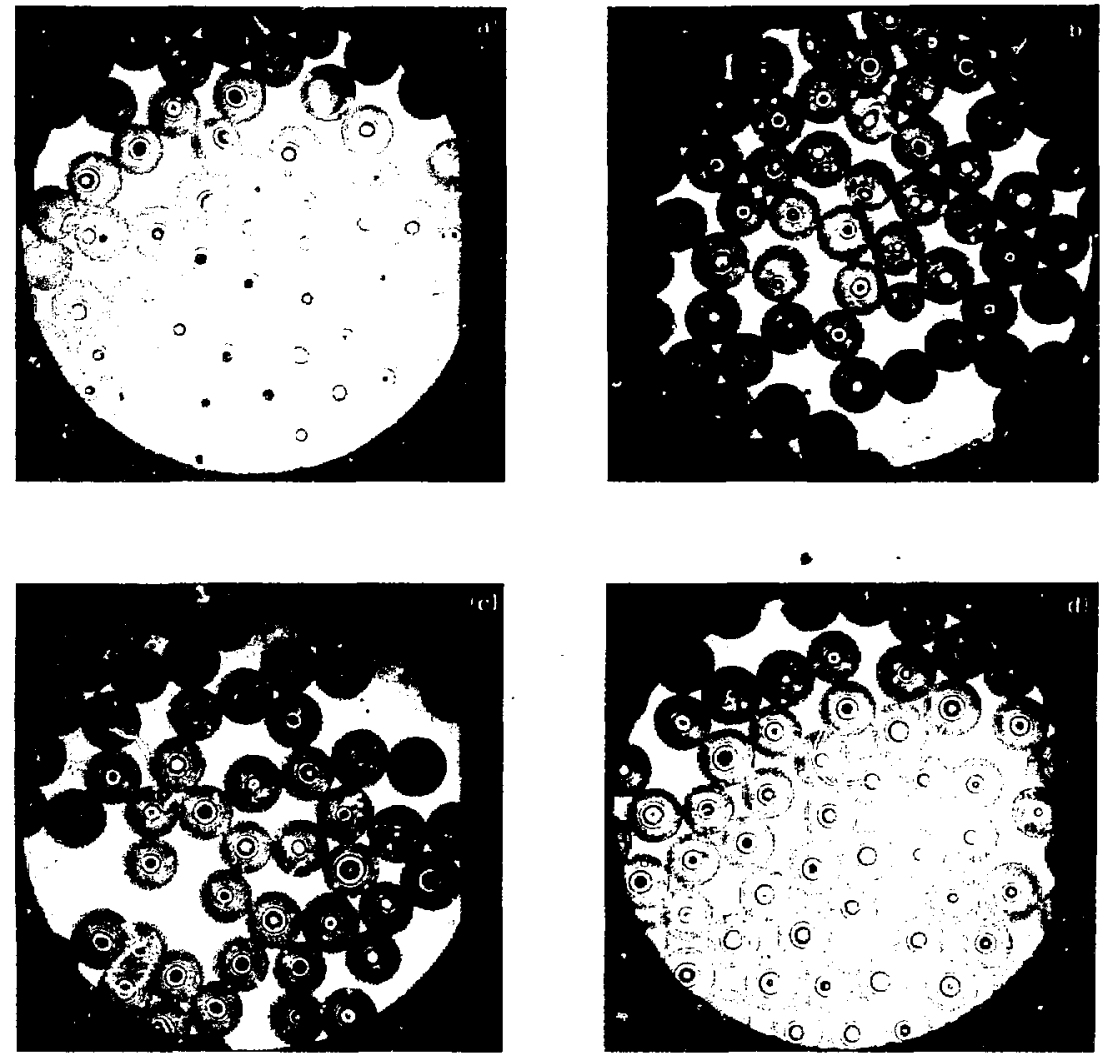

Fig. 34. Interference photos showing product quality improvement with increasing furnace temperature (a) $1200^{\circ} \mathrm{C}$, (b) $1300^{\circ} \mathrm{C}$, (c) $1400^{\circ} \mathrm{C}$, and (d) $1500^{\circ} \mathrm{C}$.

model that simulates the microsphere formation process. The major assumptions we used to develop the model are summarized in Table? and discussed in further detail in the paragraphs that follow. The numerical values used for the various transport coefficients and other parameters are summarized in Table 8 .

\section{Droplet Drying and Gas Diffusion}

The basic equations used to calculate the droplet velocity and rates of heat and mass transfer during the drop drying stage are summarized
Table 7. Summary of major assumptions used in 1-D microsphere model.

- Transport properties can be represented by average values across the boundary layer.

- Conduction is only heat transfer mode in the drying zone.

- Once free moisture has been removed the microsphere temperature tracks that of the heated column.

- Film oyer occurs instantaneously once the critical concentration is reached.

- Shell collapse (in fusion zone) occurs uniformly in a time short compared to the residence time. 
Table 8. Summary of values for various transport coefficients and other key parameters used in model calculations (argon/water system) ( $T$ in kelvin).

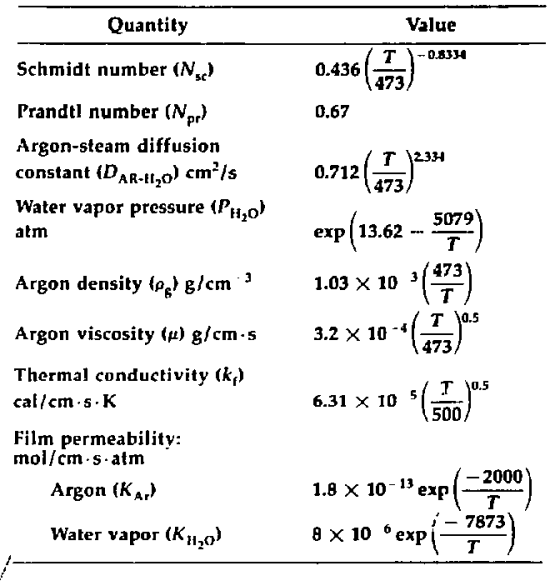

in Table 9. Also given is a brief physical description of the corresponding drying conditions. The variables and dimensionless numbers used in our calculations are defined in the symbol table.

The evaporation rate for a droplet in a moving gas stream is simply a product of the masstransfer coefficient, $h_{\mathrm{m}}$, the droplet surface area, and the concentration difference across the gas boundary layer

$\frac{d m}{d t}=h_{\mathrm{m}} \pi D_{\Gamma}^{2} \frac{\Delta p_{\mathrm{v}}}{R T} M_{\mathrm{w}}$.

The water vapor loss by evaporation accumulates in the purge-gas stream to produce a slight increase in steam content down the axial length of the column. For a nonzero purge-gas flow this soon reaches a steady-state value.

The corresponding equation describing the rate of heat transport is

$\frac{d Q}{d t}=h_{\mathrm{q}} \pi D_{\mathrm{p}}^{2}(\Delta T)$,

where the driving force is the temperature drop, $\Delta T$, across the boundary layer, and $h_{\mathrm{q}}$ is the heattransfer coefficient.
Both heat- and mass-transport coefficients can be represented in terms of the dimensionless Nusselt (Nu) and Sherwood (Sh) numbers

$\mathrm{Nu}=H_{\mathrm{q}} \frac{D_{\mathrm{p}}}{k_{\mathrm{f}}}$

and

$\mathrm{Sh}=h_{\mathrm{m}} \frac{D_{\Gamma}}{D_{\mathrm{v}}}$.

Substitution of the dimensionless groups into Eqs. (17) and (18) leads to the expressions given in Table 9.

Numerous experimental measurements of heat- and mass-transfer rates under different flow conditions have established the following we!lknown empirical correlations for the Nusselt and

- Sherwood numbers in terms of other dimensionless groups $\mathrm{s}^{\mathrm{f} 3.72}$

$\mathrm{Nu}=2+0.6(\mathrm{Re})^{1 / 2}(\mathrm{Pr})^{1 / 3}$

and

$\mathrm{Sh}=2+0.6(\operatorname{Re})^{1 / 2}(\mathrm{Sc})^{1 / 3}$

The Reynolds, Prandtl, and Schmidt numbers in Eqs. (21) and (22) are defined, respectively, as

$\operatorname{Re}=\frac{D_{\mathrm{p}} v \rho_{\mathrm{g}}}{\mu}$,

$\operatorname{Pr}=C_{\mathrm{p}} \frac{\mu}{k_{\mathrm{f}}}$.

$\mathrm{Sc}=\frac{\mu}{D_{\mathrm{v}} \rho_{\mathrm{g}}}$

Using Eqs. (21) through (25), it is now possible to calculate the heat- and mass-transfer rates from measured physical properties of the system.

During the initial drying stages, before a film forms around the droplet, the rates of $h$ at and mass transport are in dynamic equilibrium. Under these conditions, the particle temperature remains at the adiabatic saturation value, and the rate of evaporation is simply

$\frac{d m}{d t}=\frac{1}{\Delta H_{Q}} \frac{d Q}{d t}$

whire $\Delta H_{\ell}$ is the latent heat of vaporization. 
Table 9. Summary of drying stages and governing equa...ns used in model calculations.

\begin{tabular}{|c|c|c|}
\hline $\begin{array}{l}\text { Drying } \\
\text { stage }\end{array}$ & Physical description & Governing equations \\
\hline 1a & $\begin{array}{l}\text { Unsaturated solution; droplet deceleration to } \\
\text { terminal velocity; droplet at adiabatic } \\
\text { saturation temperature. }\end{array}$ & $\begin{array}{l}\text { deceleration": } \frac{d v}{d t}=\frac{3}{4} \frac{C_{\mathrm{d}} \rho_{\mathrm{g}} v^{2}}{D_{\mathrm{p}} \rho_{\mathrm{p}}}-8 \\
\text { mass transfer: } \frac{d m}{d t}=\pi D_{\mathrm{p}} D_{\mathrm{v}} \mathrm{Nu}\left(\frac{\Delta P_{\mathrm{v}} M_{\mathrm{v}}}{N T}\right) \\
\text { heal transfer: } \frac{d Q}{d t}=\pi D_{\mathrm{p}} k_{\mathrm{i}} \mathrm{Sh}(\Delta T)\end{array}$ \\
\hline $1 b$ & $\begin{array}{l}\text { Unsaturated solution; droplet at terminal } \\
\text { velocity and adiabatic saturation } \\
\text { temperature. }\end{array}$ & 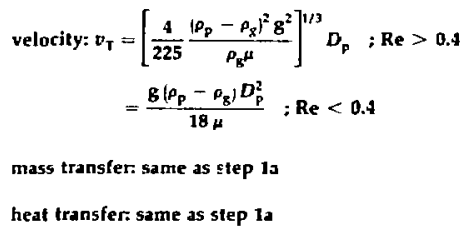 \\
\hline 2 & $\begin{array}{l}\text { Saturated solution, skin formation occurs; } \\
\text { mass transfer rate decreases. }\end{array}$ & $\begin{array}{l}\text { velocity: same as in step } 1 \mathrm{~b} \\
\text { mass transfer: } \frac{d m}{d t}=h_{\mathrm{o}} \approx D_{\mathrm{p}}^{2}\left(\frac{\Delta P_{\mathrm{v}} M_{\mathrm{w}}}{R T}\right) \\
\text { heat transfer: same as in slep } \mathrm{la}_{\mathrm{a}}\end{array}$ \\
\hline 3 & $\begin{array}{l}\text { Membrane encloses vapor and liquid phases. } \\
\text { Temperature - boiling point of solution. }\end{array}$ & $\begin{array}{l}\text { velocity: sime as in step Ib } \\
\text { mass transfer: same as in step } 2 \\
\text { heat transfer: } \frac{d Q}{d t}=h_{q} A_{e t f}(\Delta T)\end{array}$ \\
\hline 4 & $\begin{array}{l}\text { Liquid evaporation is complefe: particle heats } \\
\text { to furmace temperature. }\end{array}$ & $\begin{array}{l}\text { velocity: sime as in step Ib } \\
\text { mass transfer: } \frac{d m}{d t}=\frac{A_{4}}{f_{w}}\left(K_{g} \Delta P_{g}-K_{s} \Delta P_{a}\right) \\
\text { heat transfer: same } J^{\prime} \text {, in step } I_{a}\end{array}$ \\
\hline
\end{tabular}

"The drag coefticiont is computed using the particle velccity at the previous time step, i.e., $C_{D}=10 / R^{1 / 2} ; R_{e} ; 0.4$.

As mentioned previously, once the droplet solution $r$ aches the critical concentration and a surface filu, forms, the mass-transfer rate drops dramatically. During this drying stage, the rate of mass transport is calculated using an overall mass-transfer coefficient, $h_{v}$, given by

$h_{\mathrm{c}}=\frac{h_{\mathrm{m}} h_{\mathrm{b}}}{h_{\mathrm{m}}+h_{\mathrm{b}}}$,

where $h_{b}$, is the mass-transfer coefficient across the barrier membrane of thickness, $\ell$, given by

$h_{\mathrm{b}}=\frac{K_{\mathrm{m}} \Delta p_{\mathrm{t}}}{\ell}$.
As the liquid continues to evaporate, a gas bubble begins to form inside the film membrane (provided the membrane permeability is low enough). As a consequence, the effective area for heat transter, $A_{\mathrm{eff}}$, is equivalent to the area of the spherical segment of height, $h$, containing the remaining liquid [see Fig. 28(c)]:

$A_{\mathrm{eff}}=2 \pi r_{\mathrm{s}} h$.

Mass transfer, however, continues over the entire droplet surface. 


\section{Model Description of Glass Fusion}

The gove:ning equations used to simulate the glass fusion s:ep are summarized in Table 10. As in the previous section, a short physical description of each s:ep is also included in Table 10.

The first step treated in the fusion process is the transition of the large, dry, unfused sphere from the drying zone to the high temperature re. gion. In the transition region, the particle Reynolds nuniber is always below 0.4 . We assume the size of the sphere remains about 1000 to $1500 \mu \mathrm{m}$ and is strong enough to withstand the pressure drop across the wall. The terminal velocity of the sphere changes only siightly witi. the small temperature induced changes in purge-gas sensity (sfe velocity eusdion, Table 10).

The diffusion of purge gas into, and water vapor out of the shell is simulated using the per reability expressions developed in the previous section. The pressure within the sphere changes inol. with the mass flux across the walls but also with the increase in temperature of the sphere; we dssume ideal gas behavior to calculate the gus fressuci and volume.
In the model calculations it is assumed that once the sphere reaches $1000^{\circ} \mathrm{C}$ the glass viscosity becomes low enough that the internal and exterral gas pressures are in equilibrium; i.e.

$r_{1}=P_{0}+\frac{\delta_{p}}{d}$

where $\gamma$ is the surface tension of the glass and $t$ is the diameter of the sphere. $H$ ing fused, the permeability of the plass decre 'es 's that no significant mass thansfer occurs across the wall dui ing the short residence time in the furnace.

In the molten state, the ratius of the sphere shanges with the changes in temperatures accors ing to the ideal gas law.

$\frac{i_{0}}{d_{u}}=\left(\begin{array}{c}T \\ T_{n}\end{array}\right)^{1:}$

As the spitere changes sise, it terminat velocity also changes. Howerer, the perind of time needed to accelerate or decelerile to terminal velocity is

Table 10. Summary of various stages in microsphere glass fusion and the associated governing equations v!:ed in model cafculations.

\begin{tabular}{|c|c|c|}
\hline $\begin{array}{l}\text { Fusion } \\
\text { sta }{ }^{e}\end{array}$ & Physical description & Governing equations \\
\hline 1 & $\begin{array}{l}\text { Trarsition from drying cone to fusion zone; } \\
\text { continued diffusion of water vapor out and } \\
\text { purge gas in. }\end{array}$ & 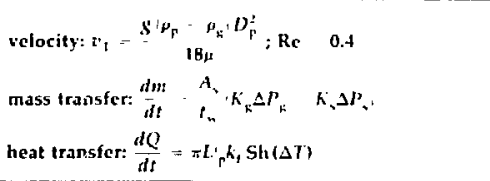 \\
\hline 2 & Sliell collapse and refining. & 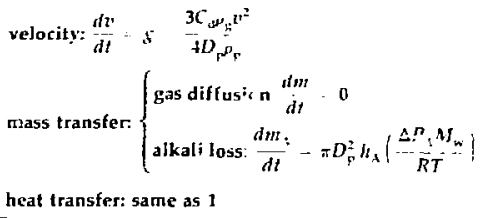 \\
\hline 3 & Snell solidification and cool down. & 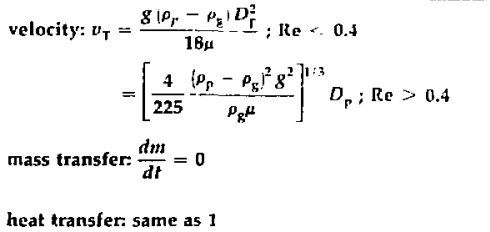 \\
\hline
\end{tabular}


short $(<0.1 \mathrm{~s})$ compared to the time in the furnace.

Although gas flux through the sphere wall is assumed negligible, mass loss due to alkali volatilization is not. We have treated this in the same way as water loss during the drying step. Unfortunately, good estimates of an effective masstransport coefficient $\left(h_{A}\right)$ can only be obtained by fitting the alkali loss data. Therefore extrapolation of the model predictions of alkali loss to other temperatures should be done with caution.

As the sphere exits the furnace and cools, it becomes rigid at about $1000^{\circ} \mathrm{C}$ and there is no further dimensional change. The heat loss from the sphere is so rapid that it can be assumed to be in equilibrium with the surrounding purge gas temperature.

\section{Input and Solution Method}

Apart from the data in Tabie 8, the input requirect to complete the model calculation is summarized in Table 11. Reference values for the various input parameters are also given in Table 11. A description of the reference system is given in the Reference System section later in this paper. The equations given in Tables 9 and 10 are then solved numerically using this input.

For on applications we are primarily interested in what occurs di various axial locations in the columir, 4o the motel is solved using increments in spatial lecation rather than time. The corresponding time at each step is then calculated from the particle velocity and step distance:

$t_{i}=\frac{x_{i}}{i_{1}}+t_{i}$

Table 11. Summary of model input data and typical values used for the reference case.

\begin{tabular}{ll}
\hline & \multicolumn{1}{c}{ Value(s) } \\
\hline Cnlumn temperature profite (K) & (Sec Fig. 19) \\
Uroplet diameter (cm) & 0.027 \\
Droplet initial solids content (wt\%) & 18 \\
Concentration at film over (wt\%) & 52 \\
Solution density $\left(\mathrm{g} / \mathrm{cm}^{3}\right)$ & 1.14 \\
Initial droplet velocily (cm/s) & 700 \\
Initial droplet temperature $\left({ }^{\circ} \mathrm{C}\right)$ & 25 \\
Drop!et frequency (Hz) & 7000 \\
Selection ratio & $35 / 1$ \\
Inlet flow rate (L/min, STP) & 2.4 \\
Inle: watcr vapor content (vol\%) & 2.7 \\
\hline
\end{tabular}

The size of the steps can be given any arbitrarily small value; a value of $1 \mathrm{~cm}$ is used for the work described here, which provides sufficient detail and still allows rapid calculational speed. The validity of this step size was proven by $\mathrm{t}$ standard method of using smaller steps and finding no change in the solution.

In general the model contains sufficient physical detail to simulate accurately the process, yet is simple enough to be used on any small, laboratory computer system. This provides the experimentalist with a rapid means of analyzing his data during the course of the experiments and making further variations on the basis of these results.

\section{Results from Model Calculations}

In this section the results from several model calculations are summarized. We begin by discussing a reference case and then examine the effects of changing various process parameters on the final sphere product.

\section{Reference System}

For our reference system we assume an initial droplet of $270 \mathrm{\mu m}$ in diameter of our standard alkali silicate glas: solution (18 wt\% solids). The other input values for this calculation are summarized in Table 11. Note that the reference system has no particular significance other than as a test case with which to compare changes in process conditions. The droplet system operates over a wide range of size and frequency conditions so any number of possible reference cases are possible.

Typical output from the model calculations includes the droplet/sphere dimensions, velocity, temperature, and composition (solid, liquid, and gas) as a function of either time or distance down the column. Examples of results for the reference system are plotted in Figs. 35 and 36 .

It is interesting now to compare the model predictions with the $x$ perimental observations that were given in a previous section. The initial droplet velocity is $-700 \mathrm{~cm} / \mathrm{s}$ as it leaves the generator. The droplet rapidly decelerates to terminal velocity over about the first $0.5 \mathrm{~m}$ as shown in Fig. 35. During this time water is evaporating and the droplet decreases in diameter from 270 to about $230 \mu \mathrm{m}$. The drop remains at the adiabatic saturation temperature of approximately 40 to $45^{\circ} \mathrm{C}$. The slight increase in temperature during this time results from the small decrease in vapor 

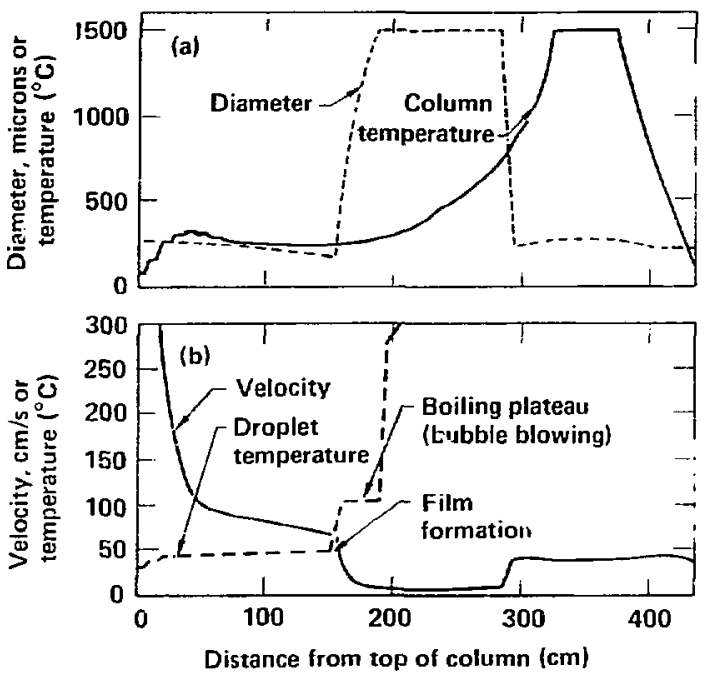

Fig. 35. Results for model calculations as a function of aistance down the column for the "reference system." The plots show (a) droplet diameter $(\mu \mathrm{m})$ and input furnace profile $\left({ }^{\circ} \mathrm{C}\right)$; and (b) the droplet velocity $(\mathrm{cm} / \mathrm{s})$ and droplet temperature $\left({ }^{\circ} \mathrm{C}\right)$.

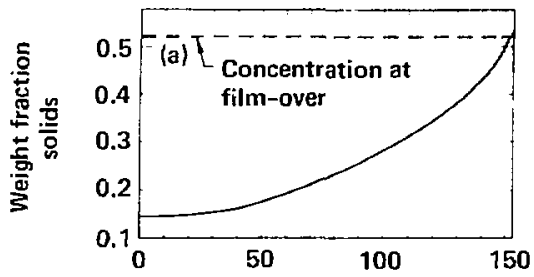

Distance from top of column $(\mathrm{cm}$ !

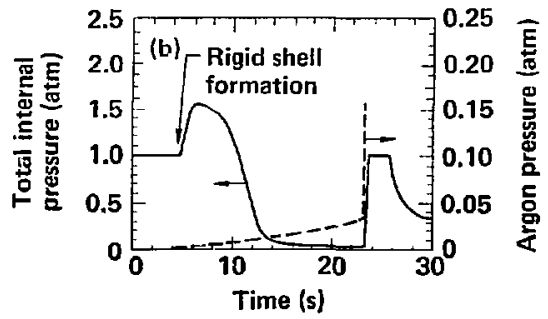

pressure associated with the change in solution concentration (Fig. 36).

After the droplet has fallen about $1.5 \mathrm{~m}$, the solution concentration reaches saturation (i.... $52 \mathrm{wt}$ w solids) and a film begins to form. With the formation of the film, the evaporation rate is reduced and the temperature rapidly increases from the adiabatic saturation temperature to the solu tion boiling point (Fig. 35).

Once the solution begins to boil, $\bar{a}$ butble forms and grows within the droplet. This in turn causes the terminal velocity to fall off dramaticall: [Fig. 35(b)]. After all the free water has evaporated, the temperature of the sphere rapidly increases to that of the surrounding gas. From this

Fig. 36. Results from model calculations as a function of distance down the column for the "reference system." The plots show (a) the solution composition and (b) the bubble composition and pressure. 
point on, the sphere temperature remains equal to that of the furnace gas.

The calculated diameter of the hollow, unfused sphere that is formed by the end of the drying step is about $1400 \mu \mathrm{m}$. This is in good agreement with our experimental observations of 1300 to $1450 \mu \mathrm{m}$. We have assumed in the model that the sphere has sufficient strength so thit it does not collapse as water vapor diffuses out (Fig. 36). Counter diffusing into the shell, although at a much slower rate, is the argon purge gas.

The sphere now slowly drifts from the drying zone to the fusion fumace. As it dces, argon continues to diffuse in through the thin shell wall. The time spent in this transition region is critical since it controls the size of the final sphere (via the internal gas pressure). Note also that by the time the sphere enters this zone it must be thoroughly dry. If it isn't, the rapid evaporation rate caused by the sharp change in temperature would rupture the shell.

As the unfused sphere heats, the glass viscosity drops dramatically. By the time it reaches $900^{\circ} \mathrm{C}$, the viscosity is low enough that the sphere undergoes rapid and uniform collapse [Fig. 35(a)]. Because of the corresponding reduction in drag and increase in density, the sphere also accelerates and soon reaches a higher terminal velocity $(\sim 40 \mathrm{~cm} / \mathrm{s})$.

At this stage the glass is fluid enough that it can respond to changes in internal gas pressure. Thus increasing the temperature up to $1500^{\circ} \mathrm{C}$ protuces a slight increase in sphere diameter. Similarly as the sphere exits the furnace region, the size decreases slightly until at about $1000^{\circ} \mathrm{C}$ the glass hecomes rigid and no further flow is possible. The final pressure in the sphere after cool down is about $0.2 \mathrm{~atm}$, in good agreement with measured values.

The residence time for the sphere in the various segments of the furnace is shown in Fig. 37; we plotted the droplet/sphere axial position as a function of time. Note that the total residence time in the fumace is approximately $27 \mathrm{~s}$, which is also in good agreement with experimental observations.

\section{Effects of Various Process Parameters}

Besides being used to simulate microsphere formation for a given set of operating conditions, the model can be used to study the effects of changing varjous parameters while holding others constant. This allows one to evaluate methuds for making various sphere sizes as well as determine the operating limits of the apparatus.
For a given droplet size, changing the solution concentration produces a corresponding change in sphere size and wall thickness (Fig. 38). Increasing the concelitration increases both the diameter and wall thickness. The reason for this is that the final sphere size is dependent on the droplet size at the film-formation point (i.e., 52 wt $\%$ solids). The higher the solids concentration of the initial droplet, the larger the droplet size at the point of film formation and, thus, the larger the sphere. We have confirmed this prediction experimentally; we currently use slight variations in solution concentration to fine tune sphere diameter and wall thickness.

Increasing the droplet size (Fig. 39) also changes the product sphere size. Note that the product sphere diameter goes through a maximum (Fig. 39). Above a droplet size of about $230 \mu \mathrm{m}$, the sphere spends less time in the drying/gas diffusion region resulting in lower gas pressure within the sphere. For very large droplets $(>300 \mu \mathrm{m}$ ) the product quality declines. Usually increasing the drying rate (by increasing columis temperature or purge-gas thermal conductivity) will allow larger droplets to be handled and still maintain good product quality.

Varying the purge-gas composition can affect all stages of the microsphere process because it changes both the heat transfer/drying characteristics and the sphere size (via permeability). Two examples are given here although similar calculations could be run for any number of gases. In the first case we changed the purge gas to $100 \%$ helium. Helium has about an order of magnitude higher thermal conductivity than argon, and the helium permeability through glass is very high (see Fig. 9). The net effect of He addition is that the droplets dry extremely rapidly. Note that since the model does not contain failure modes it predicts the formation of large, thin spheres (Fig. 40),

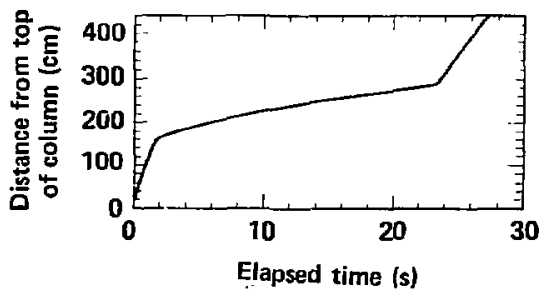

Fig. 37. Axial position in the column as a function of time for the reference droplet drying case. 


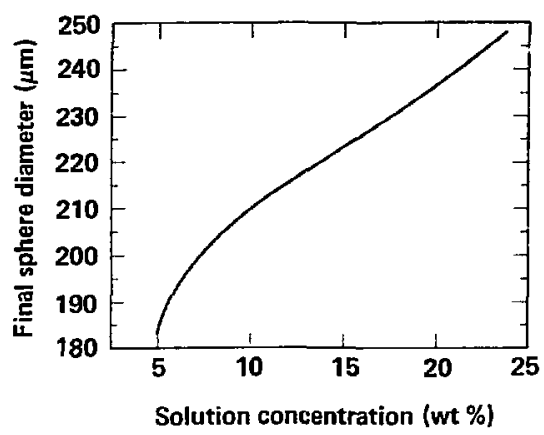

Fig. 38. Effect of solution concentration on shell size (for a fixed droplet size). All other conditions are the same as the reference case.

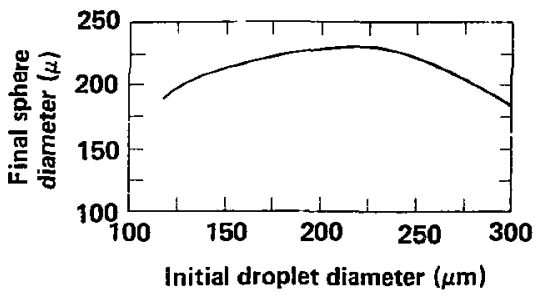

Fig. 39. Effect of initial droplet size on final shell size; all other conditions are the same as the reference case.

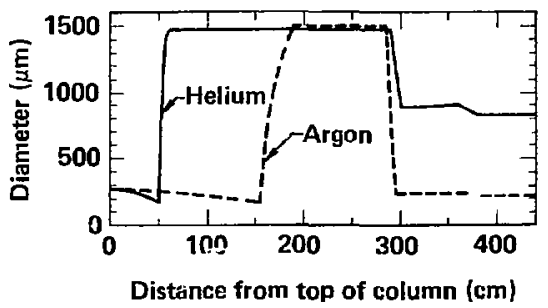

Fig. 40. Effect of $100 \%$ He purge gas on drying distance and sphere dimensions (see text for details).

although in reality these spheres would undoubtly rupture and remelt to solid spheres. Smaller concentrations of $\mathrm{He}$ in argon would pro-
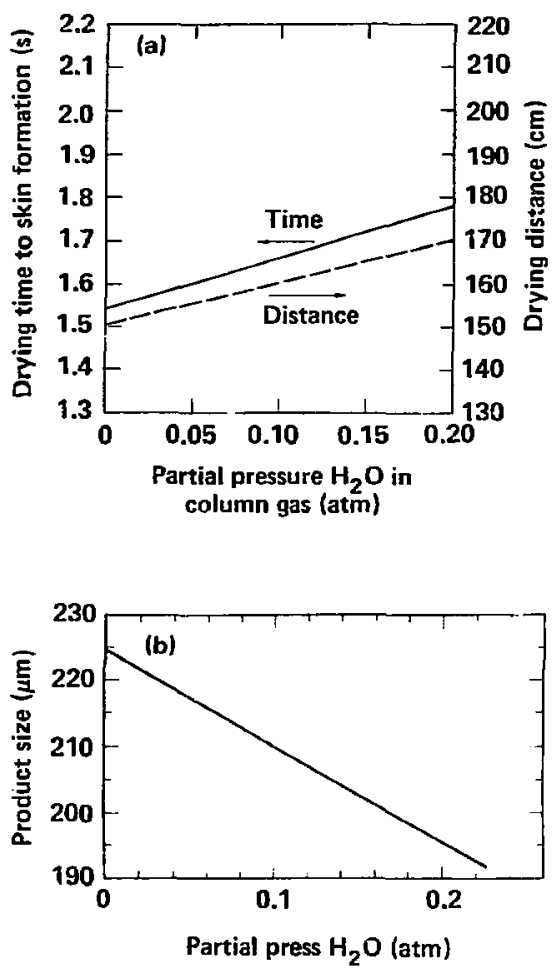

Fig. 41. Effect of steam additions to argon purge gas on (a) drying distance and (b) final sphere size.

duce smaller changes in thermal conductivity and also correspondingly larger internal gas pressures. Although we have not used $\mathrm{He}$ /Ar purge gas mixtures in the glass work, we have used these mixtures when making polyvinyl alcohol spheres; the model simulations agreed quite well with our observations for those experiments (see Ref. 73).

During the course of our work with glass, we found that small additions (3\%) of steam to the purge gas help the refining of the spheres. The model does not contain details of glass flow during refining so we could not simulate the effects of steam on this step. However, we did simulate its effect on the drying stage (Fig. 41). Shown here are data for 20 vol\% steam addition. Steam has 
the effect of slightly retarding the drying rate (because $\Delta P_{\mathrm{H}_{2} \mathrm{O}}$ is smaller-see Table 9) ultimately producing slightly smaller, thicker walled spheres.

The model can be used to simulate changes in any number of process conditions. Above we have presented only a few examples to help illustrate the value of the model for simulating the effects of certain process parameters. As with all models, however, the predictions are oniy as good as the accuracy with which the physics and chemistry of the process are represented. The model presented above is quite simple and could indeed be made more rigorous. In fact, perhaps one of the greatest volues of the model is to point out those areas of the process that are not well understood and need further experimental study. 


\section{References}

1. P. C. Souers, R. T. Tsugawa, and R. R. Stone, Fabrication of the Glass Microhalloon Laser Target, Lawrence Livermore National Laboratory, Livermore, Calif., UCRL-51609 (July 1974).

2. P. C. Souers, R. T. Tsugan'a, and R. R. Stone, "Manufacture of DT-Filled, Hollow Glass Microsphere, Laser Targets," Rcv. Sci. Instrum. 46, 682 (1975).

3. C. D. Hendricks and J. L. Dressler, "Production of Glass Balloons for Laser Targets," Bull. Amer. Phys. Soc Series II 21, 1137 (1976).

4. A. Rosencwaig, J. L. Dressler, J. C. Koo, and C. D. Hendricks, Laser Fusion Hollow Glass M'icrosphteres by the Liquid-Droplet Method, Lawence Livermore National Laboratory; Livermore, Calif., UCRL81421 (1978).

5. C. D. Hendricks, A. Rosencwaig, R. L. Woerner, I. C. Koo, J. L. Dressler, J. W. Sherohman. S. L. Weinland, and M. Jeffries, Fabrication of Glass Sphere Laser Fusion Targets, Lawrence Livermore National Laboratory, Livermore, Calif., UCRL-81415, Rev. 1 (1979).

6. J. M. Schneider and C. D. Hendricks, "Source of Uniform-Sized Liquid Droplets," Rei. Sci. Instrum. 35, 1349 (1964).

7. C. D. Hendricks and S. Babil, J. of Plyys. E 5, 905 (1972).

8. R. L. Nolen, R. L. Downs, W. J. Miller, M. A. Elmer, N. E. Doletsky, and D. E. Solomon, "Fahrication of Glass Shells," Paper $T_{u} E 1-1$ in the Technical Digest on the Topical Meeting on Inertial Confinement Fusion (Feb. 7-9, 1978), San Diego, Calif. Digest No. $78 \mathrm{CH} 1310-2 \mathrm{QEA}$ (Optical Society of America).

9. 1981 Inerial Fusion Research ,Anmual Technical Report, D. E. Solomon, Ed., KMS Fusion inc., Ann Arbor, Mich., DOE/DP/40030-4, KMSF-U1198 (1981).

10. Amual Techinical Report-1980, KMS Fusion, Inc. Ann Arbor, Mich.

11. M. Nogami, J. Hayakawa, and Y. Moriya, "Fabrication of Hollow Glass Microspheres in the $\mathrm{Na}_{2} \mathrm{O}$ $\mathrm{B}_{2} \mathrm{O}_{3}-\mathrm{SiO}_{2}$ System from Metal Alkoxides," I. Matcrial Sci. 17, 2845 (1982).

12. D. E. Clark, C. G. Pantano, Jr., and L. L. Hench, "Corrosion of Glass," Mag'tazities for Industry, Inc. 4, (1979).

13. R. J. Charles, "The Mixed Alkali Effect in Glasses," J. Amer. Ceram. Soc. 48(3), 432-434, (1965).

14. R. M. Hakim and D. R. Uhimann, "On the Mixed Alkali Effect in Glass," Phys. and Chem. of Glasses 8(5), 174-177 (1967).

15. S. Sen and F. V. Tooley, "Effect of $\mathrm{Na}_{2} \mathrm{O} / \mathrm{K}_{2} \mathrm{O}$ Ratios on Chemical Durability of Alkali-Lima-Silica Glasses," I. Amcr. Ceram. Soc. 38(5), 175-177 (1955).

16. 1. R. Hendrickson and P. 1. Bray, "A Theory for the Mixed Alkali Effect in Glass," Phys. ant Chom. of Glasses, Part I, 13i2), 43-'9, (1972); Pt. II (ibid), 13(4), 107-115 (1972).

17. R. H. Doremus, Glass Science (Wiley-Interscience, New York, 1973), PP. 160-163.

18. E. M. Levin, C. R. Robbins, and H. F. McMurdie, Phase Diagrams for Ceramists (American Ceramic Soc., 1964), p. 94, Fig. 192; Original data from F. C. Kracek, J. Phys. Chem. 34, 1588 (1930); J. Am. Chem. Sit. 61, 2869 (1939).

19. G. Urbain, Y. Bottinga, and P. Richet "Viscosity of Liquid Silica, Silicates, and Alumino-Silicates," Geochimica et Cosmochimica Acta 46, 1061 (1982).

20. E. M. Levin, C. R. Robbins, and H. F. McMurdie, Phasc Dingrams for Céramists (Amencan Ceramic Soc., 1964), p. 184, Fig. 515; Original data irom G. W. Morey, J. Soc. Glass Tech. 35, 270 (1951).

21. E. M. Levin, C. R. Robbins, and H. F. McMurdie, Phase Diagrams for Ceramists (American Ceramic Soc., 1964), p. 148, Fig. 381; Original data from F. C. Kracek, I. Phys. Chem. 36, 2538 (1932).

22. W. Haller, D. H. Blackburn, F. E. Wagstaff, and R. J. Charles, I. Am. Ccram. Soc. 53, 34 (1970).

23. M. M. Ammar, S. A. Gharib, M. H. Halawa, H. A. El-Batal, and K. El-Badry, "Thermal Conductivity of Silicate and Borate Glasses," Communications of Am. Ccram. Soc. C76 (May 1983).

24: Y. S. Touloukian and E. H. Buyco, Thermal Physical Properties cf Matter. Vol. 5, Specific Heat NonMetallic Solids (IFI/Plenum, New York, 1970).

25. Y. S. Touloukian, R. W. Powell, C. Y. Ho, and P. G. Klemeus, Thermul Prissical Praperties of Matter. Vol. 2 Thermal Conductivity of Non-Metallic Solids (IF1/Plenum, New York, 1970).

26. G. Morey, The Properties of Glass (Reinhold Publish. Corp., New York, 1954), 2nd ed,, p. 272.

27. J. R. Hutchins, III and R. V. Harrington, "Glass" in Encyclopedia of Chemical Tech. (John Wiley \& Sons, :c., New York, N.Y., 1966), 2nd ed., vol. 10, p. 575. 
28. G. Morey. The Properties of Glnss (Reinhold Publish. Corp., New York, 1954), 2nd ed., Pp. 333-339.

29. J. T. Weir, "Argon in Target Spheres," Lawrence Livermore National Laboratory Target Fabrication Group, Lawrence Livermore National Laboratory, Livermore, Calif., internal memorandum IF 83281 (Miay 6, 1983).

30. W. D. Kingery, H. K. Bowen, and D. R. Uhlmann, Introduction to Ceramics (John Wiley \& Sons, New York, N.Y., 1976), 2nd ed., p. 207.

31. L. Zagar, O. E. Klinger, W. Stumpfe, and K. Löwer, "Surface Energy of Silicate Melts and Its Importance in Sinterey Processes," Sintering-Theory and Practice (Elsevier, Amsterdam, 1982), p. 75.

32. W. Haller, National Bureau of Standards, Wash., D.C. private communication $(1982,1983)$.

33. W. Haller, National Bureau of Standards, Wash., D.C., private communication (1982).

34. J. O'M. Bockris, J. D. Mackenzie, and J. A. Kitchner, "Viscous Flow in Silica and Binary Silicates," Trans. Farniay Soc. 51, 1734 (1955).

35. S. English and W. E. S. Turner, J. Am. Ceram. Soc. 10, 551 (1927) with revisions in I. Am. Ceram. Soc. 12, 760 (1929).

36. G. Morey, The Propertics of Gliss (Reinhold Publish. Corp., New York, N.Y, 1954), 2nd ed., p. 335.

37. R. L. Woerner, B. W. Weinstein, I. M. Moen, and J. G. Rittmann, Working Strr'rgihs and D-T Fill Proce'tures for Glass Microspltere Laser Fusion Targets, Lawrence Livermore National Laboratory, Livermore, Calif, UCRL-82728 (1979).

38. W. D. Kingery, H. K. Bowen, and D. R. Uhlmann, Introduction to Ceramics John Wiley \& Sons, New York, N.Y., 1970), 2nd ed., p. 798.

3y. R. Downs, KMS Fusion, Inc., Ann Arbor, Mich., private communication (1983).

40. J. E. Shelby, "Hlelium Migration in Glass-Forming Oxides," I. Appl. Plyss. 43, $3068-72$ (1972).

41. J. E. Shelby, "Temperature Dependence of Helium Diffusion in Vitreous $\mathrm{SiO}_{2}, " \mathrm{~J}$. Amer. Ceram. Soc. 54, 125- 226 (1971).

42. J. E. Shelby, A Comprehensive Review of Gas Permeation, Diffusion, and Solubility in Inorganic Glasses. Sandia Livermore Laboratory, Livermore, Calif., SLL-73-0259 (1973), p. 40.

43. J. E. Shelby, "Effect of Phase Separation on Helinn: Migration in Sodium Silicate Glasses," I. Amer. Coram. Soc. 56, 263-266 (1963).

44. J. E. Shelby, "Helium Diffusion and Solubility in $\mathrm{K}_{2} \mathrm{O}-\mathrm{SiO}_{2}$ Glasses," I. Amer. Cerann. Soc. 260-263 (1974).

45. J. E. SheJby, "Helium, Deuterium, and Neon Migration in a Common Borosilicate Glass," I. Appl. Phys. 45, 2146-2149 (1974).

46. I. E. Shelby and G. L. McVay, "Helium Diffusion in $\mathrm{Na}_{2} \mathrm{O}-\mathrm{K}_{2} \mathrm{O}-\mathrm{SiO}_{2}$ Glasses," I. Amer. Ceram. Soc. 58, (1975).

47. V. O. Altemose, "Helium Diffusion Through Glass," ]. Appl. Phys. 32, 1309-1316 (1961).

48. V. O. Altemose, "Effect of Alkali Oxides on the Diffusion of Helium in a Simple Borosilicate Glass," J. Amer. Cirant. Soc, 56, 1-4 (1973).

49. P. C. Souers, I. Moen, R. O. Lindahl, and R. T. Tsugawa, "Permeation Eccentricities of He, Ne, and D-T from Soda-Lime Glass Microbubbles," I. Am. Ceram. Soc. 61, 42 (1978).

50. R. J. Moore, "Viscosity of Glass Solution," Lawrence Livermore National Laboratory, Livermore, Calif, internal memorandum TF-80-472 (June 16, 1980).

51. I. W. S. Rayleigh, Proc. London Mathematical Soc. 10, 4 (1878).

52. R. R. Stone, D. W. Gregg, and P. C. Souers, J. Appl. Phys. 46, 2693 (1975).

53. R. R. Stone, P. C. Souers, G. C. Abell, and J. W. Reed, Light lnterference in Hollow Glass Microsphere Laser Targels, Lawrence Livermore National Laboratory, Livermore, Calif., UCRL-77487 (1975).

54. B. W. Weinstein, "White-light Interferometric Measurements of the Wall Thickness of Hollow Glass Microspheres," ]. Applied Plyys. 46, 5305 (1975).

55. B. W. Weinstein and C. D. Hendricks, Interferometric Measurement of Laser Fusion Targets, Lawrence Livermore National Laboratory, Livermore, Calif, UCRL-78477 (1977).

56. 1981 Inertial Fusion Research Almual Techitical Report, D. E. Solomon editor, KMS Fusion Inc., Ann Arbor, Mich., Report DOE/DP/40030-4, KMSF-U1198 (1981), PP. 1-19 to 1-25.

57. - F. P. Roberts, R. P. Turcotte, and W. J. Weber, Materials Criaracterization Center Workshop on the Irratiation Effects in Nuclear Wiste Forms, Pacific Northwest Laboratory, Richland, Wash., PNL-3588 (1981). 
58. J. F. Natate, D. K. McElfresh, and D. G. Howilt, "Radiation Effects in Nuclear Waste Glasses," The Scientific Basis for Nuclear Wiste Management, S. V. Topp, Ed. (Elsevier Science Publisining Co., New" York, N.Y., 1982), p. 697.

59. A. Rosencwaig, S. L. Weinland, J. C. Koo, and J. L. Dressler, Surface Treatment of Laurence Livermore National Laboratory Glass Microspheres, Lawrence Livermore National Laboratory, Livermore, Calif., UCRL-81436 (1978).

60. E. H. Farnum, A. R. Gutacher, and R. Mulford, "A Cleaning Procedure for Inertial Fusion Targets," $I$. Vac. Sci. Techinol. 18, 1195 (1981).

61. 1979 Inertial Fusion Resentch Ammal Technical Report, D. E. Solomon, Ed., KMS Fusion Inc., Ann Arbor, Mich. (1979), pp. 1-1 to 1-10.

62. W. Haller, National Bureau of Standards, Washington, D.C. private conımunication (1983).

63. K. Mesters, Spray Drying (CRC Press Cleveland, Ohio, 1972), Chapter 8.

64. D. H. Charlesworth and W. R. Marshall, Jr., "Evaporation from Drops Containing Dissolved Solids," A. 1. Ch. E. Journal 6, 9 (1960).

65. J. A. Duffie and W. R. Marshall, Jr., "Factors Influencing the Properties of Spray Dried Materials," Chem. Eng. Progress, Part I 49, 417 (1953); Part Il 49480 (1953).

66. W. E. Ranz and W. R. Marshall, Jr., "Evaporation from Drops," Chem. Eng. Progress 48, 173 (1952).

67. E. J. Crosiby and W. R. Marshall, Jr., "Effects of Drying Conditions on the Properties of Spray-Dried Particles," Chem. Eng. Progress, 54, 56 (1958).

68. W. R. Marshall, Jr., "Heat and Mass Transfer in Spray Drying," Trans. Amer. Soc. Mech. Eng. 77, 1377 (1955).

69. D. R. Dickinson and W. R. Marshall, A. l. Ch. E. Journal 14, 541 (1960).

70. R. Hopper, Shrinkage of Microballoons During Manufacture, Lawrence Livermore National Laboratory, Livermore, Calif., internal memorandum (March 1983).

71. 1977 Amnual Technical Report, KMS Fusion, Inc., Ann Arbor, Mich. (1977), p. I-10.

72. F. Sjenitzer, Chem. Eng. Sci, 1, 101 (1952).

73. J. Campbell, J. Grens, J. Poco, and B. Ives, The Preparation and Properties of Polyvinylalcohol Microspineres, Lawrence Livermore National Laboratory, Livermore, Calif. UCRL (in preparation) (1984). 


\section{Appendix A \\ Droplet Formation, Charging and Deflection: A Simplified Analysis}

The physics of droplet formation from a fluid jet has been studied for many years. ${ }^{\mathrm{Al}-\mathrm{A} 3}$ In this appendix, the basic principles of droplet formation are used to present a simplified description of our present droplet generator system.

Many of the relationships used in our analysis are taken from the original work by Rayleigh as applied by Sweet to the formation and deflection of ink jets. ${ }^{A 4}$ Sweet's paper is particularly valuable because it provides good physical insight to the droplet formation process, coupled with a set of simple design/operation equations that can be used to predict the performance of a particular generator system. These relationships provide a means for rapidly evaluating the effects of various process variables without extensive experimentation.

\section{Jet and Droplet Formation}

A schematic diagram of our droplet generator during operation is given in Fig. A1. Details of the various generator components have been discussed in earlier sections of this report as well as in previous publications by Hendricks et al. ${ }^{A 5, A 6}$

The alkali glass solution is fed to the droplet generator under pressure and forms a cylindrical jet as it is forced through an orifice. The jet is broken up by applying small velocity perturbations to the stream using two piezoelectric ceranic disks. These piezoeiectric ceramic disks use an oscillating voltage source set at the desired droplet formation frequency.

Typical uperating conditions for our droplet system are summarized in Table A1. These conditions are used for preparing glass spheres in the 170 to $250 \mu \mathrm{m}$ region and will differ somewhat from those needed to piofuce other size spheres.

The total fluid pressure needed to operate the generator is the sum of the pressure drop $\left(P_{\mathrm{F}}\right)$ due to frictiona! loss as the liquid flows through the external tubing, generator housing and orifice and the pressure $\left(P_{\mathrm{KL}}\right)$ associated with the kinetic energy of the jet:

$\Delta P_{\mathrm{T}}=\Delta P_{\mathrm{F}}+\Delta P_{\mathrm{Kl}}:$

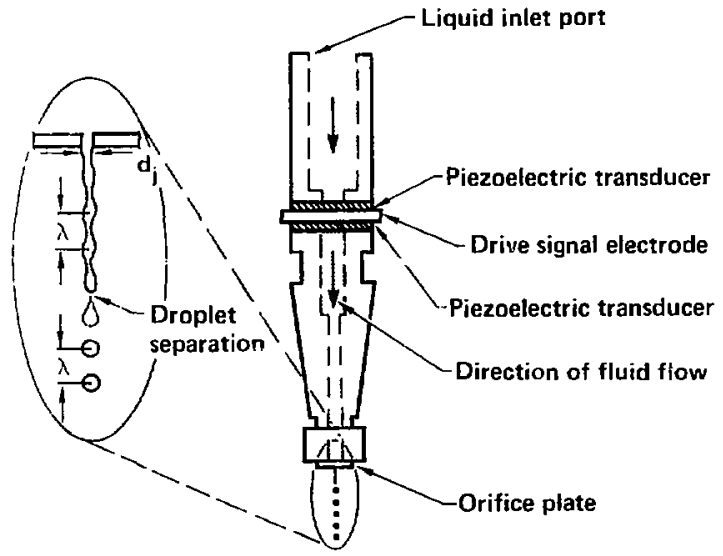

Fig. A1. Schematic diagram of droplet generator showing the main driver system and expanded view of liquid jet region. 
Table A1. Typical droplet generalor operating conditions and related system praperties for production of glass solution droplets.

\begin{tabular}{|c|c|}
\hline & Measured value \\
\hline \multicolumn{2}{|l|}{ Generator system } \\
\hline Driving frequency $\left(f_{d}\right)$ & $7830 \mathrm{~s}^{-1}$ \\
\hline Liquid feed pressure $\left(\Delta P_{I}\right)$ & 7 psi \\
\hline Orifice diameter $\left(d_{o}\right)$ & $119 \mu \mathrm{m}$ \\
\hline Initial jet diameter $\left(d_{0}\right)$ & $119 \mu \mathrm{m}$ \\
\hline Drop spacing* $(\lambda)$ & $950 \pm 20 \mu \mathrm{m}$ \\
\hline Drop size $\left(d_{s}\right)$ & $270 \pm 10 \mu \mathrm{m}$ \\
\hline Disturbance wavelength $(\lambda)$ & $950 \pm 20 \mu \mathrm{m}$ \\
\hline Deflection plate potential $\left(v_{d}\right)$ & $2000-3000 \mathrm{~V}$ \\
\hline Deflection field $\left(E_{\mathrm{d}}\right)$ & $8000-12000 \mathrm{~V} / \mathrm{cm}$ \\
\hline Approximate orifice-vibration amplitude $\left(A_{0}\right)$ & $0.3 \mu \mathrm{m}$ \\
\hline Drop spacing-to-jet diameter ratio $\left(\lambda / d_{a}\right)$ & 8.25 \\
\hline Jet breakup distance $\left(X_{b}\right)$ & $0.7-1.0 \mathrm{~cm}$ \\
\hline Jet length inside charging electrode $\left(X_{f}\right)$ & $-0.5 \mathrm{~cm}$ \\
\hline Spacing across charging efectrode $\left(X_{\mathrm{e}}\right)$ & a.: $\mathrm{cm}$ \\
\hline \multicolumn{2}{|l|}{ Solution properties } \\
\hline Density $\left(\rho_{f}\right)$ & $1.11 \mathrm{~g} / \mathrm{cm}^{3}$ \\
\hline Viscosity $\left(\mu_{t}\right)$ & $2.8 \mathrm{cp}$ \\
\hline Surface tension $\left(\sigma_{1}\right)$ & $-70 \mathrm{dync} / \mathrm{cm}$ \\
\hline Volume resistivity $\left(R_{f}\right)$ & $9.00 \mathrm{ohm}-\mathrm{cm}$ \\
\hline Mass fraction solids $\left(m_{s}\right)$ & 0.146 \\
\hline
\end{tabular}

Also equal to the disturbance wavelength.

The jet velocity $\left(v_{j}\right)$,

$v_{\mathrm{i}}=\lambda_{\mathrm{a}} f_{\mathrm{d}}$

is calculated to be $695 \mathrm{~cm} / \mathrm{s}$ from the data in Table A1 where $\lambda_{\mathrm{d}}$ and $f_{\mathrm{d}}$ are the wavelength (cm) and frequency $\left(s^{-1}\right)$ of the disturbance, respectively. Thus, the pressure drop associated with the kinetic energy of the jet,

$\Delta P_{\mathrm{KE}}=\frac{\rho_{\mathrm{s}} V_{\mathrm{i}}^{2}}{2}$

is $2.7 \times 10^{5}$ dyne $/ \mathrm{cm}^{2}$ (3.9 psi) for a fluid density $\left(\rho_{t}\right)$ of $1.11 \mathrm{gm} / \mathrm{cm}^{3}$.

The flow rate,

$q=\frac{\pi d_{0}^{2} v_{i}}{4}$

is calculated to be $7.7 \times 10^{-2} \mathrm{~cm}^{3} / \mathrm{s}$ based on the measured jet velocity and an orifice diameter $\left(d_{\mathrm{n}}\right)$ of $0.0119 \mathrm{~cm}$. Note that all of the material within a given perturbation wavelength eventually forms a droplet (see Fig. A1). Consequently the size of liquid droplet can be calculated from a simple mass balance

$\rho_{f} \frac{\pi d_{d}^{3}}{6}=\frac{\pi d_{0}^{2} \lambda \rho_{f}}{4}$. 
where $d_{\mathrm{d}}$ is the radius of the drop. From this equation the droplet diameter was ralculated to be $266 \mu \mathrm{m}$ is a good agreement with our optically measured value of $270 \pm 10 \mu \mathrm{m}$.

Rearranging Eq. (A5) provides a useful relationship for estimating the droplet diameter for a given orifice diameter and perturbation wavelength,

$\frac{d_{\mathrm{d}}}{d_{\mathrm{o}}}=\left(\frac{3 \lambda}{2 d_{\mathrm{o}}}\right)^{1 / 3}$.

This equation is plotted in Fig. A2. For comparison, our measured $d_{d} / d_{0}$ value was 2.35 , which is in excellent agreement with the predicted value of 2.31 .

The measured feed solution pressure is 7.0 psi hence, from Eqs. (A1) and (A3), the pressure drop due to frictional loss for our generator is $3.1 \mathrm{psi}$. It is obvious from the design of the system that most of this loss occurs across the orifice plate. For an incompressible fluid, the rate of flow (q) through an orifice is related to the pressure drop $\left(\Delta P_{0}\right)$ by ${ }^{A 7}$ :

$\eta=C A\left(\frac{2 \Delta \nu_{0}}{\rho_{i}}\right)^{1 / 2}$.

where $A$ is the orifice area, and $C$ the flow coefficient for that particular orifice plate. In principle the flow coefficient, $C$, can be estimated from the ratio of the orifice-to-upstream pipe diameter and the Reynolds number. ${ }^{\prime 7}$ Usually, however, this is only approximate and $C$ should be determined by calibration. Based on our measured flow rate, orifice area and pressure drop ( $3.1 \mathrm{psi}$ ) $C$ is determined to be 1.12 for this orifice plate. For comparison, this value is about $50 \%$ greater than $C$ determined from published correlations based on the feed-pipe Reynolds number and the ratio of orifice to feed-pipe diameters (see Ref. A7).

Note that combining Eqs. (A1), (A3), and (A7) gives a useful expression relating the feed pressure and jet velocity for this generator design

$$
\begin{aligned}
\Delta p_{\mathrm{T}} & =\frac{\rho_{\mathrm{l}}}{2}\left(\frac{q}{A}\right)^{2}\left(\frac{1}{C^{2}}+1\right) \\
& =\frac{\rho_{\mathrm{f}} v_{\mathrm{j}}^{2}}{2}\left(\frac{1}{\mathrm{C}^{2}}+1\right) .
\end{aligned}
$$

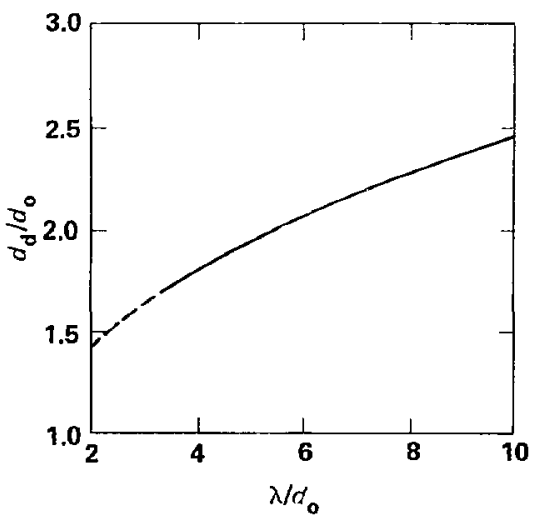

Fig. A2. Ratio of droplet-to-orifice diameter $\left(d_{\mathrm{d}} / d_{0}\right)$ as a function of $\lambda / d_{0}$. 
The liquid jet that forms is in unstable equilibrium. Small perturbations in the radius of the jet will grow as a result of surfact tension forces and ultimately cause the jet to break up into. droplets. It follows that if regularly spaced perturbations can be applied to the jet then these will ulfimately cause the stream to break up into uniform droplete =

In order for the perturbation to grow, the wavelength of the disturbance, as measured along the jet axis in Fig. Al, must exceed $\pi d_{0}$ where $d_{\mathrm{o}}$ is the jet diameter at the orifice. ${ }^{A 2}$

Rayleigh showed that small sinusoidal variations in the jet diameter will grow exponentially as they travel down the axis of the jet, ${ }^{A 2, A 4}$ i.e.,

$$
\begin{aligned}
A_{\mathrm{t}} & =A_{\mathrm{o}} \exp \left(t / \tau_{\mathrm{d}}\right) \\
& =A_{\mathrm{o}} \exp \left(\frac{x}{v_{\mathrm{i}} \tau_{\mathrm{d}}}\right),
\end{aligned}
$$

where $A_{\mathrm{o}}$ is the initial amplitude of the radial perturbation, and $A_{t}$ is its value at time, $t$, or axial position $x$. The time constant for the growth of the disturbance, $\tau_{\mathrm{d}}$, is given by ${ }^{A 2, A 4}$

$\tau_{\mathrm{d}}=\frac{1}{l_{\mathrm{f}}}\left(\frac{\rho_{\mathrm{f}} d_{\mathrm{o}}^{3}}{8 \sigma_{\mathrm{f}}}\right)^{\mathrm{L} / 2}$

where $\sigma_{f}$ is the surface tension of the liquid. $I_{f}$ is the instability factor derived by Rayleigh. The value of $I_{f}$ is plotted in Fig. A3 as a function of $\lambda / d_{0}$. Note that the maximum perturbation growth rate, which is equal to the maximum $I_{f}$, occurs at $\lambda / d_{\mathrm{o}}=4.5$ and, as stated il $h$, ye, for a disturbance to grow, $\lambda / d_{\mathrm{o}}$ must be greater than $\pi$. For our current operations we typically oputate at a $\tau / d_{0}$ value near 8.0 (see Table $\mathrm{A} 1$ ).

The breakup of the liquid jet into droplets will occur at the point where the disturbance amplitude, $A_{1}$, has grown to a value equal to the initial jet diameter. The axial distance down the jet where this will occur can be calculated either from Eq. (A9) or determined directly from Fig. A4.

For example, given the particular generator conditions in Table $A 1, l_{1}$ has a value of about 0.23 (see Fig. A3). Therefore, from, the tabulated properties of the glass solution (Table A1), $\tau_{d}$ is calculated to be $2.4 \times 10^{-4} \mathrm{~s}$ [Eq. (A10)]. The amplitude of the initial perturbation to the liquid jet can be estimated from strain developed by the two piezoelectric ceramics at the peak osillator voltage. The strain $\left(\mathrm{d}_{33}\right)$ is $3.74 \times 10^{-10} \mathrm{~m} / \mathrm{V}$ for each piezoelectric, or at our driving voltage of $400 \mathrm{~V}$, about $0.15 \mu \mathrm{m}$ per ceramic disk.

Assuming an initial perturbation of $0.3 \mu \mathrm{m}$ then $A_{\mathrm{t}} / A_{\mathrm{o}}$ must grow to 382 to break the $119 \mu \mathrm{m}$ jet into a droplet. From Fig. A4, this corresponds to $X /\left(v_{i} \tau_{\mathrm{d}}\right)$ of about 5.9. The distance down the jet where breakup

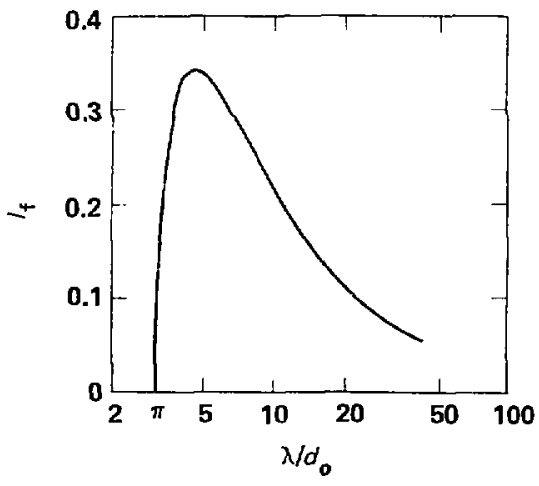

Fig. A3. Rayleigh instability factor, $I_{\mathrm{f}}$, plotted as a function of $\lambda / d_{0^{*}}{ }^{A 4}$ 


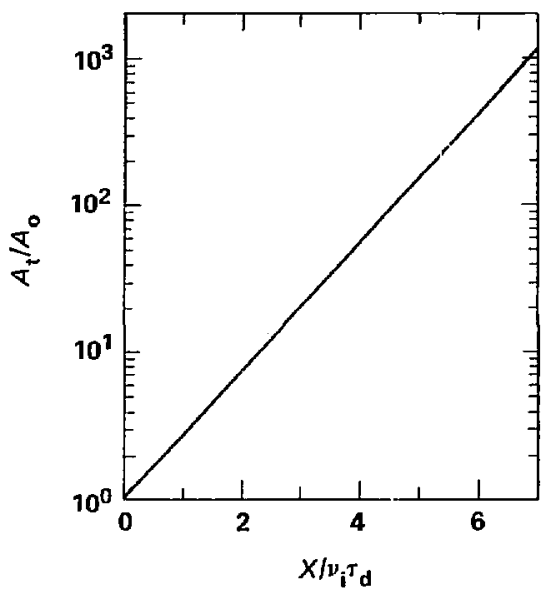

Fig. A4. Growth of disturbance amplitude as a function of distance down the axis of the fluid jet.

occurs (i.e., $X_{\mathrm{b}}$ ) is predicied to be $0.98 \mathrm{~cm}$. The experimentally observed breakup distance is between about 0.7 to $1.0 \mathrm{~cm}$, in good agreement with this prediction. The distance down the jet must also be an integral multiple of the disturbance wavelength. Note that in this case the predicted length is about $10 \lambda$ and thus satisfies this condition. The range in breakup distances that we observe probably depends on how close we are to a resonant frequency of the generator system.

It is important to realize that the above Rayleigh-type analysis is for an inviscid ideal laminar flow jet. In reality the characteristics of the jet also depend on the design and machined qualir' of the orifice or nozzle and, in certain cases, the material from which it is made. Also, for highly viscuus fluid, a more rigorous treatment is required. Consequently, the above analysiz can provide useful estimates (for low viscosity fluids) of nozzle performance for design purposes, or the effects of certain system parameters. However, without some experimental verification, one cannot expect to predict quantitatively the operation of any given nozzle for a broad range of operating conditions.

\section{Droplet Charging and Deflection}

Although the size is corre $:$, the rate at which drops are formed by the droplet generator is tco rapid to be fed directly to the processing oven. The droplet spacing is so close that during the course of their fall through the oven, numerous inter-droplet collisions occur that ultimately produce glass spheres of the wrong size and with a wide dimensional spread. To alleviate this problem, a method was developed by Hendricks and Dressler ${ }^{\mathrm{A} 5}$ for charging and deflecting most of the droplets formed by the droplet generator. Thus orly a few drops, at large inter-droplet spacings, enter the heated column.

The charging and deflection section of the generator is shown schematically in Fig. 15 of the main text. The charging electrode is located below the orifice plate at a point such that jet breakup occurs within the envelope of the ring.

The magnitude of the charge, $\phi_{d}$, that is induced on the droplet can be estimated from the expression $^{\mathrm{A} 4}$

$\phi_{\mathrm{d}}=C_{\mathrm{p}} V_{\mathrm{e}}$ 
where $V_{e}$ is the potential between the charging electrode and ground and $C_{e}$ is the car actance between the electrode and droplet. The capacitance for this charging geometry is ${ }^{\mathrm{At}}$

$$
C_{\mathrm{c}}=\frac{2 \pi \epsilon_{\mathrm{o}} \lambda}{\ln \left(\frac{4 X_{\mathrm{c}}}{\pi d_{\mathrm{o}}}\right)},
$$

where $X_{\mathrm{e}}$ is the spacing across the electrode envelope, which is $\sim 0.4 \mathrm{~cm}$ for our case, $\epsilon_{\mathrm{a}}$ is the permittivity of free space $\left(8.9 \times 10^{-12} \mathrm{farad} / \mathrm{m}\right)$, and the other variables have the same definitions as given previously. For a disturbance wavelength and jet diameter of 950 and $115 \mu \mathrm{m}$, respectively. $C_{k}$ is calculated to be $1.4 \times 10^{-14}$ farads. A potential of $+220 \mathrm{~V}$ is applied to the charging ring during operation. which, from Eq. (A11), gives the droplet an induced negative charge of abou $3.1 \times 10^{12}$ roul

During operation, the charging ring is sw.. itched off and on at regular intervals allowing some droplets to pass through the ring uncharged. Typically, 1 out of 30 is uncharged. Therefore, when the droplets enter the deflection region, 29 of the 30 are deflected and caught in a fluid aspiratro, and the remaining uncharged sphere passes down into the heated column. For the droplet to develop sufficient charge, it is important that the charging rate be greater than the droplet formation frequency. The time required to charge a drople' can be estimated by treating the system as a simple $\mathrm{RC}$ circuit; thus

$\tau_{c}=R_{\mathrm{j}} C_{\mathrm{i}}$,

where $R_{i}$ and $C_{\mathrm{j}}$ are the resistance and capacitance of the iet, respectively.

The capacitance of the jet can be estimated using an expression similar to Eq. (A12), i.e.

$C_{i}=-\frac{2 \pi \epsilon_{0} X_{c}}{\ln \left(\frac{4 X_{e}}{\pi d_{o}}\right)}$.

where $X_{\mathrm{L}}$ is the length of the jet inside the charging electrode. Because the droplet generator and orifice plate are stainless steel, the major resistance in the circuit is in the liquid jet which can be simply approximated by

$R_{\mathrm{i}}=\frac{R_{\mathrm{f}} X_{\mathrm{b}}}{\pi r_{\mathrm{n}}^{2}}$

where $X_{\mathrm{b}}$ is the length of the jet, $r_{\mathrm{o}}$ the radius of the jet at the orifice and $R_{\mathrm{f}}$ volume resistivity of the fluid.

For our particular generator, the values of the various dimensions needcat for Eqs. (A14) and (A15) are given in Table A1. The quantities are based on typical operating conditions used to producf ruminal 170to $250-\mu \mathrm{m}$ hollow glass spheres. The volume resistivity for cur glass solution has not been measured; however, because the solution is a highly concentrated electrolyte, one can esiinate this from measured values for other solutions of strong electrolytes. For the purposes of this calculation, we have assumcd a volume resistivity equivalent to that for a 1 molar $\mathrm{KCl}$ solution at $25^{\circ} \mathrm{C}^{A 8}$, i.e., $8.95 \mathrm{ohm} / \mathrm{cm}$. This is probably a conservative estimate of $R_{\mathrm{f}}$ because our solutions contain strong electrolytes with a total conceritration greater than 1 molar.

Using the values in Table $A 1$ and a volume resistivity of $8.95 \mathrm{ohm}-\mathrm{cm}, C_{\mathrm{i}}$ and $R_{\mathrm{i}}$ are estimated to be $7.4 \times 10^{-1+}$ farad and $4.3 \times 10^{4} \mathrm{ohm}$, respectively. This correspends to a circuit time constant, $\tau_{c}$ of about $3 \times 10^{-9} \mathrm{~s}$. Since the drop period $\left(t_{\mathrm{d}}^{-1}\right)$ is $1.3 \times 10^{-4} \mathrm{~s}$, then it is clear the charging rate is very rapid and no problem should be encountered in charging the droplets. Note, however, that this may not always be true. For very narrow jets and/or high volume resistivity fluids (e.g., organic solvents) the charge time may become sufficiently long to prevent adequate charge development on some or all of the droplets.

The charged droplets are deflected and collected using a set of parallel electrodes located beneath the charging ring (Fig. 15 in main text). One of the electrodes is connected to ground and the other held at a 
negative potential of 2000 to $3000 \mathrm{~V}$. The spacing between the electrodes is about $0.3 \mathrm{~cm}$ resulting in an electric field of 8 to $12 \mathrm{kV} / \mathrm{cm}$.

The force $(F)$ exerted on the drop!et in the deflection electric field $(E)$ is given by

$F=E \phi_{\mathrm{d}}$,

where $\phi_{\mathrm{d}}$ is the droplet charge. This force produces a transverse acceleration of the droplet:

$n_{\mathrm{Y}}=\frac{F}{m_{\mathrm{d}}}=\frac{E \phi_{\mathrm{d}}}{m_{\mathrm{d}}}$

that results in a parabolic trajectory through the deflection electrode region. The trajectory coordinates are:

$Z=v_{\mathrm{d}} t$

and

$y=1 / 2 a_{y} t^{2}=\frac{E \phi_{d} t^{2}}{2 m_{d}}$,

where $v_{\mathrm{d}}$ is the drop velocity normal to the electric field and $m_{\mathrm{d}}$, the drop mass. Because the vertical velocity component is approximately constant, then the magnitude of deflection $(y)$ at any given vertical position $(Z)$ in the electrode region is

$y=\frac{E \phi_{\mathrm{d}}}{2 m_{\mathrm{d}}}\left(\frac{z}{v_{\mathrm{d}}}\right)^{2}$

We calculated the trajectory of tic drop through the deflection electrodes based on the operating conditions given in the earlier part of this section. During operation we observed that the vertical travel of the drop before it hits the collector electrode is about twice the calculated distance. From Eq. (A19) this would imply that the drop charge is about half the value we calculated (note the other parameters in Eq. (A19) can be measured directly). This could possibly result from some charge leakage from the drop

Table A2. Summary of calculated operating characteristics for glass solution droplet system.

\begin{tabular}{ll}
\hline Jet formation and breakup & \\
\hline Jet velocity $\left(v_{\mathrm{j}}\right)$ & $695 \mathrm{~cm} / \mathrm{s}$ \\
Fluid flow rate $(q)$ & $7.7 \times 10^{-2} \mathrm{~cm}^{3} / \mathrm{s}$ \\
Drop diam $\left(d_{\mathrm{d}}\right)$ & $266 \mu \mathrm{m}$ \\
Drop-to-orifice diam ratio $\left(d_{\mathrm{d}} / f_{\mathrm{o}}\right)$ & 2.31 \\
Jet breakup distance $\left(X_{\mathrm{b}}\right)$ & $0.9 \% \mathrm{~cm}$ \\
Pressure drop; kir'etic $\left(P_{\mathrm{KE}}\right)$ & $3.9 \mathrm{psi}$ \\
Pressure drop; oritice $\left(P_{\mathrm{F}}\right)$ & $3.1 \mathrm{psi}$ \\
Orifice plate coefficient $(C)$ & 1.12 \\
Disturbance growth time constant $\left(r_{\mathrm{d}}\right)$ & $2.4 \times 10^{-4} \mathrm{~s}$ \\
Drop charging/deflection & \\
\hline Drop charge $\left(\phi_{\mathrm{d}}\right)$ & $3.1 \times 10^{-12} \mathrm{coul}$ \\
Jet resistance $\left(R_{\mathrm{i}}\right)$ & $4.3 \times 10^{4} \mathrm{ohm}$ \\
Jet capacitance $\left(C_{\mathrm{i}}\right)$ & $7.4 \times 10^{-14} \mathrm{farad}$ \\
Charging time $(\tau)$ & $3.0 \times 10^{-9} \mathrm{~s}$ \\
Vertical deflection length $(z)$ & $0.34 \mathrm{~cm}$ \\
Horizontal deflection length $(y)$ & $0.25 \mathrm{~cm}$ \\
\hline
\end{tabular}


during travel between the charging and deflection electrodes or lower charge generation on the drop than is predicted by our simple analysis.

A summary of all the operating characteristics of our droplet generation that were calculated in this section is given in Table A2. These results, combined with the data in Table A1, provide a fairly complete description of the performance of our droplet generator system.

\section{References}

A1. J. W. S. Rayleigh, Proc. London Mathematical Soc. 10,4 (1878).

A2. Lord Rayleigh, The Theory of Sound, "Capillarity" (Dover Publications, Inc., New York, 1945), 2nd cd. Vol. II, Chap. XX.

A3. C. V. Boys, Sonp Bubbles, Their Colours and the Forces Which Mold Them (Dover Publications, Inc., New York, N.Y., 1959), pp. 62-84.

A4. R. G. Sweet, High-Frequency Oscillography with Elect rostatically Deflected ink lets, Stanford Electronics Lab, Stanford University, Stanford, Calif., Technical Report 1722-1 (March 1964).

A5. C. D. Hendricks and J. L. Dressler, Production of Glass Balloons for Lnser Target5, Lawrence Livermore National Laboratory, Livermore, Calif., UCRL-78481, Rev. 1 (September 28, 1982).

A6. C. D. Hendricks and S. Bakil, "Generation of Uniform 0.5 to 10 Micron, Solid Particles," J. of Physics E5, 905-909 (September 1972).

A7. Flow of Fluids through Valves, Fittings and Pipe (published by the Engineering Division of Crane Co., New York, N.Y., 1980), 19th ed.

A8. G. M. Barrow, Physical Chemistry (McGraw Hill, Ne:v York, N.Y., 1973), 3rd ed., 619. 


\section{Appendix B \\ Microsphere Formation: Back-of-the-Envelope Calculations}

In many instances one would like to evaluate the effect of changing various parameters on the liquid droplet process without having to run a complete model calculation. This is particularly true when evaluating new column/process designs, extrapolating to larger (or smaller) sphere sizes and trouble shooting daily operations.

Designing and sizing equipment for use in droplet drying experiments also requires estimates of the times, or duration of the major process steps, as well as velocity of the dropiet during that time. The product of these two values determines the axial length of column needed to complete that step.

In this appendix we outline simple methods for estimating different characteristics of the process (e.g., droplet drying time) and also an example of the application of these to hypothetical design and operating problems.

\section{Estimates of Droplet Drying Time}

The approximate time req'sired to dry a water droplet down to the point of film formation is easily estimated via the expression

$t_{1}=\frac{\rho_{o} \Delta H_{\mathrm{v}}\left(D_{\mathrm{o}}^{2}-D_{f}^{2}\right)}{8 k_{\mathrm{f}} \Delta T}$

where $t_{1}$ is time in seconds, $\rho_{\mathrm{o}}$ the density of the solution $\left(\mathrm{g} / \mathrm{cm}^{3}\right), \Delta H_{\mathrm{v}}$ the latent heat of water (cal/g) at the wet bulb temperature and $k_{\mathrm{f}}$ is the thermal conductivity of the gas boundary layer $(\mathrm{cal} / \mathrm{cm} \cdot \mathrm{s} \cdot \mathrm{K}) . D_{\mathrm{o}}$ and $D_{f}$ refer to the droplet diameter initially and at the fuint of film formation, respectively. $\Delta T$ is the temperature driving force across the boundary layer:

$\Delta T=T_{\mathrm{g}}-T_{\mathrm{s}}$

where $T_{g}$ is thie purge-gas (furnace) temperature and $T_{s}$ the adiabatic saturation, or wet bulb temperature. $T_{\mathrm{s}}$ is easily estimated from a psychrometric chart knowing the water vapor load in the purge gas.

Equation ( $B 1$ ) is derived from a simple energy balance on the droplet. Assuming equilibrium between the rate of heat and mass transfer then

$\frac{d m}{d t}=\frac{1}{\Delta H_{v}} \frac{d Q}{d t}=\frac{h_{\mathrm{q}}}{\Delta H_{\mathrm{v}}} A \Delta T$,

where $h_{q}$ is the overall heat transfer coefficient [given by Eq. (19) of the main text], and $A$ is the area $\left(\pi D^{2}\right)$. The mass $(m)$ of the particle is

$m=\rho \frac{\pi D^{3}}{6}$

which, when substituted into Eq. (B3) gives

$\frac{d m}{d t}=\frac{\rho \pi D^{2}}{2}\left(\frac{d D}{d t}\right)=\frac{h_{\mathrm{q}}\left(\pi D^{2}\right) \Delta T}{\Delta H_{\mathrm{v}}}$ 
or, in terms of $D$,

$\frac{d D}{d f}=\frac{2 h_{q} \Delta T}{\rho \Delta H_{v}}$.

As discussed in the main text, the convective heat transfer coefficient is given by

$$
\begin{aligned}
2 h_{\mathrm{q}} & =\frac{k_{\mathrm{f}} \mathrm{Nu}}{D} \\
& =\frac{k_{1}}{D}\left[2+0.6(\operatorname{Re})^{1 / 2}(\mathrm{Pr})^{1 / 3}\right] .
\end{aligned}
$$

where $k_{\mathrm{f}}$ is the thermal corductivity and $\mathrm{Re}$ and $\mathrm{Pr}$, the Reynolds and Prandtl numbers, respectively: Combining (B6) and (B7) and integrating gives the well known expression ${ }^{\text {t3 }}$ for the drying time to film formation, $\mathrm{t}_{\mathrm{l}}$ :

$I_{1}=\frac{\rho \Delta H_{v}}{2 k_{\mathrm{s}} \Delta T} \int_{D_{11}}^{D_{\mathrm{l}}} \frac{D}{\left[2+0.6(\operatorname{Re})^{t / 2}(\operatorname{Pr})^{1 / 3}\right]} d D$.

Note that the Reynolds number is a function of $D$ and $v$ so must be included in the integral. In the case of a still gas (i.e., Re $=0$ ) then $\mathrm{Eq}$. (B8) can be integrated to give (B1). For most of our cises the Reynolds number is small so Eq. (B1) gives a good estimate of the drying time.

In the event the Reynolds number is significant then the integral in Eq. (-) must be evaluated. Masters $^{6 \cdot}$ and Duffie and Marshall ${ }^{65}$ have tabulated values of this integral for use in such cases.

Once the film forms around the droplet, a simple analytical expression of drying time is difficult to obtain. Ranz and Marshall ${ }^{66}$ have suggested the following expression based on empirical results irom drying a large number of different materials:

$t_{2} \approx \frac{\Delta H_{1} D_{f}^{2} \rho_{f} W_{f}}{12 k_{f} \Delta l_{\mathrm{avg}}}$,

where $\Delta T_{\mathrm{avg}}$ is the average temperature during the second stage of drying and $\rho_{\mathrm{f}}$ and $W_{1}$ are the droplet density and weight fraction solids at the point of film over. Combining (B1) and (B9) gives an estimate for the total drying time, $t_{\mathrm{d}}$

$t_{d} \approx \frac{s H_{v}}{k_{i}}\left[\frac{\rho_{\mathrm{o}}\left(D_{\mathrm{o}}^{2}-D_{\mathrm{f}}^{2}\right)}{8 \Delta T}+\frac{\rho_{\mathrm{f}} D_{\mathrm{i}}^{2} W_{\mathrm{f}}}{12 \Delta T_{\mathrm{uvg}}}\right]$.

For our system, accurate estimates of the time to dry down to the point of film formation are essential for proper design of the column length. This is because duting this time the drop veiocity is highest. Once the film forms and the shell starts to blow, the velocity drops dramatically (see main text). Thus, large errors in estimating the second stage of drying, for example, $t_{2}$, Eq. (B9), will have only small effects on sizing the equipment.

It can easily be shown that the ratio of initial droplet diameter to the diameter at the point of film formation is

$\frac{D_{f}}{D_{\mathrm{o}}}=\left[\frac{\rho_{\mathrm{o}}\left(1-f_{\mathrm{H}_{2} \mathrm{O}}^{\mathrm{\prime}}\right)}{\rho_{\mathrm{r}}\left(1-f_{\mathrm{H}_{2} \mathrm{O}}^{\mathrm{O}}\right)}\right]^{1 / 3}$, 
where $f_{\mathrm{H}_{2} \mathrm{O}}^{\mathrm{O}}$ and $\mathrm{f}_{\mathrm{H}_{2} \mathrm{O}} \mathrm{O}$ are the weight fractions of water in the initial solution and at the point of film formation, respectively. As discussed in the main text, film formation occurs at about 50 wt $\%$ solids for our glass solutions.

Using a standard psychrometric chart and the results in Fig. B1, it is now possible to estimate drying times for small droplets of glass solution. For example, given a $230-\mu \mathrm{m}$ droplet of an 18 wt\% glass solution, the drying time in a $200^{\circ} \mathrm{C}$ column is quickly estimated from Eq. (B10) to be:

$$
\begin{array}{r}
t=\frac{(540 \mathrm{cal} / \mathrm{g})}{\left(6.14 \times 10^{-5} \mathrm{cal} / \mathrm{s} \cdot \mathrm{cm} \cdot \mathrm{K}\right)}\left[\frac{1.15 \mathrm{~g} / \mathrm{cm}^{3}(0.023 \mathrm{~cm})^{2}-(0.0152 \mathrm{~cm})^{2}}{8\left(200^{\circ} \mathrm{C}-45^{\circ} \mathrm{C}\right)}\right. \\
\left.+\frac{1.50 \mathrm{~g} / \mathrm{cm}^{3}(0.0152 \mathrm{~cm})^{2}(0.48)}{12\left(200^{\circ} \mathrm{C}-100^{\circ} \mathrm{C}\right)}\right]
\end{array}
$$

$t-3.6 \mathrm{~s}$,

where $t_{1} \sim 2.4 \mathrm{~s}$ and $t_{2} \sim 1.2 \mathrm{~s}$.

\section{Droplet/Shell Fall Velocities}

\section{Deceleration}

The droplet leaves the generator at a speed much greater than its terminal velocity (see Appendix A). Consequently in the upper region of the drying column the droplet rapidly decelera es. Estimates of the fall distance during deceleration can be derived from a simple force balance

$F=-m g+C \imath^{n}$,

where $m$ is the droplet mass in grams, $g$ the acceleration of gravity $\left(980.6 \mathrm{~cm} / \mathrm{s}^{2}\right)$ and $v$ the droplet velocity $(\mathrm{cm} / \mathrm{s}) . C$ is a constant that relates the friction drag force to the droplet velocity. At large Reynolds numbers $(>500)$ the drag force increases with the square of the droplet velocity (i.e., $n=2)$ whereas at intermediate $(0.5<\operatorname{Re}<500)$ and low values $(<0.5)$, the drag force varies as $v^{3 / 2}$ and $v$, respectively. For the case given here we assume $n=1$, however a similar treatment can be used for the other velocity functions. In our simple analysis, evaporation is neglected, hence:

$$
\begin{aligned}
F & =\frac{d(m v t)}{d t}=m \frac{d v}{d t} \\
& =m v \frac{d v}{d x},
\end{aligned}
$$

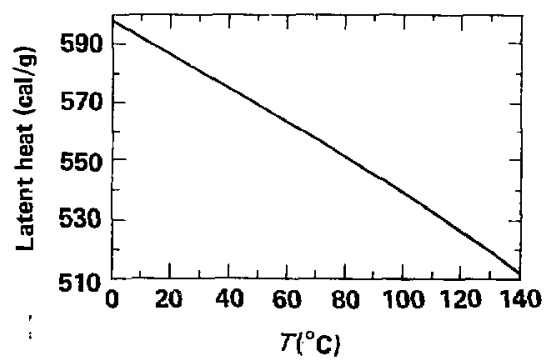

Fig. B1. Latent heat of vaporization for water as a function of temperature. 
which, when equated with (B15) (assuming $n=1$ ) gives

$v \frac{d v}{d x}=g+\frac{c}{m} v$

At the terminal velocity $\left(v_{1}\right)$, the forces on the droplet sum to zero, therefore.

$v_{1}=-\frac{m g}{c}$.

Substituting (B16) into (B15) gives the differential equation

$v \frac{d v}{d x}=\frac{g}{v_{1}}\left(v-v_{1}\right)$,

which, upon integration gives the desired result:

$x=\frac{v_{1}}{g}\left[\left(v_{1}-v_{1}\right)+\left(v_{0}-v_{t}\right)-v_{1} \ln \left(\frac{v-v_{t}}{v_{0}-v_{t}}\right)\right]$.

As an example, the terminal velocity for a $200-\mu \mathrm{m}$ droplet of glass solution, is ahout $100 \mathrm{~cm} / \mathrm{s}$ (see next section). Assuming it leaves the droplet generator at $700 \mathrm{~cm} / \mathrm{s}$, (see Appendix A) the velocity as function of distance down the column is easily calculated from Eq. (B18) (Fig. B2). The results show the droplet approaches to within $1 \%$ of terminal velocity after a distance of about $100 \mathrm{~cm}$.

Terminal Velocity

The terminal velocity of a spherical particle can be stimated from

$v_{t}=\left[\frac{4 g D\left(\rho-\rho_{g}\right)}{3 \rho_{g} C_{d}}\right]^{1 / 2}$

where $\rho$ and $\rho_{g}$ are the droplet/sphere and gas densities, respectively, and $C_{a}$ is the drag coefficient.

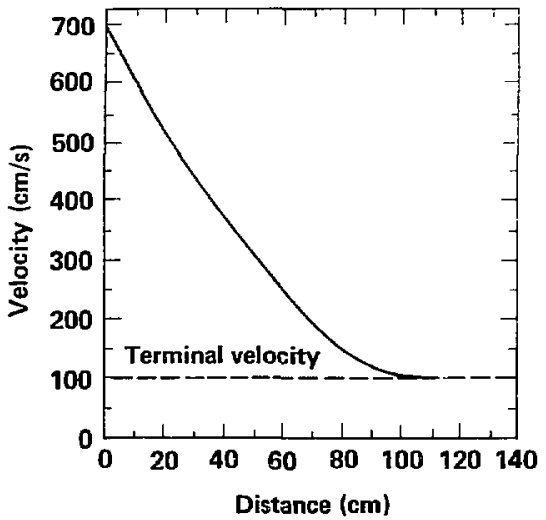

Fig. B2. Droplet velocity as a function of distance. The droplet terminal velocity is assumed to be $100 \mathrm{~cm} / \mathrm{s}$. 
$v_{\mathrm{t}}$ can be c'etermined from a plat of the dimensionless quantities $C_{d} \operatorname{Re}^{2}$ and $\operatorname{Re}(\mathrm{Fig}$. B3) where

$C_{\mathrm{d}} \operatorname{Re}^{2}=\frac{4 g D^{3} \rho_{\mathrm{g}}\left(\rho-\rho_{\mathrm{g}}\right)}{3 \eta_{\mathrm{g}}^{3}}$

and

$\operatorname{Re}=\frac{\rho v_{\mathrm{t}} D}{\eta_{\mathrm{g}}}$

$\eta_{\mathrm{g}}$ is gas viscosity. Note that $C_{\mathrm{d}} \operatorname{Re}^{2}$ is independent of velocity. Therefore to find $v_{\mathrm{l}}$, first calculate $C_{\mathrm{d}} \operatorname{Re}^{2}$ from $\rho_{r} \rho_{g^{\prime}} \eta_{\mathrm{g}}$ and $D$ and then find the corresponding Reynolds number from Fig. B3. $v_{\mathrm{t}}$ is then calculated from Eq. (B21).

$v_{1}$ can also be calculated from Eq. (B19) if the drag coefficient is known. $C_{d}$ varies with Reynolds number as shown in Fig. B4. Although no single expressions have been fcund that represents $C_{\mathrm{d}}$ at all $\mathrm{Re}$ values, $C_{d}$ can be estimated in different flow regimes by the following simple equations.

$C_{d}=24 / \operatorname{Re} ; \operatorname{Re}<0.4$

$C_{\mathrm{d}}=10 / \mathrm{Re}^{1 / 2} ; 0.4 \leq \operatorname{Re} \leq 500$

$C_{\mathrm{d}}=0.43 ; 500<\operatorname{Re}<200000$.

Substituting these equations for $C_{\mathrm{d}}$ into Eq. (319) gives the following well known equations for $v_{\mathrm{t}}$

$v_{1}=\frac{g\left(\rho-\rho_{g}\right) D^{2}}{18 \eta} \quad ; \quad \operatorname{Re}<0.4$

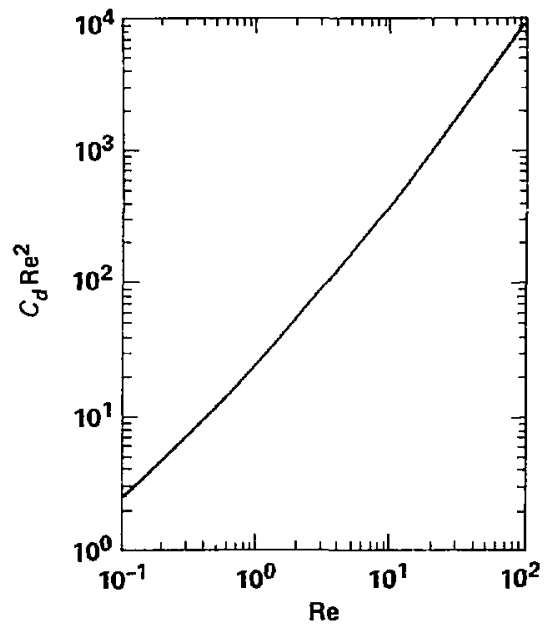

Fig. B3. $C_{d} \operatorname{Re}^{2}$ vs $R e$ for spherical particles. 


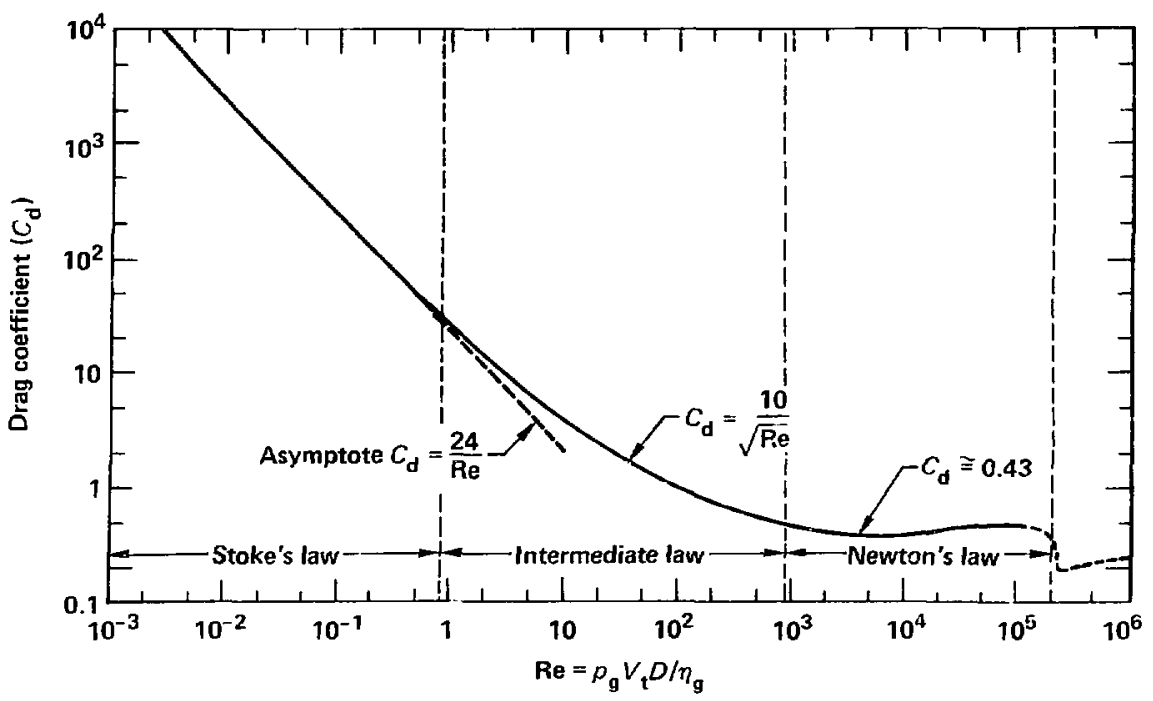

Fig. B4. Drag coefficient $\left(C_{d}\right)$ vs Reynolds number (Re) for a sphere.

$\eta_{l}=\left[\frac{4}{225} \frac{\left(\rho-\rho_{\mathrm{g}}\right)^{2} g^{2}}{\rho_{\mathrm{g}} \eta}\right]^{1 / 3} D ; 0.4 \leq \operatorname{Re} \leq 500$
$v_{:}=\left[\frac{3.1 \mathrm{~g}\left(\rho-\rho_{\mathrm{g}}\right) D}{\nu_{\mathrm{g}}}\right]^{1 / 2} ; 500<\operatorname{Re}<200000$.

Equations (B22) to (B27) and Fig. B4 can be used to estimate velocities for both drops and hollow shells. For thin walled hollow shells the density of the sphere is

$\rho \approx \frac{6 t_{w} \rho_{\mathrm{s}}}{D}$

where $\rho_{\mathrm{s}}$ is the density of glass and $t_{w}$ the wall thickness.

To illustrate the use of the above method, we have calculated the terminal velocities of droplet; and hollow glass shells in argon at 200 and $1500^{\circ} \mathrm{C}$, respectively (Table B1, Fig. B5). A size range of from 100 to $1000 \mu \mathrm{m}$ diameter has been used; the hollow shells are assumed to have an aspect ratio $\left(t_{w} / D\right)$ of 0.025 . Values for the viscosity and density of argon (needed to determine $C_{d} \operatorname{Re}^{2}$ ) are given in Table 8 of the main text.

We have used Fig. B3 to estimate Re from the values of $C_{d} \operatorname{Re}^{2}$ (see Table B1). The terminal velocity was then calculated via Eq. (B21). The major limitation in this method is the accuracy with which one can read Fig. B3. 
Table B1. Estimates of terminal velocities for liquid droplets and hollow glass spheres in 200 and $1500^{\circ} \mathrm{C}$ argon, respectively. ${ }^{2}$ The density of the solution and glass are assumed to be $\mathbf{1 . 1 5}$ and $2.4 \mathrm{~g} / \mathrm{cm}^{3}$.

\begin{tabular}{|c|c|c|c|}
\hline & $C_{\mathrm{d}} \mathrm{Re}^{2}$ & $\mathbf{R e}^{\mathbf{b}}$ & $(\mathrm{cm} / \mathrm{s})$ \\
\hline \multicolumn{4}{|c|}{ Droplet diam. $(\mu \mathrm{m})$} \\
\hline 100 & 16.1 & 0.65 & 20.8 \\
\hline 200 & 129.0 & 4.6 & 73.6 \\
\hline 300 & 435,0 & 11 & 117 \\
\hline 500 & 2010. & 33 & 211 \\
\hline 800 & $\mathbf{B 2 4 0}$ & 90 & 360 \\
\hline 1000 & $1.61 \times 10^{4}$ & $>100$ & $490^{\circ}$ \\
\hline \multicolumn{4}{|c|}{ Shell diam. ( $\mu \mathrm{m})$} \\
\hline 100 & 0.379 & $<0.1$ & $3.3^{d}$ \\
\hline 200 & 3.03 & 0.12 & 12.7 \\
\hline 300 & 10.23 & 0.42 & 29.7 \\
\hline 500 & 47.4 & 1.8 & 76.3 \\
\hline 800 & 194 & 5.5 & 146.0 \\
\hline 1000 & 379 & 10.0 & 212.0 \\
\hline \multicolumn{4}{|c|}{$\begin{array}{l}\therefore \eta_{\mathrm{Ar}}\left(200^{\circ} \mathrm{C}\right)=3.2 \times 10^{-4} ; \eta_{\mathrm{Ar}}\left(1500^{\circ} \mathrm{C}\right)=5.8 \times 10^{-4} \\
\text { poise; } \rho_{\mathrm{Ar}}\left(200^{\circ} \mathrm{C}\right)=1.0 \times 10^{-3} ; \rho_{\mathrm{Ar}}\left(1500^{\circ} \mathrm{C}\right)=1.74 \times 10^{-4} \\
\mathrm{~g} / \mathrm{cm}^{3} \text {. }\end{array}$} \\
\hline \multicolumn{4}{|c|}{$\begin{array}{l}\text { bstimated from Fig. B4 using the values of } C_{d} \mathbf{R e}^{2} \text { listed } \\
\text { above. }\end{array}$} \\
\hline \multicolumn{4}{|c|}{$\begin{array}{l}\text { 'Calculated from the Reynolds number unless otherwise } \\
\text { noted. } \\
{ }^{d} \text { Calculated via Eq. (B25). }\end{array}$} \\
\hline
\end{tabular}

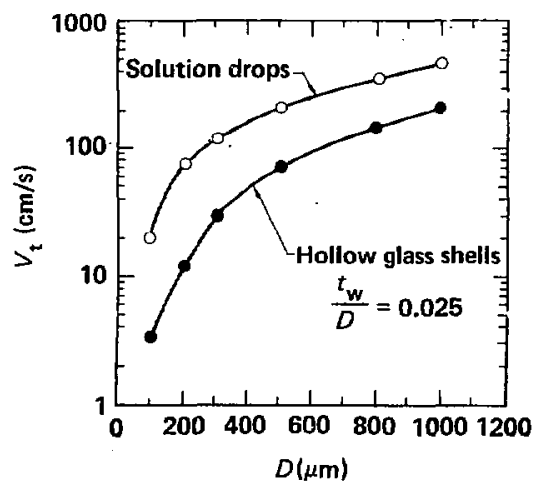

Fig. B5. Terminal velocity for hollow glass spheres and liquid droplets of varying size. The hollow sphere aspect ratio $\left(t_{\mathrm{w}} / D\right)$ is 0.025 for all diameters. 


\section{Effects of Droplet/Sphere Diameter on Column Length}

The results in the previous sections of this appendix provide an approximate means of scaling equipment needed for preparing different size spheres. From Eq. (B1) it is apparent that for aqueous glass solution of a fixed concentration the drying time is proportional to the following:

$t_{1} \propto \frac{D^{2}}{k_{f} \Delta T}$.

Similarly for diameters of $\sim 200$ to $1000 \mu \mathrm{m}$, the droplet terminal velocity is directly proportional to $D$

$z_{1} \propto D$.

It follows then that, to a first approximation, the length of column, $\bar{x}$, needed to carry out this drying step is the product of these two quantities

$$
\begin{gathered}
\bar{x}=v_{1} \cdot t_{1} \\
\propto \frac{D^{3}}{k_{\mathrm{f}} \Delta T} .
\end{gathered}
$$

The key point is that the iength of column scales as $D^{3}$. Therefore if a $1 \mathbf{m}$ drying column is needed tu dry a $200-\mu \mathrm{m}$-diam droplet to the film formation point, a $64-\mathrm{m}$-long column would be required to dry an 800 am-diam droplet assuming the same operating conditions. This effect is shown more clearly in Fig. B6 where the calculated column length [vir Eqs. (B1) and (B26)] required to dry an 18 wt \% solution siroplet to

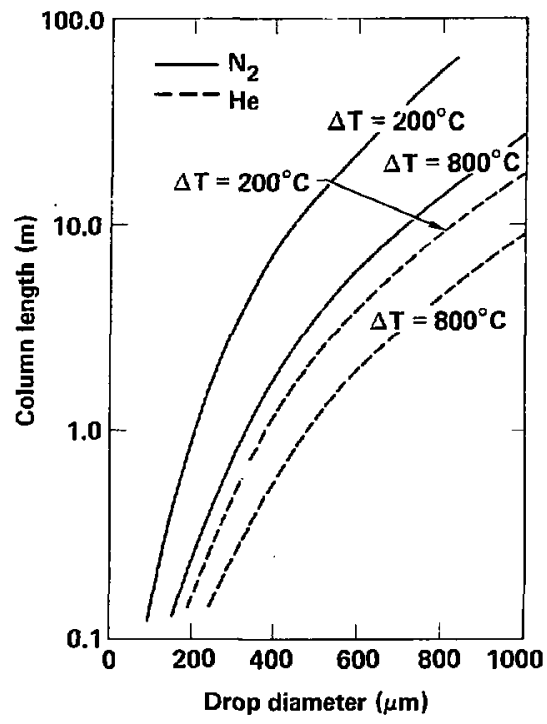

Fig. B6. Estimated column length needed to dry droplets of glass solution (18 wt\% solids) to the film "-rmation point. Results are given for two inert purge gases (He and $\mathrm{N}_{2}$ ) and two temperature gradients (200 and $\left.800^{\circ} \mathrm{C}\right)$. 
the film point is plotted versus droplet diameter. The results are for $\mathrm{N}_{2}$ and He purge gases. Although these are only estimates, the results show clearly that the drying column length soon becomes prohibitive for typical conditions.

One way to reduce the drying column length is to increase the heat transfer rate by increasing either $k_{\mathrm{f}}$ or $\Delta T$ or both. The effects of using $\mathrm{He}$ (much higher thermal conductivity; $k_{\mathrm{f}} \sim 5.5 \times 10^{-4} \mathrm{cal} / \mathrm{s} \cdot \mathrm{cm} \cdot \mathrm{K}$ at $200^{\circ} \mathrm{C}$ ) and a higher column temperature are shown in Fig. B6. The combined effect ef higher temperature $\left(\Delta T=800^{\circ} \mathrm{C}\right)$ and $\mathrm{He}$ could possibly extend the usefulness of our present column up to a droplet size of about $600 \mu \mathrm{m}$. --

One other way to reduce the drying time is to increase the droplet solids concentration. Unfortunately the droplet generator is currently limited to concentrations below about $24 \mathrm{wt} \%$ (because of viscosity effects) so this may be only a small effect.

One can conceive of other ways to reduce the column length but generally these lead to other operating difficulties. For example, flowing a purge gas counter-current to the droplet will retard the fall velocity (in the column reference frame). However, once the drop!et begins to form a sphere, the terminal velocity decreases drastically and the purge gas would then simply carry them back up the column. To overcome this would require introducing gas at some fixed point in the column and in a manner that would not disturb the fall of the sphere through that region.

It is clear from the above simple analysis that our current droplet system is probably practically limited to droplet sizes below about 400 to $500 \mu \mathrm{m}$. Furthermore, the above treaiment only examines the drying step. Some increases in length would also be required for the glass fusion region.

One method of estimating the length of the furnace needed to refine the glass spheres is to assume that the glass viscosity $\eta_{g}(T)$ divided by the sphere residence time $\left(\tau_{r}\right)$ at the furnace temperature must be less than some critical value, $\beta_{c}$, i.e.,

$\frac{\eta_{g}(T)}{\tau_{r}(T)} \leq \beta_{c}$

For our glass, the viscosity at $1500^{\circ} \mathrm{C}$ is about 100 poise (see Fig. 6 main text), and the residence time is approximately 4 to $5 \mathrm{~s}$ for a nominal $200-\mu \mathrm{m}$-diam sphere. This gives an estimate of $\beta_{c}$ of about 20 to 25 poise/s. Therefore, for a given furnace temperature, the length of the heated zone $\left(X_{h}\right)$ would need to equal or exceed the product of $\tau_{\mathrm{r}}(T)$ and the sphere terminal velocity

$X_{h} \geq \tau_{r}(T) \cdot v_{t}$

Since the terminal velocity is proportional to the sphere diameter then increasing the sphere size by a factor of four would require increasing the column length by four in order to satisfy Eq. (B32). For example, our current $1 \mathrm{~m}$ furnace can handle spheres up to $\sim 200$ to $300 \mu \mathrm{m}$. To treat material up to 1000 $\mu \mathrm{m}$ would require roughly a $4 \mathrm{~m}$ furnace based on the above simple analysis. Surprisingly, this is the approximate size of the furnace we currently use to produce glass spheres up to $1000 \mu \mathrm{m}$ in diameter from dried gel particles.

Estimates of the zone length needed for gas diffusion after the unfused hollow shell has formed is not included here. This effect is minor since the terminal velocities for these shells is very low compared to the droplets and final glass spheres. Given the purge gas permeability, however, one could estimate it from Eq. (14) (main text) and the velocity equation in this appendix [Eq. (B25)].

Note that the results presented in this appendix are conly designed to give back-of-the-envelope estimates of drying times, velocities, equipment sizes, etc. For more detailed analysis the model given in the min text should be used since it combines into one set of numerical calculations all of the points discussed above. 